\title{
Radical Relay Trichloromethylacylation of Alkenes through N-Heterocyclic Carbene Catalysis
}

Mayu Kusakabe, ${ }^{\dagger}$ Kazunori Nagao, ${ }^{* \dagger}$ and Hirohisa Ohmiya* ${ }^{\S}$

†Division of Pharmaceutical Sciences, Graduate School of Medical Sciences, Kanazawa University, Kakuma-machi, Kanazawa 920-1192, Japan

§JST, PRESTO, 4-1-8 Honcho, Kawaguchi, Saitama 332-0012, Japan

*E-mail: Kazunori Nagao: nkazunori@p.kanazawa-u.ac.jp

Hirohisa Ohmiya: ohmiya@p.kanazawa-u.ac.jp

\section{Table of Contents}

\section{- Supplementary Methods}

1. Instrumentation and Chemicals $\quad \mathrm{S} 2$

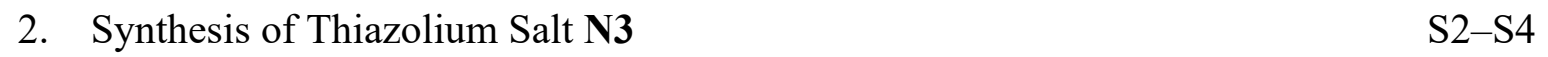

3. Procedures for Trichloromethylacylation of Alkenes $\quad$ S4

4. Characterization Data for Coupling Products $\quad$ S5-S16

5. Procedures for Synthesis of 1,1-Dichlorocyclopropanes S16

6. Characterization Data for 1,1-Dichlorocyclopropanes S17-S18

7. Procedure for Reaction with ATRA Product $\quad$ S18

$\begin{array}{lr}\text { 8. Procedure for Reaction without Styrene } & \text { S18 }\end{array}$

9. Effect of NHC Catalysts on Reactions with Aliphatic Aldehydes $\quad$ S19

$\begin{array}{ll}\text { 10. X-Ray Crystallographic Data for N3 S19-S20 } & \text { S20 }\end{array}$

- Supplementary References - $\quad$ S20

$\begin{array}{lr}\text { - NMR Spectra a } & \text { S21-S90 }\end{array}$ 


\section{- Supplementary Methods}

\section{Instrumentation and Chemicals}

NMR spectra were recorded on a Bruker AVANCE NEO 400N spectrometer, operating at 400 $\mathrm{MHz}$ for ${ }^{1} \mathrm{H}$ NMR, 100.6 MHz for ${ }^{13} \mathrm{C}$ NMR. Chemical shift values for ${ }^{1} \mathrm{H}$ and ${ }^{13} \mathrm{C}$ are referenced to $\mathrm{Me}_{4} \mathrm{Si}$ and the residual solvent resonances, respectively. Chemical shifts were reported in $\delta \mathrm{ppm}$. DART-MS (ion trap) spectra were obtained with JMS-T100TD (JEOL Ltd.). FAB-MS (ion trap) spectra were measured with JMS-700 (JEOL Ltd.). TLC analyses were performed on commercial glass plates bearing 0.25 -mm layer of Merck Silica gel $60 \mathrm{~F}_{254}$. Silica gel (Wakosil ${ }^{\circledR} 60,64 \sim 210 \mu \mathrm{m}$ ) was used for column chromatography. Biotage Selekt was used for purification. IR spectra were measured with a Thermo Scientific iD7 ATR Accessory for the Thermo Scientific Nicolet iS5 FT-IR Spectrometer. Melting points were measured on a Stanford Research Systems MPA100. Gel Permeation Chromatography (GPC) was performed with LaboACE LC-5060 using UV Detector and Refractive Index Detector. Single-crystal X-ray diffraction data was collected on R-AXIS RAPID II.

All reactions were carried out under nitrogen atmosphere. Materials were obtained from commercial suppliers or prepared according to standard procedures unless otherwise noted. Aldehydes were purchased from Tokyo Chemical Industry Co. and FUJIFILM Wako Pure Chemical Co., used as received. Tetrachloromethane and carbonate salts were purchased from FUJIFILM Wako Pure Chemical Co., used as received. Hexachloroethane was purchased from Tokyo Chemical Industry Co., used as received. Cesium hydroxide and cesium acetate were were purchased from Nacalai tesque, used as received. MeCN, THF, EtOAc, DMSO and DCM were purchased from FUJIFILM Wako Pure Chemical Co., stored under nitrogen, and used as received. Styrenes were purchased from commercial suppliers or prepread by wittig reactions. Thiazolium Salts $\mathbf{N} 1^{1}$ and $\mathbf{N} 2^{2}$ were prepared according to the previous reports.

\section{Synthesis of Thiazolium Salt N3}

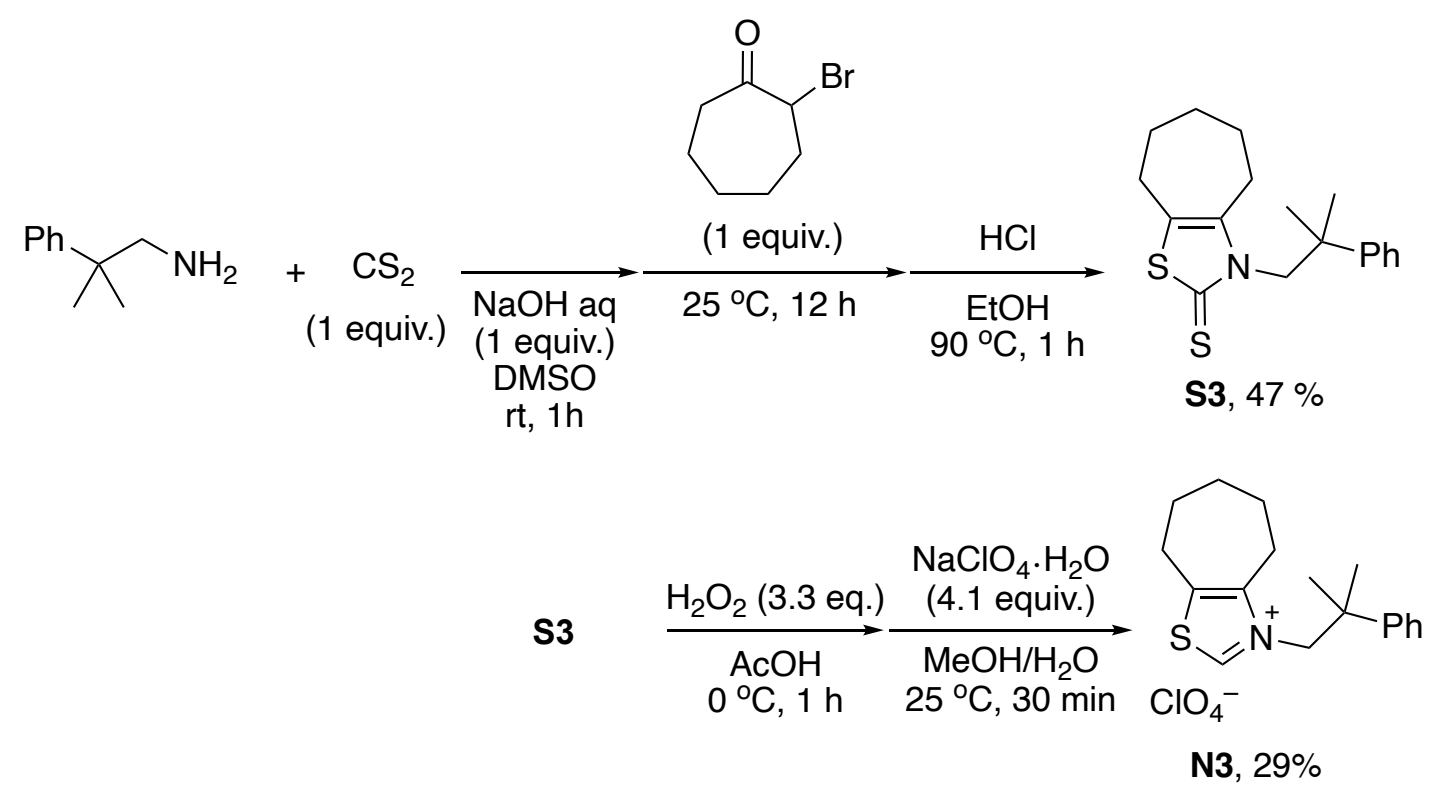

Figure S1. Synthesis of N3. 


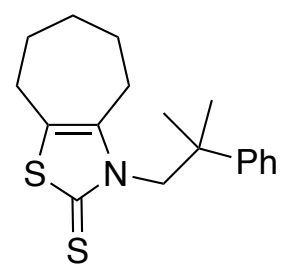

A solution of 2-methyl-2-phenylpropan-1-amine (4.48 g, $30 \mathrm{mmol})$ in DMSO (18 mL) were treated with $20 \mathrm{~N} \mathrm{NaOH}$ solution $(1.5 \mathrm{~mL}, 30 \mathrm{mmol})$. To the solution was added $\mathrm{CS}_{2}(1.81 \mathrm{~mL}, 30 \mathrm{mmol})$ dropwisely at $0{ }^{\circ} \mathrm{C}$. The resulting solution was allowed to room temperature and stirred at room temperature for $1 \mathrm{~h}$. Then, 2-bromocycloheptanone $(6.31 \mathrm{~g}, 33 \mathrm{mmol})$ was added to the reaction mixture at $0{ }^{\circ} \mathrm{C}$, and the mixture was stirred at room temperature at $12 \mathrm{~h} . \mathrm{H}_{2} \mathrm{O}(18 \mathrm{~mL})$ was added to reaction mixture at $0{ }^{\circ} \mathrm{C}$, and the mixture was stirred at the same temperature for $30 \mathrm{~min}$. The resulting supernatant solution was decanted three times. The resulting slurry was suspended in EtOH $(15 \mathrm{~mL})$, and conc. $\mathrm{HCl}(1.5 \mathrm{~mL})$ was added to the mixture. After being heated at reflux for $1 \mathrm{~h}$, the mixture was evaporated. The residue was dissolved in $\mathrm{H}_{2} \mathrm{O}(15 \mathrm{~mL})$ and mixture was extracted three times with $\mathrm{CH}_{2} \mathrm{Cl}_{2}(15 \mathrm{~mL})$. The combined organic layer was dried over $\mathrm{Na}_{2} \mathrm{SO}_{4}$. Then, the drying agent was removed by filtration and the solvent was removed under reduced pressure. The crude product was purified by flash column chromatography on silica gel (97:3-70:30, hexane/EtOAc) to yield S3 (4.51 g, $14.2 \mathrm{mmol}$ ) in $47 \%$ yield as a yellow solid. M.p. $65-69^{\circ} \mathrm{C}$. IR (neat) 558, 699, 752, 965, 1028, 1144, 1183, 1356, 1601, $2923 \mathrm{~cm}^{-1} .{ }^{1} \mathbf{H}$ NMR (400 MHz, $\left.\mathrm{CDCl}_{3}\right) \delta 7.37-7.23(\mathrm{~m}, 5 \mathrm{H}), 4.50$ (brs, 2H), 2.46-2.44 (m, 2H), $1.85(\mathrm{~s}, 2 \mathrm{H}), 1.63-1.56(\mathrm{~m}, 4 \mathrm{H}), 1.51(\mathrm{~s}, 6 \mathrm{H}), 1.26-1.21(\mathrm{~m}, 2 \mathrm{H}) .{ }^{13} \mathrm{C}$ NMR (100.6 MHz, $\left.\mathrm{CDCl}_{3}\right) \delta 186.6,146.7,142.7,128.2,126.4,126.1,123.0,57.0,41.5,30.4,28.4$, 27.5, 26.7, 26.3, 25.4. HRMS-DART $(\mathrm{m} / \mathrm{z})$ : $[\mathrm{M}+\mathrm{H}]^{+}$calcd for $\mathrm{C}_{18} \mathrm{H}_{24} \mathrm{NS}_{2}, 318.1345$; found, 318.1343 .

3-(2-Methyl-2-phenylpropyl)-5,6,7,8-tetrahydro-4H-cyclohepta[d] thiazol-3-ium

perchlorate (N3)

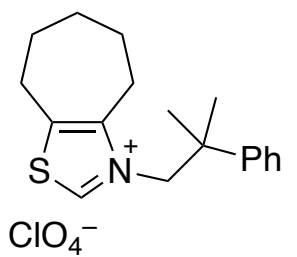

To a solution of $\mathbf{S 3}(4.51 \mathrm{~g}, 14.2 \mathrm{mmol})$ in acetic acid $(56.8 \mathrm{~mL})$ was added $30 \%$ aq. $\mathrm{H}_{2} \mathrm{O}_{2}$ solution (1.59 g, $46.9 \mathrm{mmol})$ dropwisely under water bath cooling. The mixture was stirred at the same temperature for $1 \mathrm{~h}$. Then, volatiles were removed under reduced pressure. The residue was dissolved in $\mathrm{MeOH}(10 \mathrm{~mL})$. To the solution was added a solution of $\mathrm{NaClO}_{4} \cdot \mathrm{H}_{2} \mathrm{O}(8.18 \mathrm{~g}, 58.2 \mathrm{mmol})$ in $\mathrm{MeOH} / \mathrm{H}_{2} \mathrm{O}(2: 1,49 \mathrm{~mL})$ at $0{ }^{\circ} \mathrm{C}$. The resulting solution was allowed to room temperature and stirred for $30 \mathrm{~min}$ to generate a precipitate. The precipitate was collected through filtration and dissolved in $\mathrm{CH}_{2} \mathrm{Cl}_{2}$. After addition of $\mathrm{H}_{2} \mathrm{O}$ into the organic solution, the mixture was extracted three times with $\mathrm{CH}_{2} \mathrm{Cl}_{2}(5 \mathrm{~mL})$. The combined organic layer was dried over $\mathrm{Na}_{2} \mathrm{SO}_{4}$. Then, the drying agent was removed by filtration and the solvent was removed under reduced pressure. The crude product was 
purified by flash column chromatography on silica gel (100:0-95:5, $\left.\mathrm{CH}_{2} \mathrm{Cl}_{2} / \mathrm{MeOH}\right)$ to yield $\mathbf{N 3}$ (1.59 g, $4.12 \mathrm{mmol}$ ) in $29 \%$ yield as a white solid. M.p. $156-158{ }^{\circ} \mathrm{C}$. IR (neat) 573, 621, 667, 702, 748, 950, 1075, 1443, 1572, $2931 \mathrm{~cm}^{-1} .{ }^{1} \mathbf{H}$ NMR $\left(400 \mathrm{MHz}, \mathrm{CDCl}_{3}\right) \delta 9.03(\mathrm{~s}, 1 \mathrm{H}), 7.37-7.20(\mathrm{~m}, 5 \mathrm{H})$, $4.64(\mathrm{~s}, 2 \mathrm{H}), 2.90-2.87(\mathrm{~m}, 2 \mathrm{H}), 2.45-2.43(\mathrm{~m}, 2 \mathrm{H}), 1.81-1.80(\mathrm{~m}, 2 \mathrm{H}), 1.75-1.72(\mathrm{~m}, 2 \mathrm{H}), 1.52-$ 1.47 (m, 8H). ${ }^{13} \mathbf{C}$ NMR $\left(100.6 \mathrm{MHz} \mathrm{CDCl}_{3}\right) \delta 153.6,149.0,143.1,138.2,129.0,127.6,126.2,64.1$, 40.1, 30.4, 27.7, 26.9, 26.0, 25.9, 24.5. HRMS-FAB $(\mathrm{m} / \mathrm{z}):\left[\mathrm{M}-\mathrm{ClO}_{4}\right]^{+}$calcd for $\mathrm{C}_{18} \mathrm{H}_{24} \mathrm{NS}$, 286.1624; found, 286.1626.

\section{Procedures for Trichloromethylacylation of Alkenes}

The reaction in Table 1, entry 16 is representative. Thiazolium salt $\mathbf{N 3}$ (7.7 $\mathrm{mg}, 0.02 \mathrm{mmol})$ was placed in a schlenk tube containing a magnetic stirring bar. The vial was sealed with a Teflon ${ }^{\circledR}$ coated silicon rubber septum, and then the vial was evacuated and filled with nitrogen. $\mathrm{Cs}_{2} \mathrm{CO}_{3}(78.2$ $\mathrm{mg}, 0.24 \mathrm{mmol})$ was added. Then, degassed DCM $(400 \mu \mathrm{L})$ was added to the vial. Next, benzaldehyde 1a $(20.4 \mu \mathrm{L}, 0.2 \mathrm{mmol})$, styrene $\mathbf{2 a}(46.0 \mu \mathrm{L}, 0.4 \mathrm{mmol})$ and tetrachloromethane $\mathbf{3}(38.8 \mu \mathrm{L}, 0.4$ mmol) were added. After $18 \mathrm{~h}$ stirring at $40{ }^{\circ} \mathrm{C}$ with oil bath, the reaction mixture was quenched through a pad of silica gel with DCM. The resulting solution was evaporated under reduced pressure. After volatiles were removed under reduced pressure, flash column chromatography on silica gel (100:0-88:12, hexane $/ \mathrm{Et}_{2} \mathrm{O}$ ) gave $4 \mathbf{a a}(41.3 \mathrm{mg}, 0.13 \mathrm{mmol})$ in $63 \%$ yield.

1 mmol scale. Thiazolium salt $\mathbf{N} 3(38.6 \mathrm{mg}, 0.1 \mathrm{mmol})$ was placed in a schlenk tube containing a magnetic stirring bar. The vial was sealed with a Teflon ${ }^{\circledR}$-coated silicon rubber septum, and then the vial was evacuated and filled with nitrogen. $\mathrm{Cs}_{2} \mathrm{CO}_{3}(391 \mathrm{mg}, 1.2 \mathrm{mmol})$ was added. Then, degassed DCM $(2 \mathrm{~mL})$ was added to the vial. Next, benzaldehyde 1a $(102 \mu \mathrm{L}, 1.0 \mathrm{mmol}), p$-methoxystyrene 2b $(268 \mu \mathrm{L}, 2.0 \mathrm{mmol})$ and tetrachloromethane $3(194 \mu \mathrm{L}, 2.0 \mathrm{mmol})$ were added. After $18 \mathrm{~h}$ stirring at $40{ }^{\circ} \mathrm{C}$ with oil bath, the reaction mixture was quenched through a pad of silica gel with DCM. The resulting solution was evaporated under reduced pressure. After volatiles were removed under reduced pressure, flash column chromatography on silica gel (100:0-90:10, hexane/Et $2 \mathrm{O})$ gave 4ab (254 mg, $0.71 \mathrm{mmol})$ in $71 \%$ yield. 


\section{Characterization Data for Coupling Products}

\section{4,4,4-Trichloro-1,2-diphenylbutan-1-one (4aa)}<smiles>O=C(c1ccccc1)C(CC(Cl)(Cl)Cl)c1ccccc1</smiles>

The product 4aa was purified by flash chromatography on silica gel (100:0-88:12, hexane/Et $\left.\mathrm{t}_{2} \mathrm{O}\right)$. Then the obtained solid was washed with hexane (Table 1, entry 16; $41.3 \mathrm{mg}, 0.13 \mathrm{mmol}, 63 \%$ isolated yield). White solid. M.p. 100-101 ${ }^{\circ} \mathrm{C}$. IR (neat) 535, 602, 691, 752, 783, 952, 1246, 1447, 1597, $1682 \mathrm{~cm}^{-1} .{ }^{1} \mathbf{H}$ NMR $\left(400 \mathrm{MHz}, \mathrm{CDCl}_{3}\right) \delta 8.02-8.00(\mathrm{~m}, 2 \mathrm{H}), 7.52(\mathrm{~m}, 1 \mathrm{H}), 7.44-7.41(\mathrm{~m}$, $2 \mathrm{H}), 7.35-7.22(\mathrm{~m}, 5 \mathrm{H}), 5.14(\mathrm{dd}, J=8.0,2.0 \mathrm{~Hz}, 1 \mathrm{H}), 4.26(\mathrm{dd}, J=14.8,8.0 \mathrm{~Hz}, 1 \mathrm{H}), 3.03(\mathrm{dd}, J=$ $14.8 \mathrm{~Hz}, 2.0 \mathrm{~Hz}, 1 \mathrm{H}) .{ }^{13} \mathbf{C}$ NMR $\left(100.6 \mathrm{MHz}, \mathrm{CDCl}_{3}\right) \delta 197.3,137.9,136.1,133.3,129.3,128.8$, 128.7, 128.1, 127.7, 98.6, 57.4, 51.1. HRMS-DART $(\mathrm{m} / \mathrm{z}):\left[\mathrm{M}+\mathrm{NH}_{4}\right]^{+}$calcd for $\mathrm{C}_{16} \mathrm{H}_{17} \mathrm{Cl}_{3} \mathrm{NO}$, 344.0370; found, 344.0374 .

\section{4,4,4-Trichloro-2-(4-methoxyphenyl)-1-phenylbutan-1-one (4ab)}<smiles>COc1ccc(C(CC(Cl)(Cl)Cl)C(=O)c2ccccc2)cc1</smiles>

The reaction time was modified to $12 \mathrm{~h}$. The product $\mathbf{4 a b}$ was purified by flash chromatography on silica gel (100:0-90:10, hexane/Et $2 \mathrm{O}$ ). Then the obtained solid was washed with hexane (Figure. 2; $62.8 \mathrm{mg}, 0.18 \mathrm{mmol}, 88 \%$ isolated yield). White solid. M.p. $85-86^{\circ} \mathrm{C}$. IR (neat) $689,744,786$, 833, 954, 1034, 1179, 1251, 1509, $1682 \mathrm{~cm}^{-1} .{ }^{1} \mathbf{H}$ NMR (400 MHz, CDCl $\left.{ }_{3}\right) \delta 8.01-7.99(\mathrm{~m}, 2 \mathrm{H})$, $7.52(\mathrm{~m}, 1 \mathrm{H}), 7.44-7.40(\mathrm{~m}, 2 \mathrm{H}), 7.24(\mathrm{~d}, J=8.4 \mathrm{~Hz}, 2 \mathrm{H}), 6.83(\mathrm{~d}, J=8.4 \mathrm{~Hz}, 2 \mathrm{H}), 5.09(\mathrm{dd}, J=$ 7.6, $2.0 \mathrm{~Hz}, 1 \mathrm{H}), 4.22(\mathrm{dd}, J=14.8,7.6 \mathrm{~Hz}, 1 \mathrm{H}), 3.75(\mathrm{~s}, 3 \mathrm{H}), 3.01(\mathrm{dd}, J=14.8,2.0 \mathrm{~Hz}, 1 \mathrm{H}) .{ }^{13} \mathrm{C}$ NMR (100.6 MHz, $\left.\mathrm{CDCl}_{3}\right) \delta 197.4,159.1,136.1,133.2,129.8,129.3,128.8,128.6,114.7,98.6,57.5$, 55.2, 50.2. HRMS-DART (m/z): $\left[\mathrm{M}+\mathrm{NH}_{4}\right]^{+}$calcd for $\mathrm{C}_{17} \mathrm{H}_{19} \mathrm{Cl}_{3} \mathrm{NO}_{2}, 374.0476$; found, 374.0481 .

\section{4,4,4-Trichloro-2-(4-methoxyphenyl)-1-(p-tolyl)butan-1-one (4bb)}<smiles>COc1ccc(C(CC(Cl)(Cl)Cl)C(=O)c2ccc(C)cc2)cc1</smiles>

The reaction time was modified to $12 \mathrm{~h}$. The product $\mathbf{4 b b}$ was purified by flash chromatography on silica gel (100:0-80:10, hexane/Et $\left.{ }_{2} \mathrm{O}\right)$. Then the obtained solid was washed with hexane (Figure 2; $56.6 \mathrm{mg}, 0.15 \mathrm{mmol}, 76 \%$ isolated yield). White solid. M.p. $91-93{ }^{\circ} \mathrm{C}$. IR (neat) 536, 688, 760, 954, 1033, 1177, 1249, 1508, 1606, $1678 \mathrm{~cm}^{-1} .{ }^{1} \mathbf{H}$ NMR (400 MHz, $\left.\mathrm{CDCl}_{3}\right) \delta 7.92-7.90(\mathrm{~m}, 2 \mathrm{H})$, 
7.26-7.21 (m, 4H), 6.83-6.81 (m, 2H), $5.07(\mathrm{~d}, J=7.6 \mathrm{~Hz}, 1 \mathrm{H}), 4.21(\mathrm{dd}, J=14.8,7.6 \mathrm{~Hz}, 1 \mathrm{H}), 3.74$ (s, 3H), $3.00(\mathrm{~d}, J=14.8 \mathrm{~Hz}, 1 \mathrm{H}), 2.36(\mathrm{~s}, 3 \mathrm{H}) .{ }^{13} \mathbf{C ~ N M R}\left(100.6 \mathrm{MHz}, \mathrm{CDCl}_{3}\right) \delta 197.0,159.0,144.1$, $133.5,130.1,129.3,129.2,129.0,114.7,98.7,57.4,55.2,50.0,21.6$. HRMS-DART $(\mathrm{m} / z)$ : $\left[\mathrm{M}+\mathrm{NH}_{4}\right]^{+}$calcd for $\mathrm{C}_{18} \mathrm{H}_{21} \mathrm{Cl}_{3} \mathrm{NO}_{2}, 388.0632$; found, 388.0643 .

\section{4,4,4-Trichloro-1-(3,5-dimethylphenyl)-2-(4-methoxyphenyl)butan-1-one (4cb)}<smiles>COc1ccc(C(CC(Cl)(Cl)Cl)C(=O)c2cc(C)cc(C)c2)cc1</smiles>

The product $\mathbf{4 c b}$ was purified by flash chromatography on silica gel (100:0-90:10, hexane/Et $2 \mathrm{O})$ followed by GPC (Figure 2; $76.1 \mathrm{mg}, 0.20 \mathrm{mmol}, 99 \%$ isolated yield). Yellow oil. IR (neat) 588, 684, 771, 846, 1033, 1177, 1251, 1303, 1509,1679 cm ${ }^{-1}{ }^{\mathbf{1}} \mathbf{H} \mathbf{N M R}\left(400 \mathrm{MHz}, \mathrm{CDCl}_{3}\right) \delta 7.59(\mathrm{~s}, 2 \mathrm{H}), 7.23$ $(\mathrm{d}, J=7.6 \mathrm{~Hz}, 2 \mathrm{H}), 7.15(\mathrm{~s}, 1 \mathrm{H}), 6.83(\mathrm{~d}, J=7.6 \mathrm{~Hz}, 2 \mathrm{H}), 5.06(\mathrm{~d}, J=7.6 \mathrm{~Hz}, 1 \mathrm{H}), 4.21(\mathrm{dd}, J=$ 14.8, 7.6 Hz, 1H), 3.75 (s, 3H), 2.99 (d, $J=14.8 \mathrm{~Hz}, 1 \mathrm{H}), 2.33(\mathrm{~s}, 6 \mathrm{H}) .{ }^{13} \mathbf{C ~ N M R}\left(100.6 \mathrm{MHz}, \mathrm{CDCl}_{3}\right)$ $\delta 197.7,158.9,138.2,136.2,134.9,129.9,129.2,126.5,114.6,98.7,57.5,55.1,50.1,21.2$. HRMSDART $(\mathrm{m} / \mathrm{z}):\left[\mathrm{M}+\mathrm{NH}_{4}\right]^{+}$calcd for $\mathrm{C}_{19} \mathrm{H}_{23} \mathrm{Cl}_{3} \mathrm{NO}_{2}, 402.0789$; found, 402.0795 .

\section{1-(4-Bromophenyl)-4,4,4-trichloro-2-(4-methoxyphenyl)butan-1-one (4db)}<smiles>COc1ccc(C(CC(Cl)(Cl)Cl)C(=O)c2ccc(Br)cc2)cc1</smiles>

The product $4 \mathbf{d b}$ was purified by flash chromatography on silica gel (100:0-92:8, hexane/Et $\left.\mathrm{t}_{2} \mathrm{O}\right)$. Then the obtained solid was washed with hexane (Figure 2; $72.6 \mathrm{mg}, 0.17 \mathrm{mmol}, 83 \%$ isolated yield). White solid. M.p. $114-116^{\circ} \mathrm{C}$. IR (neat) 536, 681, 752, 830, 954, 1176, 1250, 1509, 1583, $1683 \mathrm{~cm}^{-}$ ${ }^{1} .{ }^{1} \mathbf{H}$ NMR $\left(400 \mathrm{MHz}, \mathrm{CDCl}_{3}\right) \delta 7.85(\mathrm{~d}, J=8.8 \mathrm{~Hz}, 2 \mathrm{H}), 7.56(\mathrm{~d}, J=8.8 \mathrm{~Hz}, 2 \mathrm{H}), 7.23-7.19(\mathrm{~m}$, 2H), 6.85-6.82 (m, 2H), $5.01(\mathrm{dd}, J=7.6,2.4 \mathrm{~Hz}, 1 \mathrm{H}), 4.20$ (dd, $J=14.8,7.6 \mathrm{~Hz}, 1 \mathrm{H}), 3.76(\mathrm{~s}, 3 \mathrm{H})$, $2.99(\mathrm{dd}, J=14.8,2.4 \mathrm{~Hz}, 1 \mathrm{H}) .{ }^{13} \mathbf{C}$ NMR $\left(100.6 \mathrm{MHz}, \mathrm{CDCl}_{3}\right) \delta 196.4,159.2,134.8,132.0,130.3$, 129.3, 129.2, 128.4, 114.8, 98.5, 57.3, 55.2, 50.3. HRMS-DART $(m / z):[\mathrm{M}+\mathrm{H}]^{+}$calcd for $\mathrm{C}_{17} \mathrm{H}_{15} \mathrm{BrCl}_{3} \mathrm{O}_{2}, 434.9316$; found, 434.9321. 
<smiles>COc1ccc(C(=O)C(CC(Cl)(Cl)Cl)c2ccc(OC)cc2)cc1</smiles>

$\mathbf{N 2}$ was used instead of N3. The reaction time was modified to $12 \mathrm{~h}$. The product $4 \mathbf{e b}$ was purified by flash chromatography on silica gel $(100: 0-80: 20$, hexane/Et $2 \mathrm{O})$. Then the obtained solid was washed with hexane (Figure 2; $58.9 \mathrm{mg}, 0.15 \mathrm{mmol}, 76 \%$ isolated yield). White solid. M.p. 102$104^{\circ} \mathrm{C}$. IR (neat) 688, 755, 831, 953, 1029, 1165, 1245, 1508, 1597, $1672 \mathrm{~cm}^{-1} .{ }^{1} \mathbf{H}$ NMR (400 MHz, $\left.\mathrm{CDCl}_{3}\right) \delta 8.01-7.98(\mathrm{~m}, 2 \mathrm{H}), 7.26-7.23(\mathrm{~m}, 2 \mathrm{H}), 6.91-6.81(\mathrm{~m}, 4 \mathrm{H}), 5.04(\mathrm{dd}, J=7.6,2.4 \mathrm{~Hz}, 1 \mathrm{H})$, $4.21(\mathrm{dd}, J=14.8,7.6 \mathrm{~Hz}, 1 \mathrm{H}), 3.83(\mathrm{~s}, 3 \mathrm{H}), 3.75(\mathrm{~s}, 3 \mathrm{H}), 2.99(\mathrm{~d}, J=14.8 \mathrm{~Hz}, 1 \mathrm{H}) .{ }^{13} \mathbf{C}$ NMR $(100.6$ $\left.\mathrm{MHz}_{2} \mathrm{CDCl}_{3}\right) \delta 195.9,163.5,158.9,131.1,130.3,129.2,129.0,114.6,113.8,98.8,57.5,55.4,55.2$, 49.8. HRMS-DART $(\mathrm{m} / z):[\mathrm{M}+\mathrm{H}]^{+}$calcd for $\mathrm{C}_{18} \mathrm{H}_{18} \mathrm{Cl}_{3} \mathrm{O}_{3}, 387.0316$; found, 387.0308 .

\section{4,4,4-Trichloro-2-(4-methoxyphenyl)-1-(4-(methylthio)phenyl)butan-1-one (4fb)}<smiles>COc1ccc(C(CC(Cl)(Cl)Cl)C(=O)c2ccc(S(C)(=O)=O)cc2)cc1</smiles>

The product $\mathbf{4 f b}$ was purified by flash chromatography on silica gel (100:0-87:13, hexane/Et $2 \mathrm{O}$ ). Then the obtained solid was washed with hexane (Figure 2; $78.2 \mathrm{mg}, 0.19 \mathrm{mmol}, 97 \%$ isolated yield). Pale yellow solid. M.p. 88-90 ${ }^{\circ} \mathrm{C}$. IR (neat) 540, 684, 764, 952, 1092, 1177, 1247, 1508, 1586, 1673 $\mathrm{cm}^{-1} .{ }^{1} \mathbf{H}$ NMR (400 MHz, $\left.\mathrm{CDCl}_{3}\right) \delta 7.93-7.91(\mathrm{~m}, 2 \mathrm{H}), 7.25-7.21(\mathrm{~m}, 4 \mathrm{H}), 6.85-6.81(\mathrm{~m}, 2 \mathrm{H}), 5.03$ $(\mathrm{dd}, J=7.6,2.4 \mathrm{~Hz}, 1 \mathrm{H}), 4.21(\mathrm{dd}, J=14.8,7.6 \mathrm{~Hz}, 1 \mathrm{H}), 3.75(\mathrm{~s}, 3 \mathrm{H}), 2.99(\mathrm{dd}, J=14.8,2.4 \mathrm{~Hz}$, 1H), 2.48 (s, 3H). ${ }^{13} \mathbf{C}$ NMR $\left(100.6 \mathrm{MHz}, \mathrm{CDCl}_{3}\right) \delta 196.2,159.0,146.2,132.2,129.9,129.2,129.2$, 124.9, 114.7, 98.7, 57.3, 55.2, 49.9, 14.6. HRMS-DART $(\mathrm{m} / \mathrm{z}):[\mathrm{M}+\mathrm{H}]^{+}$calcd for $\mathrm{C}_{18} \mathrm{H}_{18} \mathrm{Cl}_{3} \mathrm{O}_{2} \mathrm{~S}$, 403.0088; found, 403.0085 .

\section{4,4,4-Trichloro-2-(4-methoxyphenyl)-1-[4-(trifluoromethyl)phenyl]butan-1-one (4gb)}<smiles>COc1ccc(C(CC(Cl)(Cl)Cl)C(=O)c2ccc(C(F)(F)F)cc2)cc1</smiles>

The product 4gb was purified by flash chromatography on silica gel (100:0-90:10, hexane/Et $\left.{ }_{2} \mathrm{O}\right)$ followed by GPC (Figure 2; $29.5 \mathrm{mg}, 0.07 \mathrm{mmol}, 35 \%$ isolated yield). White solid. M.p. $73-76{ }^{\circ} \mathrm{C}$. 
IR (neat) 774, 831, 953, 1066, 1127, 1167, 1252, 1321, 1509, $1689 \mathrm{~cm}^{-1} .{ }^{\mathbf{1}} \mathbf{H} \mathbf{N M R}\left(400 \mathrm{MHz}, \mathrm{CDCl}_{3}\right)$ $\delta 8.08(\mathrm{~d}, J=8.0 \mathrm{~Hz}, 2 \mathrm{H}), 7.68(\mathrm{~d}, J=8.0 \mathrm{~Hz}, 2 \mathrm{H}), 7.22(\mathrm{~d}, J=7.6 \mathrm{~Hz}, 2 \mathrm{H}), 6.85(\mathrm{~d}, J=7.6 \mathrm{~Hz}$, $2 \mathrm{H}), 5.06(\mathrm{~d}, J=8.0 \mathrm{~Hz}, 1 \mathrm{H}), 4.22(\mathrm{dd}, J=14.8,8.0 \mathrm{~Hz}, 1 \mathrm{H}), 3.76(\mathrm{~s}, 3 \mathrm{H}), 3.02(\mathrm{~d}, J=14.8 \mathrm{~Hz}, 1 \mathrm{H})$. ${ }^{13}$ C NMR (100.6 MHz, $\left.\mathrm{CDCl}_{3}\right) \delta 196.5,159.3,138.9,134.4$ (q, $\left.J_{\mathrm{C}-\mathrm{F}}=32.7 \mathrm{~Hz}\right), 129.3,129.1,128.9$, $125.7\left(\mathrm{q}, J_{\mathrm{C}-\mathrm{F}}=3.7 \mathrm{~Hz}\right), 123.5\left(\mathrm{q}, J_{\mathrm{C}-\mathrm{F}}=272.7 \mathrm{~Hz}\right), 114.9,98.4,57.3,55.2,50.7$. HRMS-DART $(\mathrm{m} / \mathrm{z}):\left[\mathrm{M}+\mathrm{NH}_{4}\right]^{+}$calcd for $\mathrm{C}_{18} \mathrm{H}_{18} \mathrm{Cl}_{3} \mathrm{~F}_{3} \mathrm{NO}_{2}, 442.0350$; found, 442.0349 .

\section{4,4,4-Trichloro-2-(4-methoxyphenyl)-1-[4-(trifluoromethoxy)phenyl]butan-1-one (4hb)}<smiles>COc1ccc(C(CC(Cl)(Cl)Cl)C(=O)c2ccc(OC(F)(F)F)cc2)cc1</smiles>

The reaction time was modified to $12 \mathrm{~h}$. The product $\mathbf{4 h b}$ was purified by flash chromatography on silica gel (100:0-95:5, hexane/Et $2 \mathrm{O}$ ) followed by GPC (Figure 2; $53.0 \mathrm{mg}, 0.12 \mathrm{mmol}, 60 \%$ isolated yield). Yellow oil. IR (neat) 691, 773, 833, 956, 1034, 1163, 1208, 1247, 1509, $1686 \mathrm{~cm}^{-1}$. ${ }^{1} \mathbf{H}$ NMR $\left(400 \mathrm{MHz}, \mathrm{CDCl}_{3}\right) \delta 8.06-8.04(\mathrm{~m}, 2 \mathrm{H}), 7.26-7.22(\mathrm{~m}, 4 \mathrm{H}), 6.86-6.84(\mathrm{~m}, 2 \mathrm{H}), 5.03(\mathrm{~d}, J$ $=8.0 \mathrm{~Hz}, 1 \mathrm{H}), 4.21(\mathrm{dd}, J=15.2,8.0 \mathrm{~Hz}, 1 \mathrm{H}), 3.76(\mathrm{~s}, 3 \mathrm{H}), 3.00(\mathrm{~d}, J=15.2 \mathrm{~Hz}, 1 \mathrm{H}) .{ }^{13} \mathbf{C} \mathbf{N M R}$ $\left(100.6 \mathrm{MHz}, \mathrm{CDCl}_{3}\right) \delta 195.8,159.2,152.6\left(\mathrm{q}, J_{\mathrm{C}-\mathrm{F}}=1.5 \mathrm{~Hz}\right), 134.3,130.8,129.3,129.2,120.4,120.2$ $\left(\mathrm{q}, J_{\mathrm{C}-\mathrm{F}}=259.0 \mathrm{~Hz}\right), 114.9,98.5,57.4,55.2,50.4$. HRMS-DART $(\mathrm{m} / \mathrm{z}):\left[\mathrm{M}+\mathrm{NH}_{4}\right]^{+}$calcd for $\mathrm{C}_{18} \mathrm{H}_{18} \mathrm{Cl}_{3} \mathrm{~F}_{3} \mathrm{NO}_{3}, 458.0299$; found, 458.0288 .

\section{4-[4,4,4-Trichloro-2-(4-methoxyphenyl)butanoyl]benzonitrile (4ib)}<smiles>COc1ccc(C(CC(Cl)(Cl)Cl)C(=O)c2ccc(C#N)cc2)cc1</smiles>

The reaction time was modified to $12 \mathrm{~h}$. The product $4 \mathrm{ib}$ was purified by flash chromatography on silica gel (100:0-80:20, hexane/ $\mathrm{Et}_{2} \mathrm{O}$ ) followed by GPC (Figure 2; $11.9 \mathrm{mg}, 0.03 \mathrm{mmol}, 16 \%$ isolated yield). Yellow oil. IR (neat) 689, 773, 834, 955, 1179, 1253, 1510, 1608, 1689, $2231 \mathrm{~cm}^{-1}$. ${ }^{1} \mathbf{H}$ NMR $\left(400 \mathrm{MHz} \mathrm{CDCl}_{3}\right) \delta 8.05(\mathrm{~d}, J=7.6 \mathrm{~Hz}, 2 \mathrm{H}), 7.72(\mathrm{~d}, J=7.6 \mathrm{~Hz}, 2 \mathrm{H}), 7.20(\mathrm{~d}, J=7.6 \mathrm{~Hz}, 2 \mathrm{H})$, $6.85(\mathrm{~d}, J=7.6 \mathrm{~Hz}, 2 \mathrm{H}), 5.02(\mathrm{~d}, J=8.0 \mathrm{~Hz}, 1 \mathrm{H}), 4.20(\mathrm{dd}, J=14.8,8.0 \mathrm{~Hz}, 1 \mathrm{H}), 3.76(\mathrm{~s}, 3 \mathrm{H}), 3.01$ $(\mathrm{d}, J=14.8 \mathrm{~Hz}, 1 \mathrm{H}) .{ }^{13} \mathbf{C}$ NMR $\left(100.6 \mathrm{MHz}, \mathrm{CDCl}_{3}\right) \delta 196.1,159.4,139.3,132.5,129.3,129.1,128.5$, 117.8, 116.4, 115.0, 98.3, 57.2, 55.3, 50.7. HRMS-DART $(\mathrm{m} / \mathrm{z})$ : $[\mathrm{M}+\mathrm{NH}]_{4}^{+}$calcd for $\mathrm{C}_{18} \mathrm{H}_{18} \mathrm{Cl}_{3} \mathrm{~N}_{2} \mathrm{O}_{2}$, 399.0428; found, 339.0417. 
<smiles>COC(=O)c1ccc(C(=O)C(CC(Cl)(Cl)Cl)c2ccc(OC)cc2)cc1</smiles>

The reaction time was modified to $12 \mathrm{~h}$. The product $\mathbf{4 j b}$ was purified by flash chromatography on silica gel (100:0-85:15, hexane/Et $\left.{ }_{2} \mathrm{O}\right)$. Then, the obtained solid was washed with hexane (Figure 2; $36.6 \mathrm{mg}, 0.09 \mathrm{mmol}, 44 \%$ isolated yield). White solid. M.p. $130-131{ }^{\circ} \mathrm{C}$. IR (neat) 751, 786, 954, 1108, 1251, 1276, 1509, 1686, $1723 \mathrm{~cm}^{-1} .{ }^{1} \mathbf{H}$ NMR (400 MHz, $\left.\mathrm{CDCl}_{3}\right) \delta 8.08-8.02(\mathrm{~m}, 4 \mathrm{H}), 7.22$ $(\mathrm{d}, J=8.0 \mathrm{~Hz}, 2 \mathrm{H}), 6.84(\mathrm{~d}, J=8.0 \mathrm{~Hz}, 2 \mathrm{H}), 5.07(\mathrm{~d}, J=7.6 \mathrm{~Hz}, 1 \mathrm{H}), 4.21(\mathrm{dd}, J=14.8,7.6 \mathrm{~Hz}, 1 \mathrm{H})$, $3.92(\mathrm{~s}, 3 \mathrm{H}), 3.75(\mathrm{~s}, 3 \mathrm{H}), 3.02(\mathrm{~d}, J=14.8 \mathrm{~Hz}, 1 \mathrm{H}) .{ }^{13} \mathbf{C} \mathbf{N M R}\left(100.6 \mathrm{MHz}, \mathrm{CDCl}_{3}\right) \delta 197.0,166.0$, $159.2,139.5,133.8,129.8,129.3,129.1,128.7,114.8,98.5,57.3,55.2,52.4,50.7$. HRMS-DART $(\mathrm{m} / \mathrm{z}):\left[\mathrm{M}+\mathrm{NH}_{4}\right]^{+}$calcd for $\mathrm{C}_{19} \mathrm{H}_{21} \mathrm{Cl}_{3} \mathrm{NO}_{4}, 432.0531$; found, 432.0529 .

\section{4,4,4-Trichloro-2-(4-methoxyphenyl)-1-(pyridin-2-yl)butan-1-one (4kb)}<smiles>COc1ccc(C(CC(Cl)(Cl)Cl)C(=O)c2ccccn2)cc1</smiles>

The product $4 \mathbf{k b}$ was purified by flash chromatography on silica gel (100:0-84:16, hexane/Et $\left.\mathrm{t}_{2} \mathrm{O}\right)$. Then, the obtained solid was washed with hexane (Figure 2; $57.7 \mathrm{mg}, 0.16 \mathrm{mmol}, 81 \%$ isolated yield). White solid. M.p. $121-122^{\circ} \mathrm{C}$. IR (neat) 584, 685, 762, 791, 979, 1033, 1178, 1249, 1508, $1670 \mathrm{~cm}^{-}$ ${ }^{1} .{ }^{1} \mathbf{H}$ NMR $\left(400 \mathrm{MHz}, \mathrm{CDCl}_{3}\right) \delta 8.71(\mathrm{~m}, 1 \mathrm{H}), 8.04(\mathrm{~m}, 1 \mathrm{H}), 7.77(\mathrm{~m}, 1 \mathrm{H}), 7.42(\mathrm{~m}, 1 \mathrm{H}), 7.33(\mathrm{~d}, J$ $=8.0 \mathrm{~Hz}, 2 \mathrm{H}), 6.80(\mathrm{~d}, J=8.0 \mathrm{~Hz}, 2 \mathrm{H}), 6.00(\mathrm{~d}, J=8.4 \mathrm{~Hz}, 1 \mathrm{H}), 4.17(\mathrm{dd}, J=14.8,8.4 \mathrm{~Hz}, 1 \mathrm{H})$, $3.73(\mathrm{~s}, 3 \mathrm{H}), 3.09(\mathrm{dd}, J=14.8 \mathrm{~Hz}, 1 \mathrm{H}) .{ }^{13} \mathbf{C} \mathbf{N M R}\left(100.6 \mathrm{MHz}, \mathrm{CDCl}_{3}\right) \delta 198.5,158.8,152.1,149.0$, 136.8, 130.0, 129.7, 127.1, 123.1, 114.3, 98.7, 57.1, 55.2, 47.4. HRMS-DART $(\mathrm{m} / \mathrm{z}):[\mathrm{M}+\mathrm{H}]^{+}$calcd for $\mathrm{C}_{16} \mathrm{H}_{15} \mathrm{Cl}_{3} \mathrm{NO}_{2}, 358.0163$; found, 358.0158 .

\section{4,4,4-Trichloro-2-(4-methoxyphenyl)-1-(thiophen-3-yl)butan-1-one (4lb)}<smiles>COc1ccc(C(CC(Cl)(Cl)Cl)C(=O)c2ccsc2)cc1</smiles>

The product 4lb was purified by flash chromatography on silica gel (100:0-82:18, hexane/Et $\left.\mathrm{t}_{2} \mathrm{O}\right)$. Then the obtained solid was washed with hexane (Figure 2; $67.9 \mathrm{mg}, 0.19 \mathrm{mmol}, 93 \%$ isolated yield). 
White solid. M.p. $120-121^{\circ} \mathrm{C}$. IR (neat) 686, 763, 792, 979, 1033, 1178, 1250, 1303, 1508, 1671 $\mathrm{cm}^{-1} .{ }^{1} \mathbf{H}$ NMR $\left(400 \mathrm{MHz}, \mathrm{CDCl}_{3}\right) \delta 8.12(\mathrm{~m}, 1 \mathrm{H}), 7.56(\mathrm{~m}, 1 \mathrm{H}), 7.28-7.23(\mathrm{~m}, 3 \mathrm{H}), 6.87-6.83(\mathrm{~m}$, $2 \mathrm{H}), 4.85(\mathrm{dd}, J=7.6,2.8 \mathrm{~Hz}, 1 \mathrm{H}), 4.16(\mathrm{dd}, J=14.8,7.6 \mathrm{~Hz}, 1 \mathrm{H}), 3.76(\mathrm{~s}, 3 \mathrm{H}), 2.98(\mathrm{dd}, J=14.8$, $2.8 \mathrm{~Hz}, 1 \mathrm{H}) .{ }^{13} \mathbf{C} \mathbf{N M R}\left(100.6 \mathrm{MHz}, \mathrm{CDCl}_{3}\right) \delta 191.5,159.1,141.1,133.0,130.0,129.2,127.4,126.4$, 114.7, 98.6, 57.1, 55.2, 52.1. HRMS-DART $(\mathrm{m} / \mathrm{z})$ : $\left[\mathrm{M}+\mathrm{NH}_{4}\right]^{+}$calcd for $\mathrm{C}_{15} \mathrm{H}_{17} \mathrm{Cl}_{3} \mathrm{NO}_{2} \mathrm{~S}, 380.0040$; found, 380.0039 .

\section{1,1,1-Trichloro-3-(4-methoxyphenyl)-8-((triisopropylsilyl)oxy)octan-4-one (4mb)}<smiles>COc1ccc(C(CC(Cl)(Cl)Cl)C(=O)CCCCOS(C)(F)F)cc1</smiles>

The product $\mathbf{4 m b}$ was purified by flash chromatography on silica gel (100:0-95:5, hexane/Et $\left.{ }_{2} \mathrm{O}\right)$ followed by GPC. (Figure 2; $33.8 \mathrm{mg}, 0.07 \mathrm{mmol}, 33 \%$ isolated yield). Pale yellow oil. IR (neat) 680, 832, 882, 1036, 1104, 1252, 1510, 1718, 2864, $2940 \mathrm{~cm}^{-1} .{ }^{\mathbf{1}} \mathbf{H}$ NMR $\left(400 \mathrm{MHz}, \mathrm{CDCl}_{3}\right) \delta 7.14(\mathrm{~d}, J$ $=8.0 \mathrm{~Hz}, 2 \mathrm{H}), 6.86(\mathrm{~d}, J=8.0 \mathrm{~Hz}, 2 \mathrm{H}), 4.12(\mathrm{~m}, 1 \mathrm{H}), 4.00(\mathrm{dd}, J=14.8,6.8 \mathrm{~Hz}, 1 \mathrm{H}), 3.79(\mathrm{~s}, 3 \mathrm{H})$, $3.60-3.58(\mathrm{~m}, 2 \mathrm{H}), 2.85(\mathrm{dd}, J=14.8,2.0 \mathrm{~Hz}, 1 \mathrm{H}), 2.51(\mathrm{t}, J=7.6 \mathrm{~Hz}, 2 \mathrm{H}), 1.72-1.51(\mathrm{~m}, 3 \mathrm{H}), 1.46-$ $1.35(\mathrm{~m}, 2 \mathrm{H}), 1.06-1.02(\mathrm{~m}, 20 \mathrm{H}) .{ }^{13} \mathbf{C}$ NMR (100.6 MHz, $\left.\mathrm{CDCl}_{3}\right) \delta 207.4,159.2,129.7,129.3,114.6$, 98.7, 62.8, 56.2, 55.3, 55.2, 41.6, 32.0, 20.3, 18.0, 11.9. HRMS-DART $(m / z):[\mathrm{M}+\mathrm{H}]^{+}$calcd for $\mathrm{C}_{24} \mathrm{H}_{40} \mathrm{Cl}_{3} \mathrm{O}_{3} \mathrm{Si}$, 509.1807; found, 509.1806.

\section{1,1,1-Trichloro-3-(4-methoxyphenyl)-6-phenylheptan-4-one (4nb)}<smiles>COc1ccc(C(CC(Cl)(Cl)Cl)C(=O)CC(C)c2ccccc2)cc1</smiles>

The product $4 \mathbf{n b}$ was purified by flash chromatography on silica gel (100:0-94:6, hexane/Et $\left.{ }_{2} \mathrm{O}\right)$ followed by GPC. (Figure 2; $66.8 \mathrm{mg}, 0.17 \mathrm{mmol}, 84 \%$ isolated yield). The ratio (1:1) of diasteromers was determined by ${ }^{1} \mathrm{H}-\mathrm{NMR}$. Pale yellow solid. M.p. $66-70{ }^{\circ} \mathrm{C}$. IR (neat) 528, 699, 761, 829, 1034 , $1178,1251,1509,1608,1716 \mathrm{~cm}^{-1} .{ }^{1} \mathbf{H}$ NMR $\left(400 \mathrm{MHz}, \mathrm{CDCl}_{3}\right) \delta 7.26(\mathrm{~m}, 1 \mathrm{H}), 7.18-7.09(\mathrm{~m}, 4 \mathrm{H})$, 7.00-6.94 (m, 2H), $6.88(\mathrm{~m}, 1 \mathrm{H}), 6.75(\mathrm{~m}, 1 \mathrm{H}), 3.88-3.98(\mathrm{~m}, 2 \mathrm{H}), 3.81(\mathrm{~s}, 0.5 \times 3 \mathrm{H}), 3.78(\mathrm{~s}, 0.5 \times$ $3 \mathrm{H}), 3.30(\mathrm{~m}, 1 \mathrm{H}), 2.83-2.76(\mathrm{~m}, 2 \mathrm{H}), 2.80(\mathrm{~m}, 1 \mathrm{H}), 1.20(\mathrm{~d}, J=6.8 \mathrm{~Hz}, 0.5 \times 3 \mathrm{H}), 1.04(\mathrm{~d}, J=6.8$ $\mathrm{Hz}, 0.5 \times 3 \mathrm{H}) .{ }^{13} \mathbf{C} \mathbf{N M R}\left(100.6 \mathrm{MHz}, \mathrm{CDCl}_{3}\right) \delta 205.8,205.5,159.2,159.0,146.0,145.7,129.5$, $129.2(\times 2 \mathrm{C}), 129.0,128.4,128.2,126.8,126.6,126.3,126.0,114.6,114.6,98.7,98.5,55.9,55.9$, 55.8, 55.8, 55.2, 55.2, 50.1. 49.7, 35.0, 34.8, 22.0, 21.5. HRMS-DART $(\mathrm{m} / z)$ : $\left[\mathrm{M}+\mathrm{NH}_{4}\right]^{+}$calcd for $\mathrm{C}_{20} \mathrm{H}_{25} \mathrm{Cl}_{3} \mathrm{NO}_{2}$, 416.0945; found, 416.0954. 
<smiles>COc1ccc(C(CC(Cl)(Cl)Cl)C(=O)C2CCCCC2)cc1</smiles>

The reaction time was modified to $12 \mathrm{~h}$. The product $40 \mathrm{~b}$ was purified by flash chromatography on silica gel (100:0-95:5, hexane/Et $2 \mathrm{O}$ ). Then the obtained solid was washed with hexane (Figure 2; $55.5 \mathrm{mg}, 0.15 \mathrm{mmol}, 76 \%$ isolated yield). White solid. M.p. $74-76^{\circ} \mathrm{C}$. IR (neat) $689,766,836,103$, $1035,1178,1252,1509,1710,2930 \mathrm{~cm}^{-1} .{ }^{1} \mathbf{H}$ NMR $\left(400 \mathrm{MHz}, \mathrm{CDCl}_{3}\right) \delta 7.13(\mathrm{~d}, J=8.8 \mathrm{~Hz}, 2 \mathrm{H})$, $6.86(\mathrm{~d}, J=8.8 \mathrm{~Hz}, 2 \mathrm{H}), 4.27(\mathrm{dd}, J=6.8,3.2 \mathrm{~Hz}, 1 \mathrm{H}), 3.98(\mathrm{dd}, J=14.8,6.8 \mathrm{~Hz}, 1 \mathrm{H}), 3.80(\mathrm{~s}, 3 \mathrm{H})$, $2.81(\mathrm{dd}, J=14.8,3.2 \mathrm{~Hz}, 1 \mathrm{H}), 2.44(\mathrm{~m}, 1 \mathrm{H}), 1.97-1.76(\mathrm{~m}, 2 \mathrm{H}), 1.66-1.60(\mathrm{~m}, 2 \mathrm{H}), 1.39-1.06(\mathrm{~m}$, 6H). $\left.{ }^{13} \mathbf{C ~ N M R ~ ( 1 0 0 . 6 ~ M H z , ~} \mathrm{CDCl}_{3}\right) \delta 210.2,159.1,129.7,129.5,114.6,98.7,56.3,55.3,53.8,50.0$, 29.6, 28.5, 25.9, 25.7, 25.2. HRMS-DART $(\mathrm{m} / \mathrm{z})$ : $\left[\mathrm{M}+\mathrm{NH}_{4}\right]^{+}$calcd for $\mathrm{C}_{17} \mathrm{H}_{25} \mathrm{Cl}_{3} \mathrm{NO}_{2}, 380.0945$; found, 380.0946 .

\section{4,4,4-Trichloro-1-cyclopropyl-2-(4-methoxyphenyl)butan-1-one (4pb)}<smiles>COc1ccc(C(CC(Cl)(Cl)Cl)C(=O)C2CC2)cc1</smiles>

The product $4 \mathbf{p b}$ was purified by flash chromatography on silica gel (100:0-93:7, hexane/Et $2 \mathrm{O})$ folloewd by GPC. (Figure 2; $41.7 \mathrm{mg}, 0.13 \mathrm{mmol}, 65 \%$ isolated yield). White solid. M.p. 61-62 ${ }^{\circ} \mathrm{C}$. IR (neat) 698, 763, 833, 995, 1033, 1178, 1250, 1381, 1509, $1699 \mathrm{~cm}^{-1} .{ }^{1} \mathbf{H} \mathbf{N M R}\left(400 \mathrm{MHz}, \mathrm{CDCl}_{3}\right)$ $\delta 7.17(\mathrm{~d}, J=7.6 \mathrm{~Hz}, 2 \mathrm{H}), 6.88(\mathrm{~d}, J=7.6 \mathrm{~Hz}, 2 \mathrm{H}), 4.30(\mathrm{~m}, 1 \mathrm{H}), 4.00(\mathrm{dd}, J=15.2,6.4 \mathrm{~Hz}, 1 \mathrm{H})$, $3.80(\mathrm{~s}, 3 \mathrm{H}), 2.86(\mathrm{dd}, J=15.2,3.6 \mathrm{~Hz}, 1 \mathrm{H}), 1.93(\mathrm{~m}, 1 \mathrm{H}), 1.07-0.97(\mathrm{~m}, 2 \mathrm{H}), 0.89(\mathrm{~m}, 1 \mathrm{H}), 0.75(\mathrm{~m}$, 1H). ${ }^{13} \mathrm{C}$ NMR (100.6 MHz, $\left.\mathrm{CDCl}_{3}\right) \delta 207.4,159.1,129.8,129.5,114.6,98.8,56.1,56.0,55.2,20.6$, 12.1, 11.4. HRMS-DART $(\mathrm{m} / \mathrm{z})$ : $\left[\mathrm{M}+\mathrm{NH}_{4}\right]^{+}$calcd for $\mathrm{C}_{14} \mathrm{H}_{19} \mathrm{Cl}_{3} \mathrm{NO}_{2}, 338.0476$; found, 338.0478 .

\section{1,1,1-Trichloro-3-(4-methoxyphenyl)-5,9-dimethyldec-8-en-4-one (4qb)}<smiles>COc1ccc(C(CC(Cl)(Cl)Cl)C(=O)C(C)CCC=C(C)C)cc1</smiles>

The product $\mathbf{4 q b}$ was purified by flash chromatography on silica gel (100:0-96:4, hexane/Et $\left.\mathrm{t}_{2} \mathrm{O}\right)$ followed by GPC. (Figure 2; $50.6 \mathrm{mg}, 0.13 \mathrm{mmol}, 65 \%$ isolated yield). The ratio (1:1) of diasteromers 
was determined by ${ }^{1} \mathrm{H}-\mathrm{NMR}$. Pale yellow oil. IR (neat) 690, 770, 833, 983, 1035, 1178, 1251, 1509, 1713, $2932 \mathrm{~cm}^{-1} .{ }^{1} \mathbf{H}$ NMR (400 MHz, $\left.\mathrm{CDCl}_{3}\right) \delta 7.15-7.12(\mathrm{~m}, 2 \mathrm{H}), 6.87-6.85(\mathrm{~m}, 2 \mathrm{H}), 5.06(\mathrm{~m}, 0.5$ $\times 1 \mathrm{H}), 4.73(\mathrm{~m}, 0.5 \times 1 \mathrm{H}), 4.22(\mathrm{~m}, 1 \mathrm{H}), 3.96(\mathrm{~m}, 1 \mathrm{H}), 3.80-3.79(\mathrm{~m}, 3 \mathrm{H}), 2.89(\mathrm{~m}, 1 \mathrm{H}), 2.64(\mathrm{~m}, 1 \mathrm{H})$, $1.98(\mathrm{~m}, 1 \mathrm{H}), 1.75-1.70(\mathrm{~m}, 2 \mathrm{H}), 1.58-1.52(\mathrm{~m}, 4 \mathrm{H}), 1.42-1.16(\mathrm{~m}, 3 \mathrm{H}), 1.13(\mathrm{~d}, J=6.8 \mathrm{~Hz}, 0.5 \times$ $3 \mathrm{H}), 0.85(\mathrm{~d}, J=6.8 \mathrm{~Hz}, 0.5 \times 3 \mathrm{H}) .{ }^{13} \mathbf{C} \mathbf{~ N M R}\left(100.6 \mathrm{MHz}, \mathrm{CDCl}_{3}\right) \delta 210.8,210.1,159.2,159.1$, $132.5,131.7,129.8,129.7,129.7,129.3,123.6,123.5,114.5(\times 2 \mathrm{C}), 98.8(\times 2 \mathrm{C}), 56.0,55.2,54.9$, 54.4, 44.6, 44.2, 33.7, 32.4, 25.7, $25.5(\times 2 \mathrm{C}), 25.2,17.7,17.6(\times 2 \mathrm{C}), 17.5,16.3(\times 2 \mathrm{C})$. HRMSDART (m/z): $[\mathrm{M}+\mathrm{H}]^{+}$calcd for $\mathrm{C}_{19} \mathrm{H}_{26} \mathrm{Cl}_{3} \mathrm{O}_{2}, 391.0993$; found, 391.0987 .

\section{4,4,4-Trichloro-2-(3,5-dimethylphenyl)-1-phenylbutan-1-one (4ac)}<smiles>Cc1cc(C)cc(C(CC(Cl)(Cl)Cl)C(=O)c2ccccc2)c1</smiles>

The product 4ac was purified by flash chromatography on silica gel (100:0-95:5, hexane/Et $\left.{ }_{2} \mathrm{O}\right)$ followed by GPC (Figure 2; $43.3 \mathrm{mg}, 0.12 \mathrm{mmol}$, 61\% isolated yield). Pale yellow solid. M.p. 100$102{ }^{\circ} \mathrm{C}$. IR (neat) 686, 725, 786, 852, 950, 1238, 1321, 1447, 1598, $1684 \mathrm{~cm}^{-1}$. ${ }^{1} \mathbf{H}$ NMR (400 MHz, $\left.\mathrm{CDCl}_{3}\right) \delta 8.03-8.01(\mathrm{~m}, 2 \mathrm{H}), 7.52(\mathrm{~m}, 1 \mathrm{H}), 7.45-7.41(\mathrm{~m}, 2 \mathrm{H}), 6.93(\mathrm{~s}, 2 \mathrm{H}), 6.86(\mathrm{~s}, 1 \mathrm{H}), 5.05(\mathrm{~d}, J$ $=8.0 \mathrm{~Hz}, 1 \mathrm{H}), 4.26(\mathrm{dd}, J=14.8,8.0 \mathrm{~Hz}, 1 \mathrm{H}), 2.98(\mathrm{~d}, J=14.8 \mathrm{~Hz}, 1 \mathrm{H}), 2.26(\mathrm{~s}, 6 \mathrm{H}) .{ }^{13} \mathbf{C}$ NMR $\left(100.6 \mathrm{MHz} \mathrm{CDCl}_{3}\right) \delta 197.4,139.0,137.7,136.2,133.2,129.4,128.8,128.6,125.8,98.7,57.5,50.9$, 21.3. HRMS-DART $(\mathrm{m} / \mathrm{z}):[\mathrm{M}+\mathrm{H}]^{+}$calcd for $\mathrm{C}_{18} \mathrm{H}_{18} \mathrm{Cl}_{3} \mathrm{O}, 355.0418$; found, 355.0408 .

\section{2-[4-(Benzyloxy)phenyl]-4,4,4-trichloro-1-phenylbutan-1-one (4ad)}<smiles>O=C(c1ccccc1)C(CC(Cl)(Cl)Cl)c1ccc(OCc2ccccc2)cc1</smiles>

The product 4ad was purified by flash chromatography on silica gel (100:0-85:15, hexane/Et $\mathrm{H}_{2} \mathrm{O}$ ). Then, the obtained solid was washed with hexane (Figure $2 ; 86.8 \mathrm{mg}, 0.20 \mathrm{mmol}$, qunat.). White solid. M.p. $107-108^{\circ} \mathrm{C}$. IR (neat) 690, 742, 786, 831, 953, 1176, 1242, 1507, 1607, $1681 \mathrm{~cm}^{-1}$. ${ }^{1} \mathbf{H}$ NMR $\left(400 \mathrm{MHz}, \mathrm{CDCl}_{3}\right) \delta 8.01-7.99(\mathrm{~m}, 2 \mathrm{H}), 7.52(\mathrm{~m}, 1 \mathrm{H}), 7.44-7.30(\mathrm{~m}, 7 \mathrm{H}), 7.26-7.23(\mathrm{~m}, 2 \mathrm{H}), 6.92-$ $6.90(\mathrm{~m}, 2 \mathrm{H}), 5.09(\mathrm{~d}, J=8.0 \mathrm{~Hz}, 1 \mathrm{H}), 5.00(\mathrm{~s}, 2 \mathrm{H}), 4.22(\mathrm{dd}, J=14.8,8.0 \mathrm{~Hz}, 1 \mathrm{H}), 3.01(\mathrm{~d}, J=14.8$ $\mathrm{Hz}, 1 \mathrm{H}) .{ }^{13} \mathbf{C}$ NMR $\left(100.6 \mathrm{MHz}, \mathrm{CDCl}_{3}\right) \delta 197.4,158.3,136.7,136.1,133.2,130.0,129.3,128.8$, 128.6, 128.6, 128.0, 127.4, 115.6, 98.6, 70.0, 57.5, 50.2. HRMS-DART $(\mathrm{m} / \mathrm{z}):[\mathrm{M}+\mathrm{H}]^{+}$calcd for $\mathrm{C}_{23} \mathrm{H}_{20} \mathrm{Cl}_{3} \mathrm{O}_{2}$, 433.0523; found, 433.0521. 
<smiles>O=C(c1ccccc1)C(CC(Cl)(Cl)Cl)c1ccc2c(c1)OCO2</smiles>

The product 4ae was purified by flash chromatography on silica gel (100:0-87:13, hexane/Et $\left.\mathrm{t}_{2} \mathrm{O}\right)$. Then, the obtained solid was washed with hexane (Figure 2; $52.9 \mathrm{mg}, 0.14 \mathrm{mmol}, 71 \%$ isolated yield). White solid. M.p. 89-91 ${ }^{\circ} \mathrm{C}$. IR (neat) 637, 694, 750, 786, 954, 1038, 1246, 1443, 1485, $1681 \mathrm{~cm}^{-1}$. ${ }^{1}$ H NMR (400 MHz, $\left.\mathrm{CDCl}_{3}\right) \delta 8.01-7.99(\mathrm{~m}, 2 \mathrm{H}), 7.53(\mathrm{~m}, 1 \mathrm{H}), 7.45-7.41(\mathrm{~m}, 2 \mathrm{H}), 6.81-6.78(\mathrm{~m}$, $2 \mathrm{H}), 8.23(\mathrm{~m}, 1 \mathrm{H}), 5.92(\mathrm{~s}, 1 \mathrm{H}), 5.91(\mathrm{~s}, 1 \mathrm{H}), 5.04(\mathrm{dd}, J=8.0,2.0 \mathrm{~Hz}, 1 \mathrm{H}), 4.19(\mathrm{dd}, J=14.8,8.0$ $\mathrm{Hz}, 1 \mathrm{H}), 3.00(\mathrm{dd}, J=14.8 \mathrm{~Hz}, 2.0 \mathrm{~Hz}, 1 \mathrm{H}) .{ }^{13} \mathbf{C ~ N M R}\left(100.6 \mathrm{MHz}, \mathrm{CDCl}_{3}\right) \delta 197.2,148.4,147.2$, 136.0, 133.3, 131.4, 128.8, 128.7, 121.7, 108.9, 108.3, 101.3, 98.5, 57.4, 50.6. HRMS-DART $(\mathrm{m} / z)$ : $\left[\mathrm{M}+\mathrm{NH}_{4}\right]^{+}$calcd for $\mathrm{C}_{17} \mathrm{H}_{17} \mathrm{Cl}_{3} \mathrm{NO}_{3}, 388.0269$; found, 388.0257 .

\section{Methyl 4-(4,4,4-Trichloro-1-oxo-1-phenylbutan-2-yl)benzoate (4af)}<smiles>COC(=O)c1ccc(C(CC(Cl)(Cl)Cl)C(=O)c2ccccc2)cc1</smiles>

The product 4af was purified by flash chromatography on silica gel (100:0-82:18, hexane/Et $\left.\mathrm{E}_{2} \mathrm{O}\right)$. Then, the obtained solid was washed with hexane (Figure 2; $52.6 \mathrm{mg}, 0.14 \mathrm{mmol}, 68 \%$ isolated yield). pale solid. M.p. $101-104{ }^{\circ} \mathrm{C}$. IR (neat) 710, 766, 953, 1107, 1182, 1278, 1435, 1609, 184, $1720 \mathrm{~cm}^{-}$ ${ }^{1} .{ }^{1} \mathbf{H}$ NMR $\left(400 \mathrm{MHz}, \mathrm{CDCl}_{3}\right) \delta 8.00-7.97(\mathrm{~m}, 4 \mathrm{H}), 7.54(\mathrm{~m}, 1 \mathrm{H}), 7.45-7.41(\mathrm{~m}, 4 \mathrm{H}), 5.21(\mathrm{dd}, J=$ 7.6, $2.8 \mathrm{~Hz}, 1 \mathrm{H}), 4.25(\mathrm{dd}, J=14.8,7.6 \mathrm{~Hz}, 1 \mathrm{H}), 3.88(\mathrm{~s}, 3 \mathrm{H}), 3.04(\mathrm{dd}, J=14.8 \mathrm{~Hz}, 2.8 \mathrm{~Hz}, 1 \mathrm{H}) .{ }^{13} \mathbf{C}$ NMR (100.6 MHz, $\left.\mathrm{CDCl}_{3}\right) \delta 196.7,166.4,142.8,135.8,133.5,130.6,129.6,128.8,128.8,128.3$, 98.3, 57.1, 52.2, 51.0. HRMS-DART $(\mathrm{m} / \mathrm{z})$ : $[\mathrm{M}+\mathrm{H}]^{+}$calcd for $\mathrm{C}_{18} \mathrm{H}_{16} \mathrm{Cl}_{3} \mathrm{O}_{3}, 385.0160$; found, 385.0155 .

4-(4,4,4-Trichloro-1-oxo-1-phenylbutan-2-yl)benzonitrile (4ag)<smiles>N#Cc1ccc(C(CC(Cl)(Cl)Cl)C(=O)c2ccccc2)cc1</smiles>

The product 4ag was purified by flash chromatography on silica gel (100:0-80:20, hexane/Et $\mathrm{H}_{2} \mathrm{O}$ ). Then, the obtained solid was washed with hexane (Figure 2; $43.0 \mathrm{mg}, 0.12 \mathrm{mmol}, 61 \%$ isolated yield). 
White solid. M.p. $157-161{ }^{\circ} \mathrm{C}$. IR (neat) 550, 580, 687, 737, 788, 952, 1249, 1448, 1683, $2229 \mathrm{~cm}^{-}$ ${ }^{1} .{ }^{1} \mathbf{H}$ NMR $\left(400 \mathrm{MHz}, \mathrm{CDCl}_{3}\right) \delta 7.99-7.97$ (m, 2H), 7.63-7.55 (m, 3H), 7.49-7.44 (m, 4H), $5.22(\mathrm{dd}$, $J=7.6,2.8 \mathrm{~Hz}, 1 \mathrm{H}), 4.22(\mathrm{dd}, J=14.8,7.6 \mathrm{~Hz}, 1 \mathrm{H}), 3.04(\mathrm{dd}, J=14.8 \mathrm{~Hz}, 2.8 \mathrm{~Hz}, 1 \mathrm{H}) .{ }^{13} \mathbf{C} \mathbf{N M R}$ $\left(100.6 \mathrm{MHz} \mathrm{CDCl}_{3}\right) \delta 196.4,143.0,135.5,133.8,133.1,129.1,128.9,128.8,118.2,111.9,98.0$, 57.0, 50.8. HRMS-DART (m/z): $\left[\mathrm{M}+\mathrm{NH}_{4}\right]^{+}$calcd for $\mathrm{C}_{17} \mathrm{H}_{16} \mathrm{Cl}_{3} \mathrm{~N}_{2} \mathrm{O}, 369.0323$; found, 369.0325 .

\section{2-(4-Bromophenyl)-4,4,4-Trichloro-1-phenylbutan-1-one (4ah)}<smiles>O=C(c1ccccc1)C(CC(Cl)(Cl)Cl)c1ccc(Br)cc1</smiles>

The reaction time was modified to $12 \mathrm{~h}$. The product $4 \mathbf{a h}$ was purified by flash chromatography on silica gel (100:0-95:5, hexane/Et $2 \mathrm{O}$ ). Then, the obtained solid was washed with hexane (Figure 2; $44.4 \mathrm{mg}, 0.11 \mathrm{mmol}, 55 \%$ isolated yield). White solid. M.p. $117-118^{\circ} \mathrm{C}$. IR (neat) 558, 710, 788, 954, 1011, 1074, 1248, 1448, 1486, $1685 \mathrm{~cm}^{-1} .{ }^{1} \mathbf{H}$ NMR (400 MHz, $\left.\mathrm{CDCl}_{3}\right) \delta 7.98(\mathrm{~d}, J=8.0 \mathrm{~Hz}$, 2H), $7.54(\mathrm{~m}, 1 \mathrm{H}), 7.46-7.42(\mathrm{~m}, 4 \mathrm{H}), 7.22(\mathrm{~d}, J=8.0 \mathrm{~Hz}, 2 \mathrm{H}), 5.11(\mathrm{dd}, J=7.6,2.8 \mathrm{~Hz}, 1 \mathrm{H}), 4.20$ $(\mathrm{dd}, J=15.2,7.6 \mathrm{~Hz}, 1 \mathrm{H}), 3.01(\mathrm{dd}, J=15.2 \mathrm{~Hz}, 2.8 \mathrm{~Hz}, 1 \mathrm{H}) .{ }^{13} \mathbf{C} \mathbf{N M R}\left(100.6 \mathrm{MHz}, \mathrm{CDCl}_{3}\right) \delta 196.9$, 136.9, 135.8, 133.5, 132.5, 129.9, $128.8(\times 2 \mathrm{C}), 121.9,98.3,57.2,50.4$. HRMS-DART $(\mathrm{m} / \mathrm{z})$ : $\left[\mathrm{M}+\mathrm{NH}_{4}\right]^{+}$calcd for $\mathrm{C}_{16} \mathrm{H}_{16} \mathrm{BrCl}_{3} \mathrm{NO}, 421.9475$; found, 421.9468 .

\section{4,4,4-Trichloro-2-(4-chlorophenyl)-1-phenylbutan-1-one (4ai)}<smiles>O=C(c1ccccc1)C(CC(Cl)(Cl)Cl)c1ccc(Cl)cc1</smiles>

The product 4ai was purified by flash chromatography on silica gel (100:0-95:5, hexane/Et $\left.\mathrm{t}_{2} \mathrm{O}\right)$. Then, the obtained solid was washed with hexane (Figure 2; $50.4 \mathrm{mg}, 0.14 \mathrm{mmol}, 70 \%$ isolated yield). White solid. M.p. $107-108^{\circ} \mathrm{C}$. IR (neat) 566, 685, 717, 787, 953, 1015, 1094, 1246, 1489, $1683 \mathrm{~cm}^{-}$ ${ }^{1} .{ }^{1} \mathbf{H}$ NMR $\left(400 \mathrm{MHz}, \mathrm{CDCl}_{3}\right) \delta 7.99-7.97(\mathrm{~m}, 2 \mathrm{H}), 7.54(\mathrm{~m}, 1 \mathrm{H}), 7.46-7.42(\mathrm{~m}, 2 \mathrm{H}), 7.28-7.26(\mathrm{~m}$, $4 \mathrm{H}), 5.12(\mathrm{dd}, J=7.6,2.4 \mathrm{~Hz}, 1 \mathrm{H}), 4.21(\mathrm{dd}, J=14.8,7.6 \mathrm{~Hz}, 1 \mathrm{H}), 3.01(\mathrm{dd}, J=14.8 \mathrm{~Hz}, 2.4 \mathrm{~Hz}$, 1H). ${ }^{13} \mathbf{C}$ NMR (100.6 MHz, $\left.\mathrm{CDCl}_{3}\right) \delta 197.0,136.3,135.8,133.8,133.5,129.5(\times 2 \mathrm{C}), 128.8,128.8$, 98.3, 57.3, 50.3. HRMS-DART $(\mathrm{m} / \mathrm{z})$ : $[\mathrm{M}+\mathrm{H}]^{+}$calcd for $\mathrm{C}_{16} \mathrm{H}_{13} \mathrm{Cl}_{4} \mathrm{O}, 360.9715$; found, 360.9708 . 
<smiles>O=C(c1ccccc1)C(CC(Cl)(Cl)Cl)c1ccc2ccccc2c1</smiles>

The product 4aj was purified by flash chromatography on silica gel (100:0-93:7, hexane/Et $\left.{ }_{2} \mathrm{O}\right)$. Then, the obtained solid was washed with hexane (Figure 2; $63.0 \mathrm{mg}, 0.17 \mathrm{mmol}, 83 \%$ isolated yield). White solid. M.p. ${ }^{126-127}{ }^{\circ} \mathrm{C}$. IR (neat) 477, 688, 738, 787, 817, 951, 1238, 1447, 1596, $1682 \mathrm{~cm}^{-}$ ${ }^{1} .{ }^{1} \mathbf{H}$ NMR $\left(400 \mathrm{MHz}, \mathrm{CDCl}_{3}\right) \delta 8.03-8.01(\mathrm{~m}, 2 \mathrm{H}), 7.81-7.76(\mathrm{~m}, 4 \mathrm{H}), 7.52-7.39(\mathrm{~m}, 6 \mathrm{H}), 5.31(\mathrm{~d}$, $J=7.6 \mathrm{~Hz}, 1 \mathrm{H}), 4.34(\mathrm{dd}, J=14.8,7.6 \mathrm{~Hz}, 1 \mathrm{H}), 3.11(\mathrm{~d}, J=14.8 \mathrm{~Hz}, 1 \mathrm{H}) .{ }^{13} \mathbf{C} \mathbf{N M R}(100.6 \mathrm{MHz}$, $\left.\mathrm{CDCl}_{3}\right) \delta 197.2,136.1,135.2,133.5,133.3,132.6,129.4,128.9,128.7,127.8,127.6,127.2,126.5$, 126.3, 125.8, 98.6, 57.4, 51.2. HRMS-DART $(\mathrm{m} / \mathrm{z})$ : $\left[\mathrm{M}+\mathrm{NH}_{4}\right]^{+}$calcd for $\mathrm{C}_{20} \mathrm{H}_{19} \mathrm{Cl}_{3} \mathrm{NO}, 394.0527$; found, 394.0526 .

\section{4,4,4-Trichloro-2-(6-methoxynaphthalen-2-yl)-1-phenylbutan-1-one (4ak)}<smiles>COc1ccc2cc(C(CC(Cl)(Cl)Cl)C(=O)c3ccccc3)ccc2c1</smiles>

The product 4ak was purified by flash chromatography on silica gel (100:0-82:18, hexane/Et $2 \mathrm{O})$. Then, the obtained solid was washed with hexane (Figure 2; $64.1 \mathrm{mg}, 0.16 \mathrm{mmol}, 79 \%$ isolated yield). White solid. M.p. $119-121{ }^{\circ} \mathrm{C}$. IR (neat) $687,718,786,852,954,1217,1267,1482,1604,1681 \mathrm{~cm}^{-}$ ${ }^{1} .{ }^{1} \mathbf{H}$ NMR $\left(400 \mathrm{MHz}, \mathrm{CDCl}_{3}\right) \delta 8.05-8.02(\mathrm{~m}, 2 \mathrm{H}), 7.71-7.66(\mathrm{~m}, 3 \mathrm{H}), 7.51-7.39(\mathrm{~m}, 4 \mathrm{H}), 7.13(\mathrm{~m}$, 1H), $7.07(\mathrm{~m}, 1 \mathrm{H}), 5.26(\mathrm{dd}, J=7.6,2.4 \mathrm{~Hz}, 1 \mathrm{H}), 4.32(\mathrm{dd}, J=14.8,7.6 \mathrm{~Hz}, 1 \mathrm{H}), 3.89$ (s, 3H), 3.10 $(\mathrm{d}, J=14.8,2.4 \mathrm{~Hz}, 1 \mathrm{H}) .{ }^{13} \mathbf{C}$ NMR $\left(100.6 \mathrm{MHz}, \mathrm{CDCl}_{3}\right) \delta 197.3,158.0,136.2,133.8,133.2,132.8$, $129.3,129.0,128.8,128.7,128.1,127.0,126.3,119.4,105.5,98.6,57.4,55.3,51.0$. HRMS-DART $(\mathrm{m} / \mathrm{z}):\left[\mathrm{M}+\mathrm{NH}_{4}\right]^{+}$calcd for $\mathrm{C}_{21} \mathrm{H}_{21} \mathrm{Cl}_{3} \mathrm{NO}_{2}, 424.0632$; found, 424.0638 .

\section{4,4,4-Trichloro-1-phenyl-2-(thiophen-2-yl)butan-1-one (4al)}<smiles>O=C(c1ccccc1)C(CC(Cl)(Cl)Cl)c1cccs1</smiles>

The product 4al was purified by flash chromatography on silica gel (100:0-93:7, hexane/Et $2 \mathrm{O}$ ). Then the obtained solid was washed with hexane (Figure $2 ; 48.5 \mathrm{mg}, 0.15 \mathrm{mmol}, 73 \%$ isolated yield). White solid. M.p. $74-76^{\circ} \mathrm{C}$. IR (neat) 539, 687, 696, 748, 787, 952, 1240, 1448, 1596, $1686 \mathrm{~cm}^{-1}$. 
${ }^{1} \mathbf{H}$ NMR $\left(400 \mathrm{MHz}, \mathrm{CDCl}_{3}\right) \delta 8.05-8.03(\mathrm{~m}, 2 \mathrm{H}), 7.56(\mathrm{~m}, 1 \mathrm{H}), 7.48-7.44(\mathrm{~m}, 2 \mathrm{H}), 7.21(\mathrm{~m}, 1 \mathrm{H})$, 6.92-6.91 (m, 2H), $5.42(\mathrm{~d}, J=8.0 \mathrm{~Hz}, 1 \mathrm{H}), 4.24(\mathrm{dd}, J=14.8,8.0 \mathrm{~Hz}, 1 \mathrm{H}), 3.13(\mathrm{~d}, J=14.8 \mathrm{~Hz}$, $1 \mathrm{H}) .{ }^{13} \mathrm{C}$ NMR $\left(100.6 \mathrm{MHz}, \mathrm{CDCl}_{3}\right) \delta 196.1,139.7,135.7,133.5,128.9,128.8,127.4,126.3,125.8$, 98.0, 57.8, 45.5. HRMS-DART $(\mathrm{m} / \mathrm{z})$ : $\left[\mathrm{M}+\mathrm{NH}_{4}\right]^{+}$calcd for $\mathrm{C}_{14} \mathrm{H}_{15} \mathrm{Cl}_{3} \mathrm{NOS}, 349.9934$; found, 349.9926 .

\section{4,4,5,5,5-Pentachloro-1,2-diphenylpentan-1-one (7aa)}<smiles>O=C(c1ccccc1)C(CC(Cl)(Cl)Cl)c1ccccc1</smiles>

The product 7aa was purified by flash chromatography on silica gel (100:0-95:5, hexane/Et $\mathrm{t}_{2} \mathrm{O}$ ). Then the obtained solid was washed with hexane (Figure 3A, $53.5 \mathrm{mg}, 0.13 \mathrm{mmol}, 65 \%$ isolated yield). White solid. M.p. $105-107^{\circ} \mathrm{C}$. IR (neat) 520, 608, 694, 754, 788, 809, 955, 1251, 1447, 1683 $\mathrm{cm}^{-1} .{ }^{1} \mathbf{H}$ NMR $\left(400 \mathrm{MHz}, \mathrm{CDCl}_{3}\right) \delta 8.06-8.04(\mathrm{~m}, 2 \mathrm{H}), 7.55-7.21(\mathrm{~m}, 8 \mathrm{H}), 5.30(\mathrm{dd}, J=8.4,1.6$ $\mathrm{Hz}, 1 \mathrm{H}), 4.28(\mathrm{dd}, J=14.8,8.4 \mathrm{~Hz}, 1 \mathrm{H}), 2.85(\mathrm{dd}, J=14.8 \mathrm{~Hz}, 1.6 \mathrm{~Hz}, 1 \mathrm{H}) .{ }^{13} \mathbf{C} \mathbf{N M R}(100.6 \mathrm{MHz}$, $\left.\mathrm{CDCl}_{3}\right) \delta 197.5,138.4,136.0,133.2,129.4,128.9,128.7,128.2,127.7,104.5,99.4,50.8,45.2$. HRMS-DART $(\mathrm{m} / \mathrm{z})$ : $\left[\mathrm{M}+\mathrm{NH}_{4}\right]^{+}$calcd for $\mathrm{C}_{17} \mathrm{H}_{17} \mathrm{Cl}_{5} \mathrm{NO}, 425.9747$; found, 425.9753 .

\section{Procedures for Synthesis of 1,1-Dichlorocyclopropanes}

The reaction with $4 \mathrm{aa}$ is representative. Trichloromethylacylation product 4aa $(65.5 \mathrm{mg}, 0.2 \mathrm{mmol})$ was placed in a schlenk tube containing a magnetic stirring bar. The vial was sealed with a Teflon ${ }^{\circledR}$ coated silicon rubber septum, and then the vial was evacuated and filled with nitrogen. $\mathrm{Cs}_{2} \mathrm{CO}_{3}(78.2$ $\mathrm{mg}, 0.24 \mathrm{mmol})$ was added. Then, Degassed DMSO $(400 \mu \mathrm{L})$ was added to the vial. After $4 \mathrm{~h}$ stirring at $60{ }^{\circ} \mathrm{C}$, the reaction mixture was treated with saturated $\mathrm{NH}_{4} \mathrm{Cl}$ aqueous solution $(400 \mu \mathrm{L})$, then extracted with diethyl ether (4 times) and dried over sodium sulfate. After filtration, the resulting solution was evaporated under reduced pressure. After volatiles were removed under reduced pressure, flash column chromatography on silica gel (100:0-95:5, hexane/Et $\left.{ }_{2} \mathrm{O}\right)$ gave 5aa (58.2 mg, 0.20 mmol, quant.). 


\section{Characterization Data for 1,1-Dichlorocyclopropanes}

(2,2-Dichloro-1-phenylcyclopropyl)(phenyl)methanone (5aa)<smiles>O=C(c1ccccc1)C1(c2ccccc2)CC1(Cl)Cl</smiles>

The product 5aa was purified by flash chromatography on silica gel (100:0-95:5, hexane/Et $2 \mathrm{O})$. Then the obtained solid was washed with hexane (Figure 3B; $58.2 \mathrm{mg}, 0.20 \mathrm{mmol}$, quant.). White solid. M.p. 97-99 ${ }^{\circ} \mathrm{C}$. IR (neat) 613, 694, 754, 794, 941, 1260, 1446, 1596, 1676, $3058 \mathrm{~cm}^{-1} .{ }^{1} \mathbf{H}$ NMR (400 MHz, $\left.\mathrm{CDCl}_{3}\right) \delta 8.03-8.01(\mathrm{~m}, 2 \mathrm{H}), 7.61-7.44(\mathrm{~m}, 5 \mathrm{H}), 7.33-7.24(\mathrm{~m}, 3 \mathrm{H}), 2.59(\mathrm{~d}, J=$ $7.6 \mathrm{~Hz}, 1 \mathrm{H}), 2.24(\mathrm{~d}, J=7.6 \mathrm{~Hz}, 1 \mathrm{H}) .{ }^{13} \mathbf{C} \mathbf{N M R}\left(100.6 \mathrm{MHz}, \mathrm{CDCl}_{3}\right) \delta 192.9,134.7,134.6,133.3$, 130.4, 129.8, 128.6, 128.4, 128.2, 61.3, 48.5, 31.6. HRMS-DART $(\mathrm{m} / z):\left[\mathrm{M}+\mathrm{NH}_{4}\right]^{+}$calcd for $\mathrm{C}_{16} \mathrm{H}_{16} \mathrm{Cl}_{2} \mathrm{NO}, 308.0604$; found, 308.0612.

\section{[2,2-Dichloro-1-(4-methoxyphenyl)cyclopropyl](phenyl)methanone (5ab)}<smiles>COc1ccc(C2(C(=O)c3ccccc3)CC2(Cl)Cl)cc1</smiles>

The product 5ab was purified by flash chromatography on silica gel (95:5-85:15, hexane/Et $\left.\mathrm{t}_{2} \mathrm{O}\right)$. Then the obtained solid was washed with hexane (Figure 3B; $64.2 \mathrm{mg}, 0.20 \mathrm{mmol}$, quant.). Pale solid. M.p. $95-96{ }^{\circ} \mathrm{C}$. IR (neat) 694, 767, 833, 1033, 1175, 1251, 1448, 1511, 1608, $1677 \mathrm{~cm}^{-1}$. ${ }^{1} \mathbf{H}$ NMR $\left(400 \mathrm{MHz} \mathrm{CDCl}_{3}\right) \delta 8.02-8.00(\mathrm{~m}, 2 \mathrm{H}), 7.55-7.44(\mathrm{~m}, 5 \mathrm{H}), 6.84-6.82(\mathrm{~m}, 2 \mathrm{H}), 3.75(\mathrm{~s}, 3 \mathrm{H}), 2.56$ $(\mathrm{d}, J=7.6 \mathrm{~Hz}, 1 \mathrm{H}), 2.18(\mathrm{~d}, J=7.6 \mathrm{~Hz}, 1 \mathrm{H}) .{ }^{13} \mathbf{C}$ NMR $\left(100.6 \mathrm{MHz}, \mathrm{CDCl}_{3}\right) \delta 193.1,159.3,134.8$, $133.1,131.6,129.7,128.4,126.5,114.0,61.5,55.1,47.9,31.6$. HRMS-DART $(\mathrm{m} / z):\left[\mathrm{M}+\mathrm{NH}_{4}\right]^{+}$ calcd for $\mathrm{C}_{17} \mathrm{H}_{18} \mathrm{Cl}_{2} \mathrm{NO}_{2}, 338.0709$; found, 338.0711.

\section{Methyl 4-(1-Benzoyl-2,2-dichlorocyclopropyl)benzoate (5af)}<smiles>CC(=O)c1ccc(C2(C(=O)c3ccccc3)CC2(Cl)Cl)cc1</smiles>

The reaction scale was modified to $0.1 \mathrm{mmol}$. The product 5af was purified by flash chromatography on silica gel (90:10-70:30, hexane/Et ${ }_{2} \mathrm{O}$ ) followed by GPC (Figure 3B, $28.0 \mathrm{mg}$, $0.08 \mathrm{mmol}, 80 \%$ isolated yield). Pale yellow oil. IR (neat) 695, 761, 999, 1096, 1112, 1180, 1275, 1435, 1679, $1719 \mathrm{~cm}^{-1} .{ }^{1} \mathbf{H}$ NMR (400 MHz, $\left.\mathrm{CDCl}_{3}\right) \delta 8.00-7.97(\mathrm{~m}, 4 \mathrm{H}), 7.69-7.67(\mathrm{~m}, 2 \mathrm{H}), 7.55$ $(\mathrm{m}, 1 \mathrm{H}), 7.48-7.44(\mathrm{~m}, 2 \mathrm{H}), 3.88(\mathrm{~s}, 3 \mathrm{H}), 2.65(\mathrm{~d}, J=7.6 \mathrm{~Hz}, 1 \mathrm{H}), 2.26(\mathrm{~d}, J=7.6 \mathrm{~Hz}, 1 \mathrm{H}) .{ }^{13} \mathbf{C} \mathbf{N M R}$ $\left(100.6 \mathrm{MHz} \mathrm{CDCl}_{3}\right) \delta 192.3,166.4,139.4,134.5,133.5,130.4,130.0,129.8,129.7,128.5,60.9$, 
52.2, 48.4, 31.8. HRMS-DART $(\mathrm{m} / \mathrm{z}):\left[\mathrm{M}+\mathrm{NH}_{4}\right]^{+}$calcd for $\mathrm{C}_{18} \mathrm{H}_{18} \mathrm{Cl}_{2} \mathrm{NO}_{3}, 366.0658$; found, 366.0656 .

\section{Cyclopropyl[2,2-dichloro-1-(4-methoxyphenyl)cyclopropyl]methanone (5pb)}

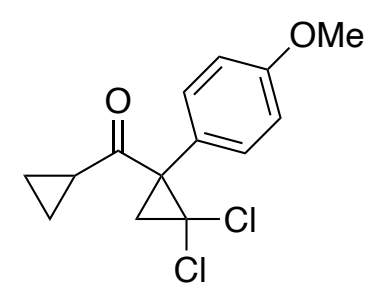

The reaction scale was modified to $0.09 \mathrm{mmol}$. The product $\mathbf{5 p b}$ was purified by flash chromatography on silica gel (90:10-70:30, hexane/Et ${ }_{2} \mathrm{O}$ ) followed by GPC (Figure 3B, $21.2 \mathrm{mg}$, $0.07 \mathrm{mmol}, 83 \%$ isolated yield). Yellow oil. IR (neat) 781, 834, 1019, 1123, 1177, 1248, 1378, 1512, 1608, $1692 \mathrm{~cm}^{-1} .{ }^{1} \mathbf{H}$ NMR $\left(400 \mathrm{MHz}, \mathrm{CDCl}_{3}\right) \delta 7.44(\mathrm{~d}, J=7.6 \mathrm{~Hz}, 2 \mathrm{H}), 6.93(\mathrm{~d}, J=7.6 \mathrm{~Hz}, 2 \mathrm{H})$, $3.83(\mathrm{~s}, 3 \mathrm{H}), 2.64(\mathrm{~d}, J=7.2 \mathrm{~Hz}, 1 \mathrm{H}), 2.31(\mathrm{~m}, 1 \mathrm{H}), 1.85(\mathrm{~d}, J=7.2 \mathrm{~Hz}, 1 \mathrm{H}), 1.10(\mathrm{~m}, 1 \mathrm{H}), 0.99-0.92$ $(\mathrm{m}, 2 \mathrm{H}), 0.83(\mathrm{~m}, 1 \mathrm{H}) .{ }^{13} \mathbf{C}$ NMR $\left(100.6 \mathrm{MHz}, \mathrm{CDCl}_{3}\right) \delta 201.9,159.6,132.1,127.1,114.0,61.6,55.2$, 50.5, 31.0, 19.4, 12.5, 12.4. HRMS-DART $(\mathrm{m} / \mathrm{z}):\left[\mathrm{M}+\mathrm{NH}_{4}\right]^{+}$calcd for $\mathrm{C}_{14} \mathrm{H}_{18} \mathrm{Cl}_{2} \mathrm{NO}_{2}, 302.0709$; found, 302.0710 .

\section{Procedure for Reaction with ATRA Product}

Figure 4A. Thiazolium salt $\mathbf{N 3}(7.7 \mathrm{mg}, 0.02 \mathrm{mmol})$ was placed in a schlenk tube containing a magnetic stirring bar. The vial was sealed with a Teflon ${ }^{\circledR}$-coated silicon rubber septum, and then the vial was evacuated and filled with nitrogen. $\mathrm{Cs}_{2} \mathrm{CO}_{3}(78.2 \mathrm{mg}, 0.24 \mathrm{mmol})$ was added. Then, degassed $\operatorname{DCM}(400 \mu \mathrm{L})$ was added to the vial. Next, benzaldehyde $1 \mathrm{a}(20.4 \mu \mathrm{L}, 0.2 \mathrm{mmol})$ and benzyl chloride $8(51.6 \mathrm{mg}, 0.2 \mathrm{mmol})$ were added. After $18 \mathrm{~h}$ stirring at $40{ }^{\circ} \mathrm{C}$ with oil bath, the reaction mixture was quenched through a pad of silica gel with DCM. The resulting solution was evaporated under reduced pressure. The desired coupling product was not observed at all on ${ }^{1} \mathrm{H}$ NMR analysis of the crude products.

\section{Procedure for Reaction without Styrene}

Figure 4B. Thiazolium salt $\mathbf{N 3}(7.7 \mathrm{mg}, 0.02 \mathrm{mmol})$ was placed in a schlenk tube containing a magnetic stirring bar. The vial was sealed with a Teflon ${ }^{\circledR}$-coated silicon rubber septum, and then the vial was evacuated and filled with nitrogen. $\mathrm{Cs}_{2} \mathrm{CO}_{3}(78.2 \mathrm{mg}, 0.24 \mathrm{mmol})$ was added. Then, degassed DCM $(400 \mu \mathrm{L})$ was added to the vial. Next, benzaldehyde 1a $(20.4 \mu \mathrm{L}, 0.2 \mathrm{mmol})$ and tetrachloromethane $3(38.8 \mu \mathrm{L}, 0.4 \mathrm{mmol})$ were added. After $18 \mathrm{~h}$ stirring at $40{ }^{\circ} \mathrm{C}$ with oil bath, the reaction mixture was quenched through a pad of silica gel with DCM. The resulting solution was evaporated under reduced pressure. The direct coupling product was not observed at all on ${ }^{1} \mathrm{H}$ NMR analysis of the crude products. 
9. Effect of NHC Catalysts on Reactions with Aliphatic Aldehydes

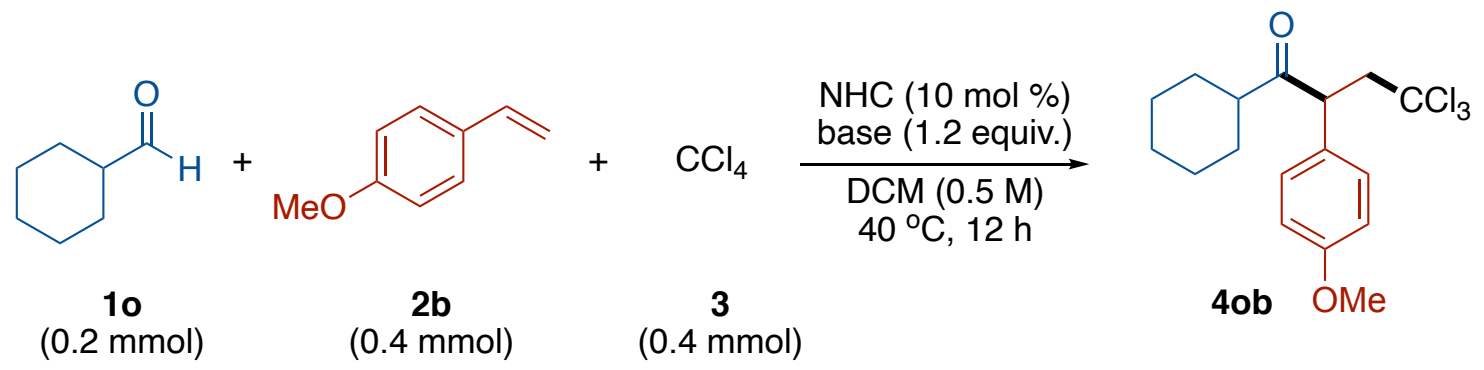

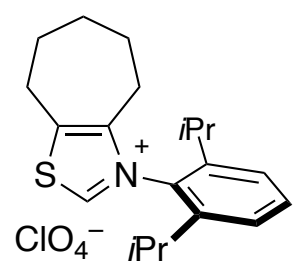

N1

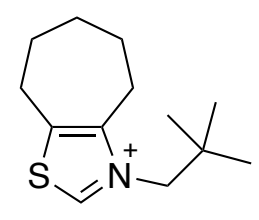

$\mathrm{ClO}_{4}^{-}$

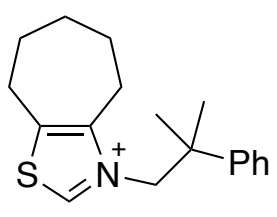

$\mathrm{ClO}_{4}^{-}$

N3

$78 \%$

Figure S2. Effect of NHC catalysts

\section{X-Ray Crystallographic Data for N3}

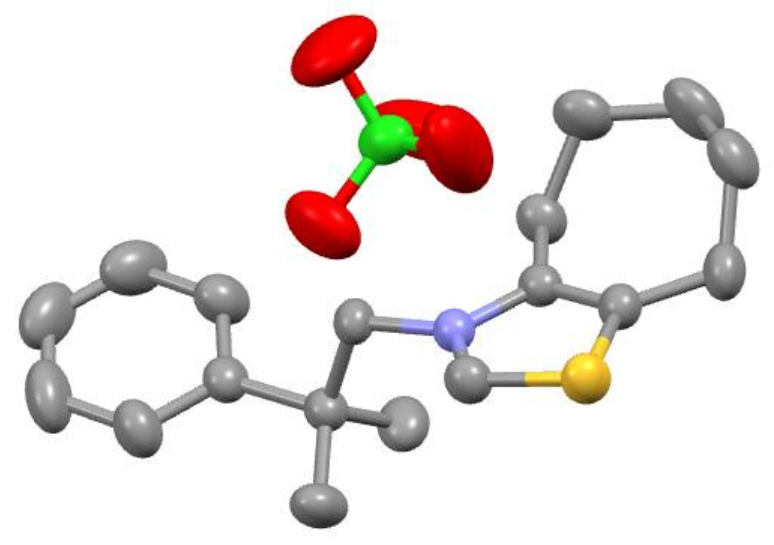

Figure S3. X-ray Crystallography Data for N3 (CCDC 2100273). Ellipsoids are drawn at 50\% probability. A colorless crystal suitable for Xray crystallography was obtained from ethyl acetate/dichloromethane solution at $0{ }^{\circ} \mathrm{C}$. Hydrogen atoms are omitted for clarity. 


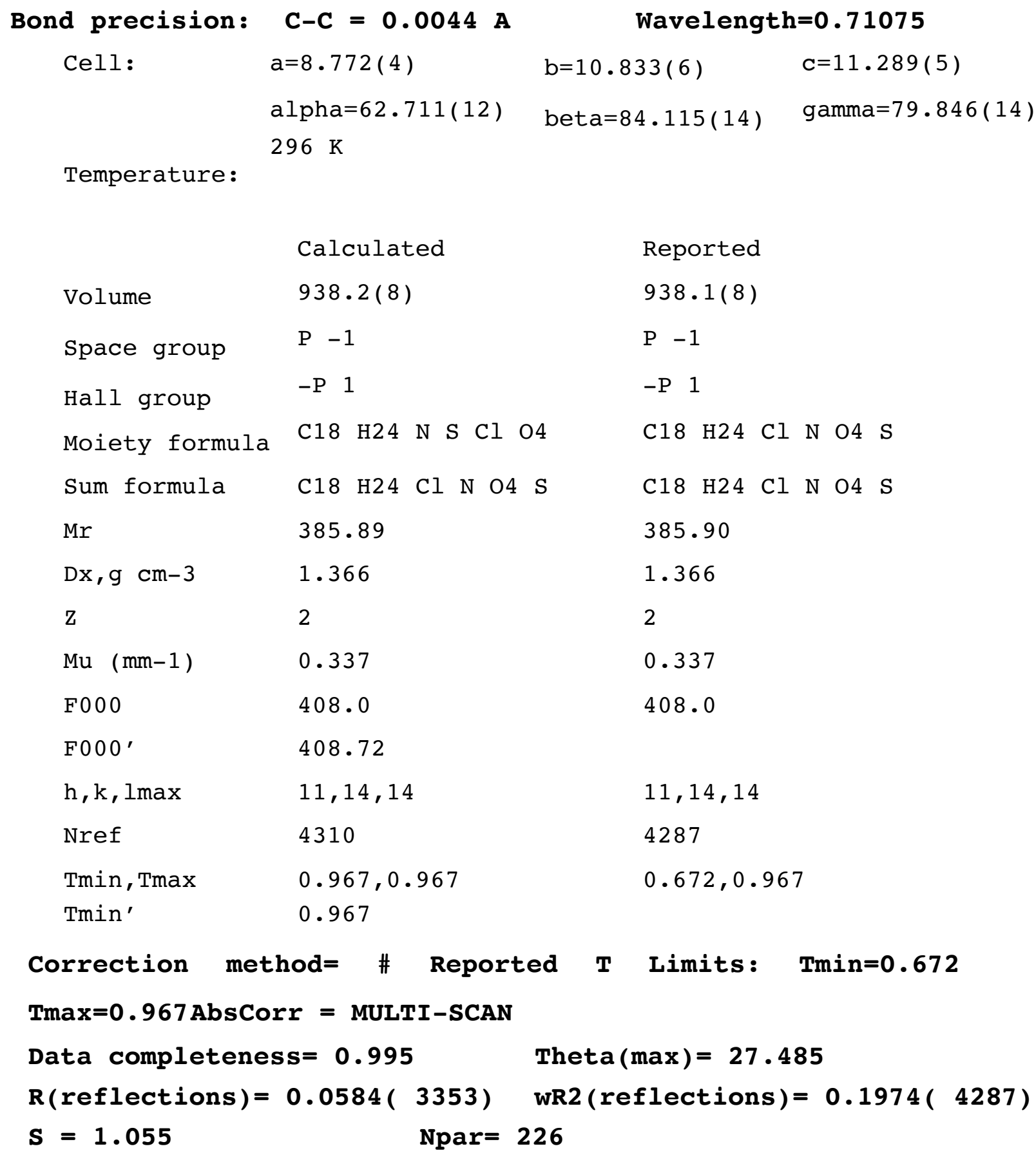

\section{Supplementary References}

(1) Piel, I.; Pawelczyk, M. D.; Hirano, K.; Fröhlich, R.; Glorius, F. Eur. J. Org. Chem. 2011, 5475.

(2) Kakeno, Y.; Kusakabe, M.; Nagao, K.; Ohmiya, H. ACS Catal. 2020, 10, 8524-8529. 


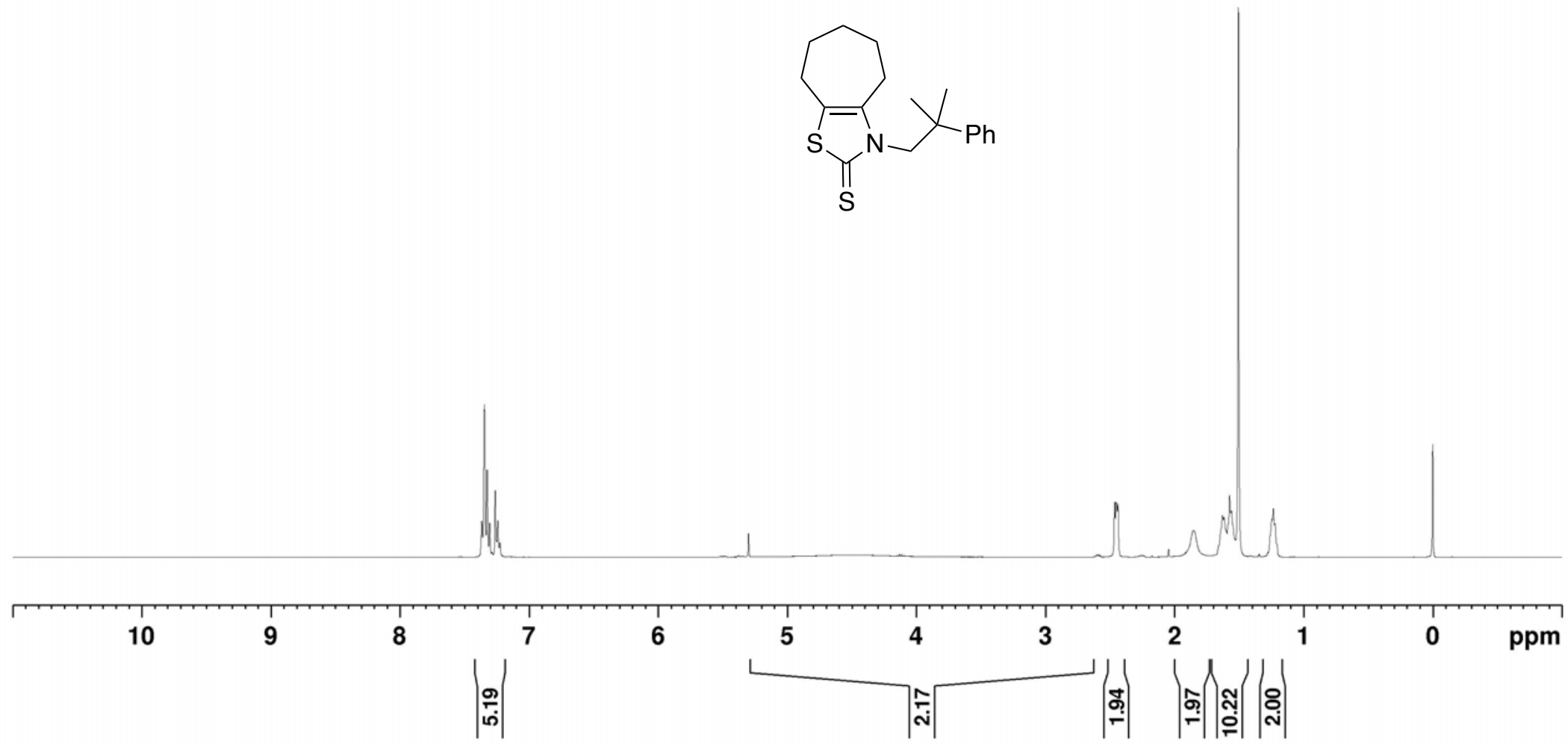

${ }^{1} \mathrm{H}$ NMR spectrum of $\mathbf{S 3}\left(\mathrm{CDCl}_{3}, 400 \mathrm{MHz}\right)$ 


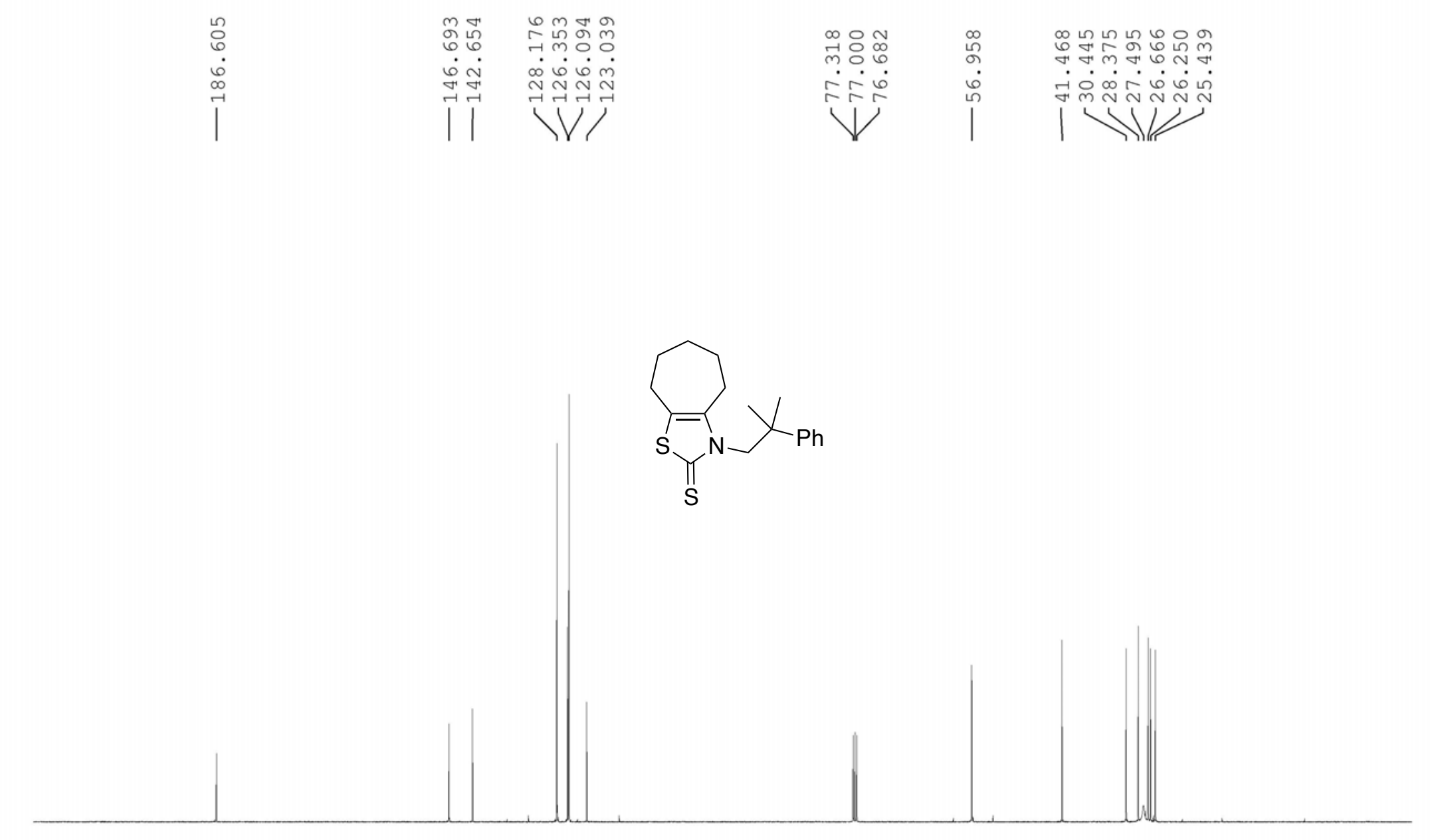

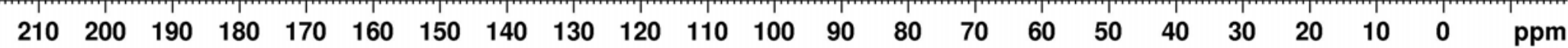



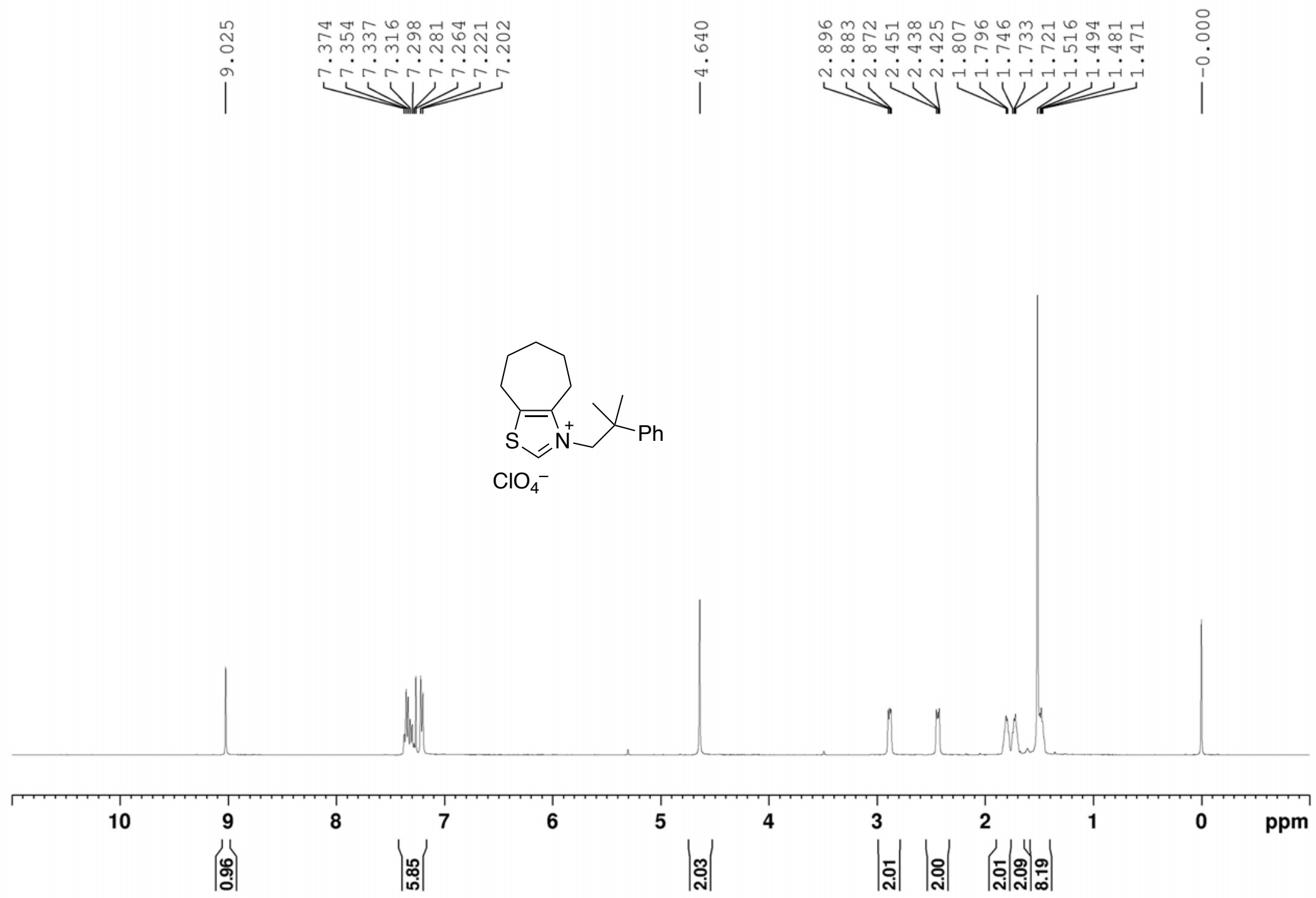

${ }^{1} \mathrm{H}$ NMR spectrum of $\mathbf{N} \mathbf{3}\left(\mathrm{CDCl}_{3}, 400 \mathrm{MHz}\right)$ 

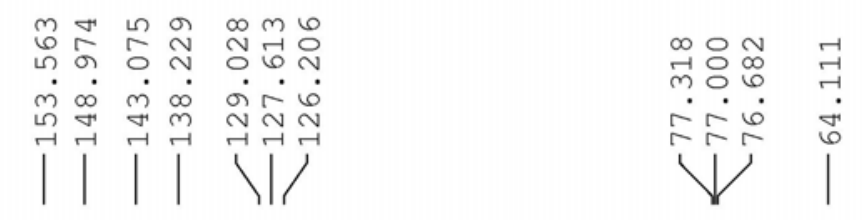

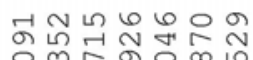

कें

$11 / /$

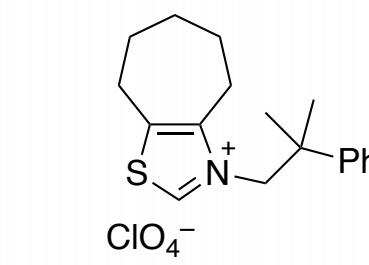

${ }^{13} \mathrm{C}$ NMR spectrum of $\mathbf{N} \mathbf{3}\left(\mathrm{CDCl}_{3}, 100.6 \mathrm{MHz}\right)$ 

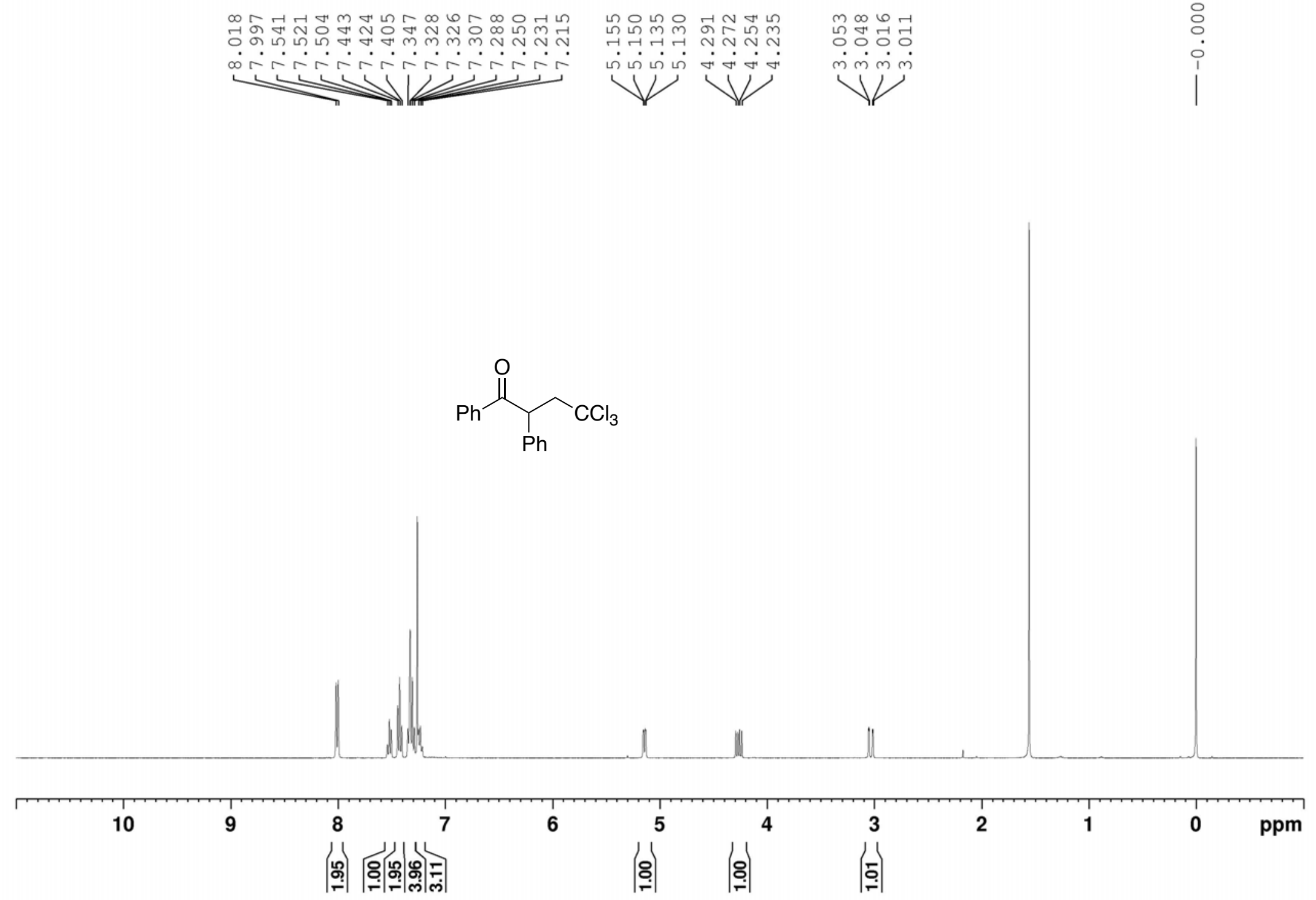

${ }^{1} \mathrm{H}$ NMR spectrum of $\mathbf{4 a a}\left(\mathrm{CDCl}_{3}, 400 \mathrm{MHz}\right)$ 

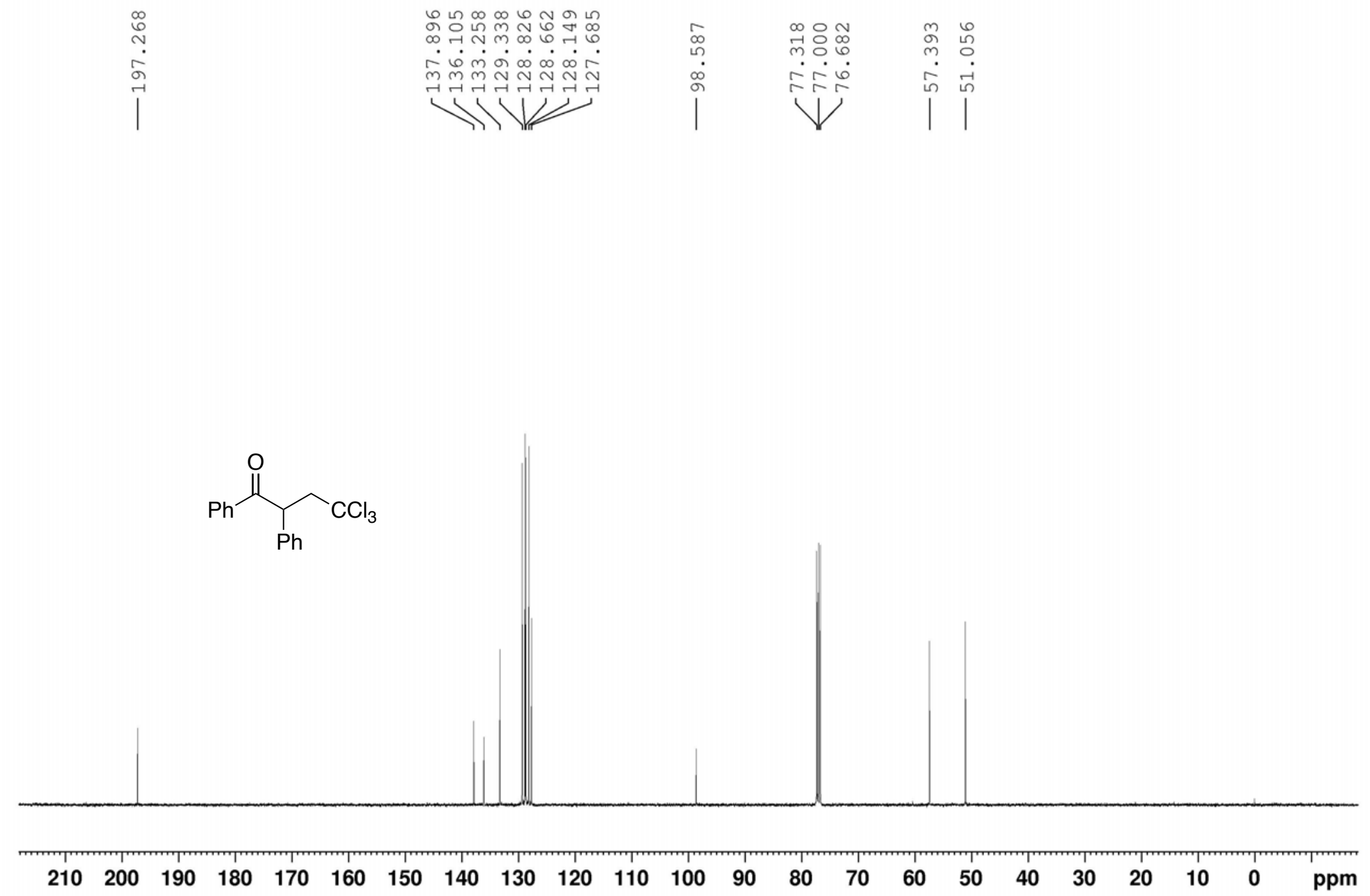

${ }^{13} \mathrm{C}$ NMR spectrum of $4 \mathbf{a a}\left(\mathrm{CDCl}_{3}, 100.6 \mathrm{MHz}\right)$ 


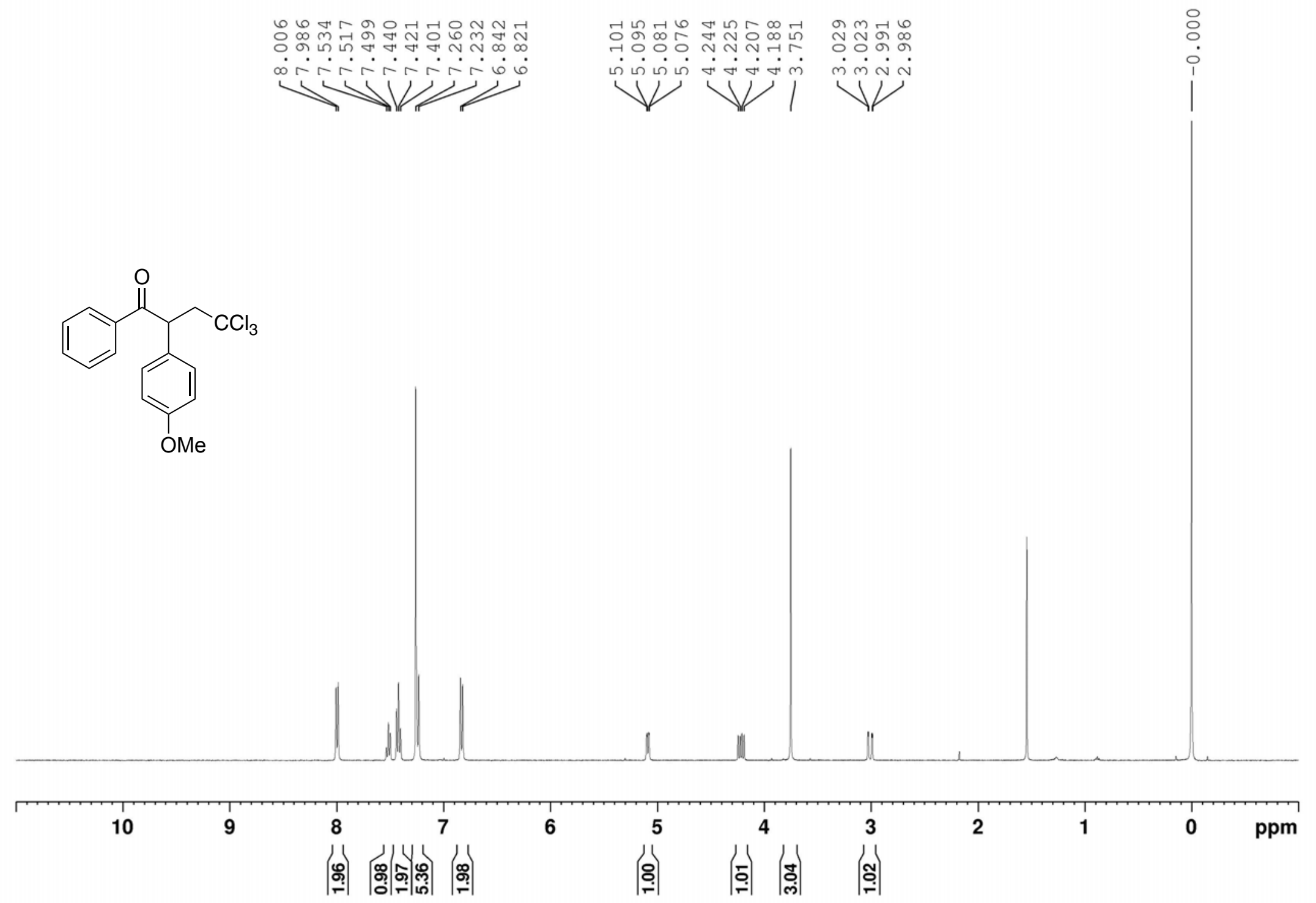

${ }^{1} \mathrm{H}$ NMR spectrum of $\mathbf{4} \mathbf{a b}\left(\mathrm{CDCl}_{3}, 400 \mathrm{MHz}\right)$ 

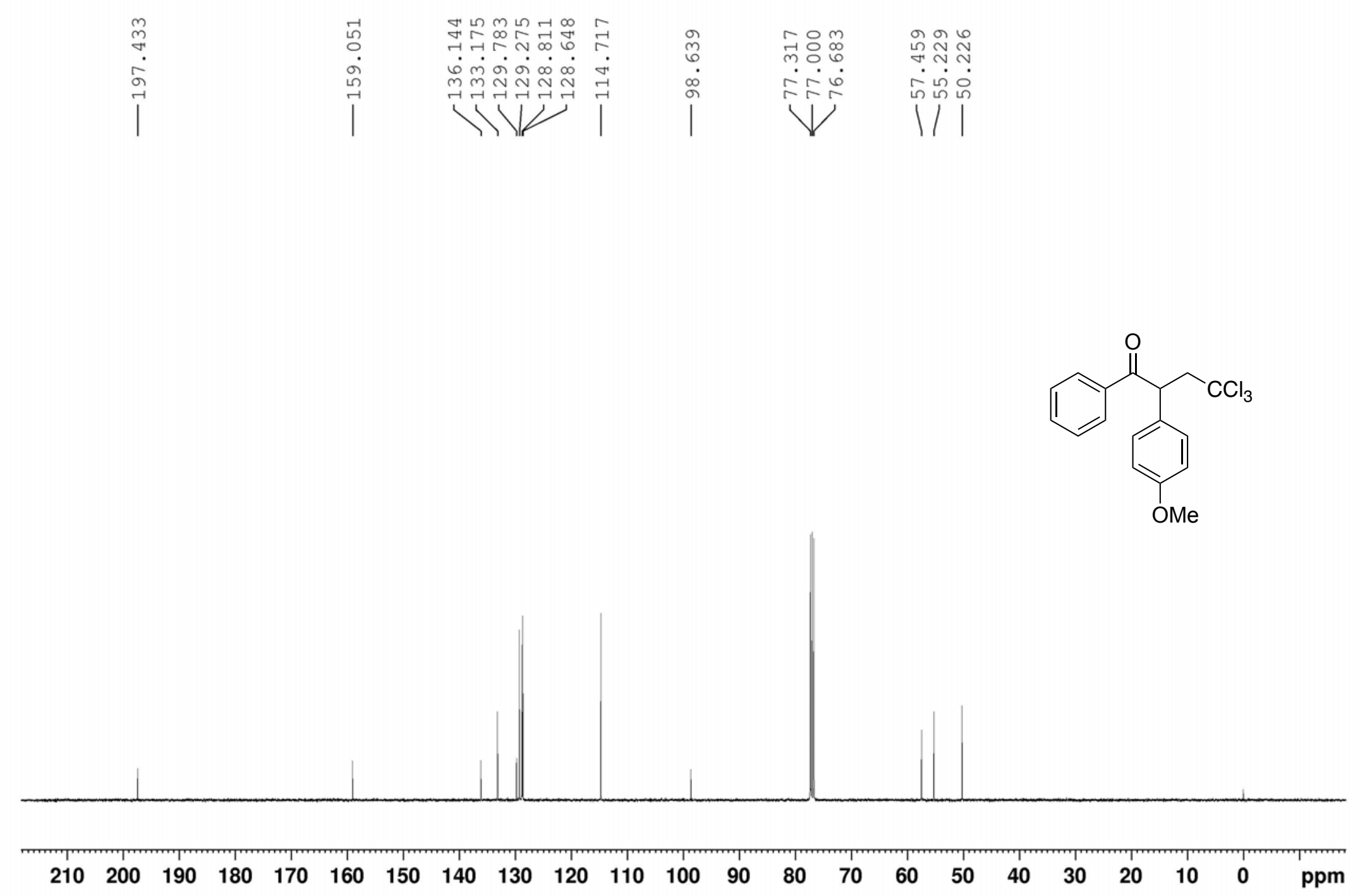

${ }^{13} \mathrm{C} \mathrm{NMR}$ spectrum of $\mathbf{4 a b}\left(\mathrm{CDCl}_{3}, 100.6 \mathrm{MHz}\right)$ 

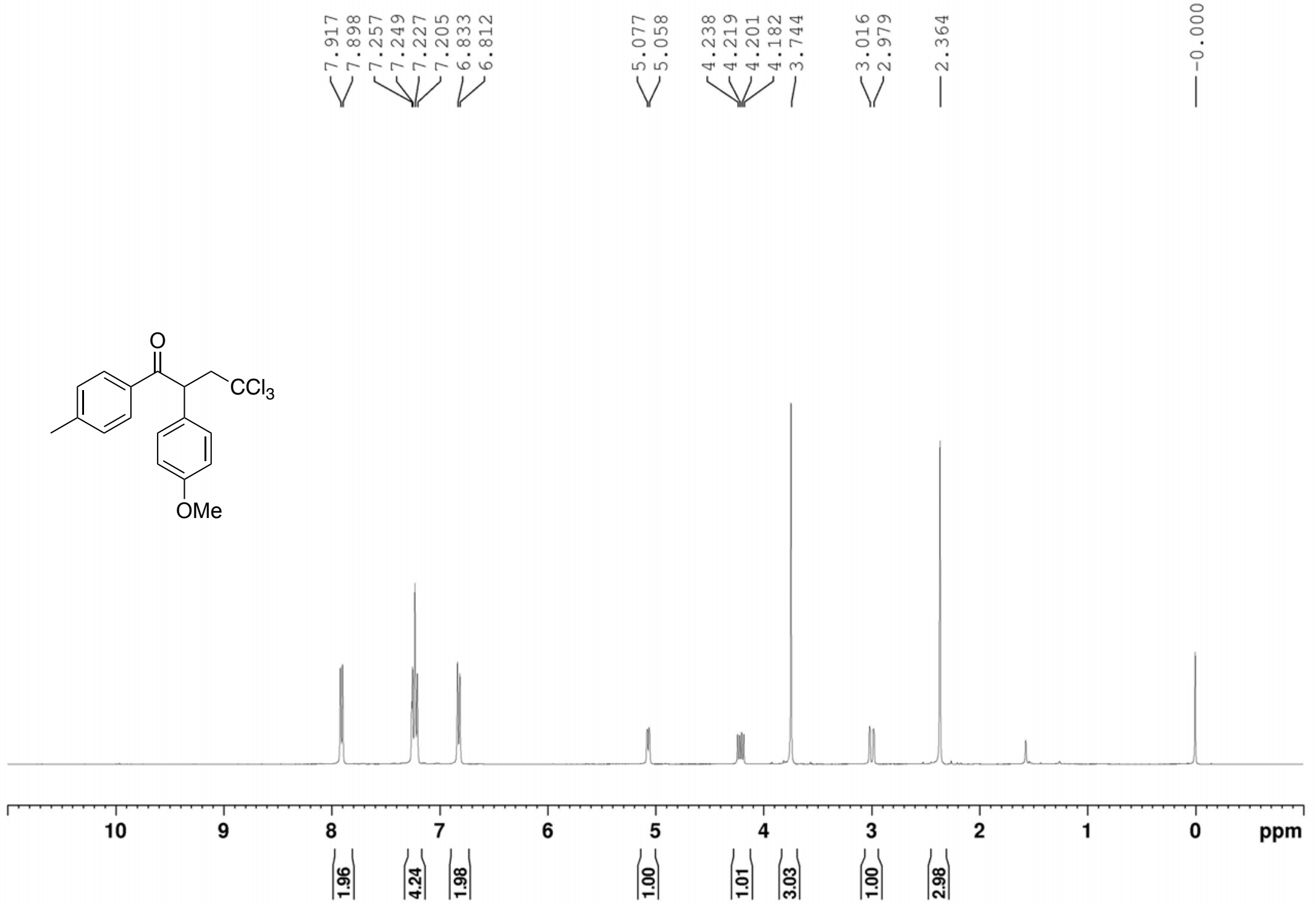

${ }^{1} \mathrm{H}$ NMR spectrum of $\mathbf{4 b b}\left(\mathrm{CDCl}_{3}, 400 \mathrm{MHz}\right)$ 


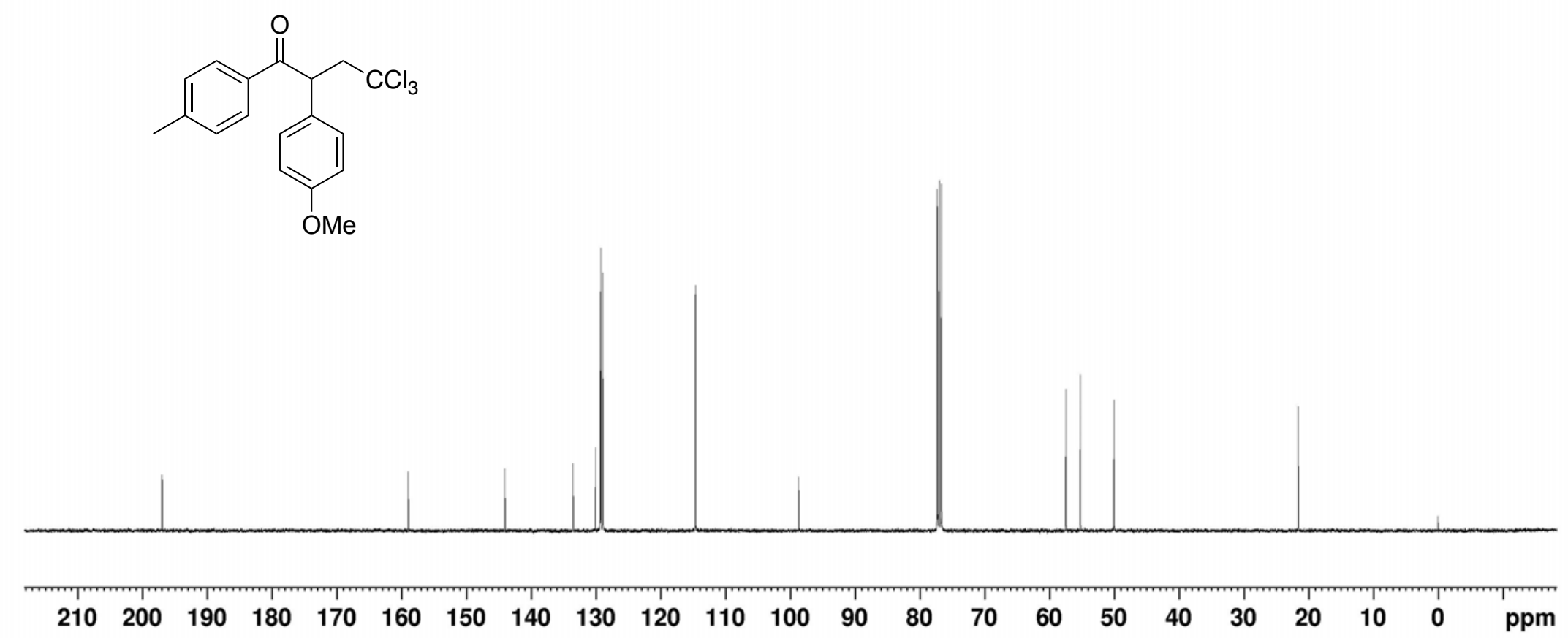

${ }^{13} \mathrm{C}$ NMR spectrum of $\mathbf{4 b b}\left(\mathrm{CDCl}_{3}, 100.6 \mathrm{MHz}\right)$ 

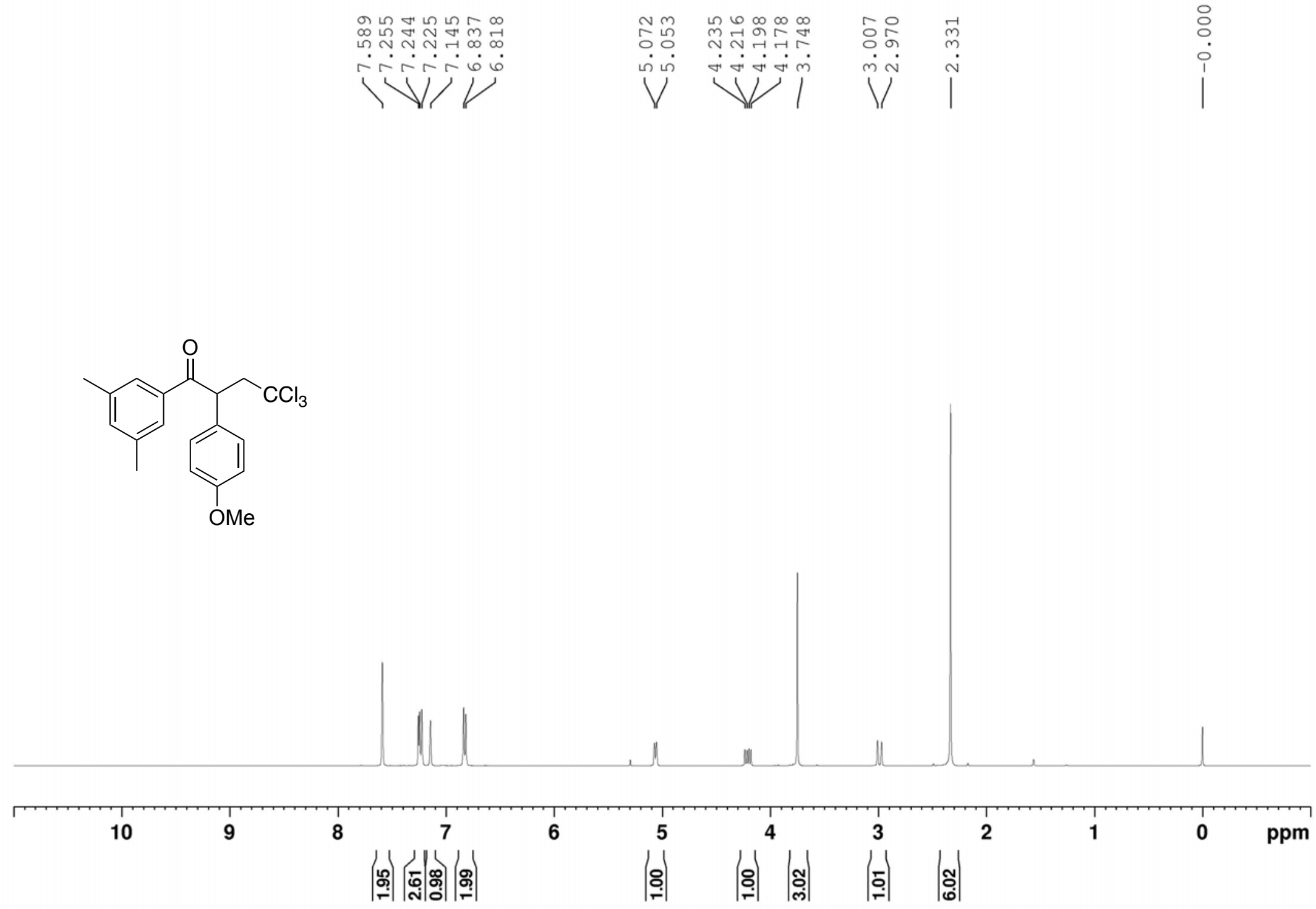

${ }^{1} \mathrm{H}$ NMR spectrum of $\mathbf{4} \mathbf{c b}\left(\mathrm{CDCl}_{3}, 400 \mathrm{MHz}\right)$ 


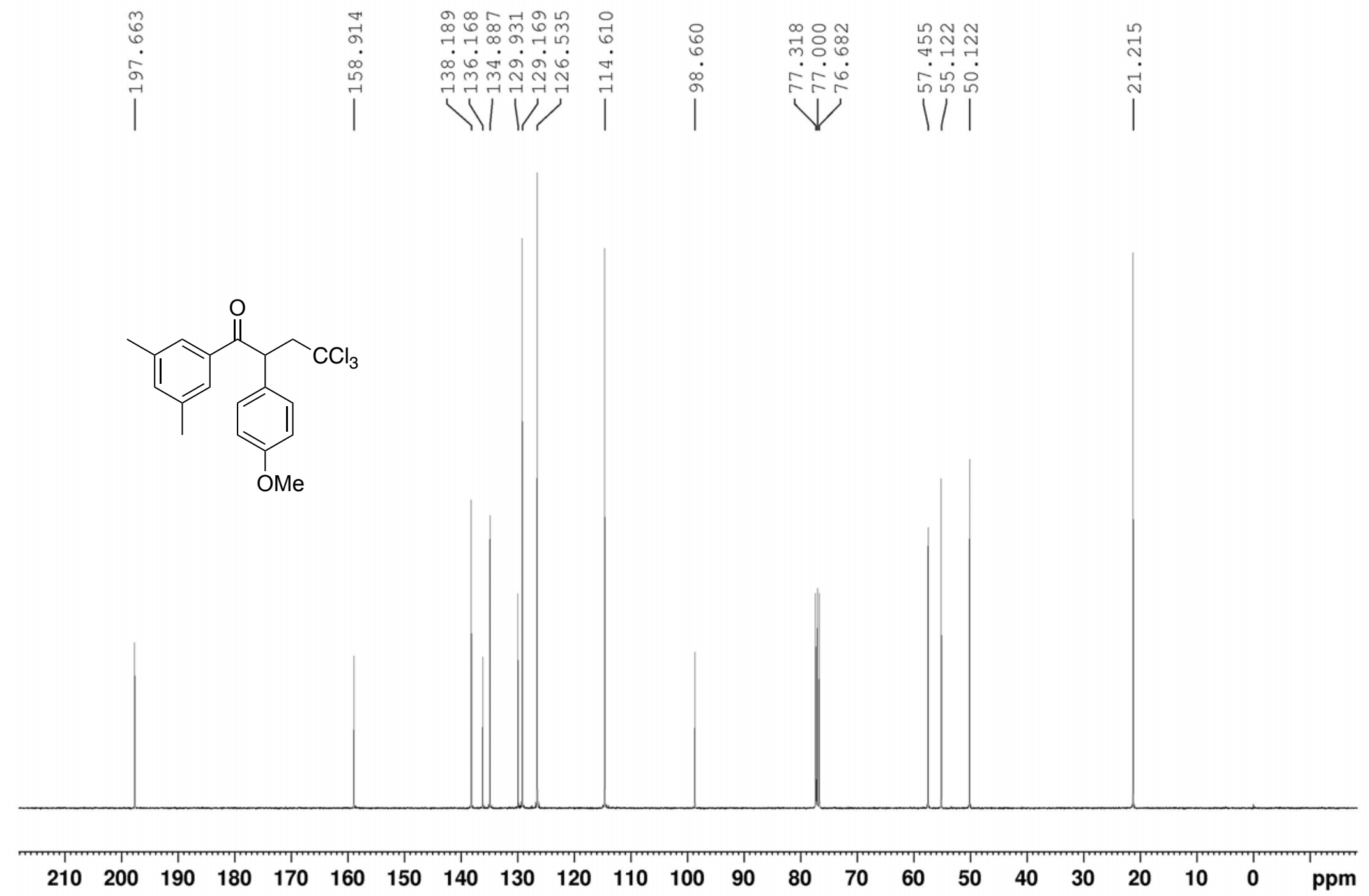

${ }^{13} \mathrm{C}$ NMR spectrum of $\mathbf{4} \mathbf{c b}\left(\mathrm{CDCl}_{3}, 100.6 \mathrm{MHz}\right)$ 

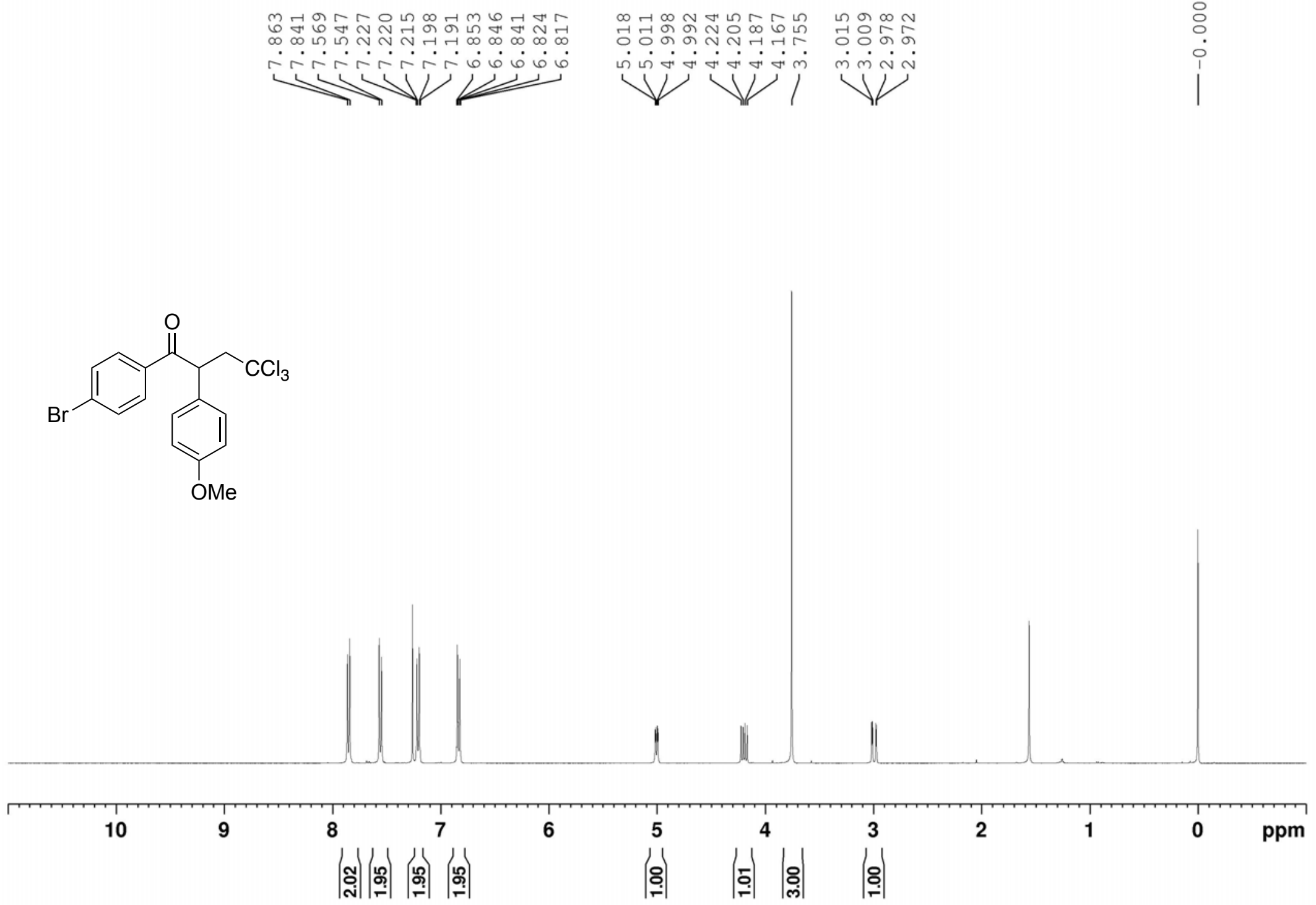

${ }^{1} \mathrm{H}$ NMR spectrum of $\mathbf{4 d b}\left(\mathrm{CDCl}_{3}, 400 \mathrm{MHz}\right)$ 


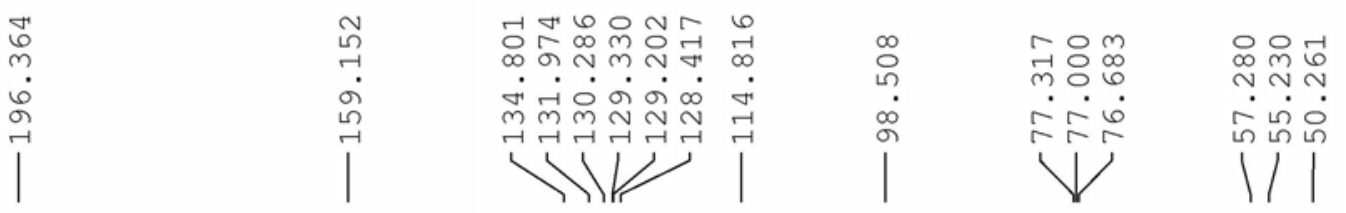

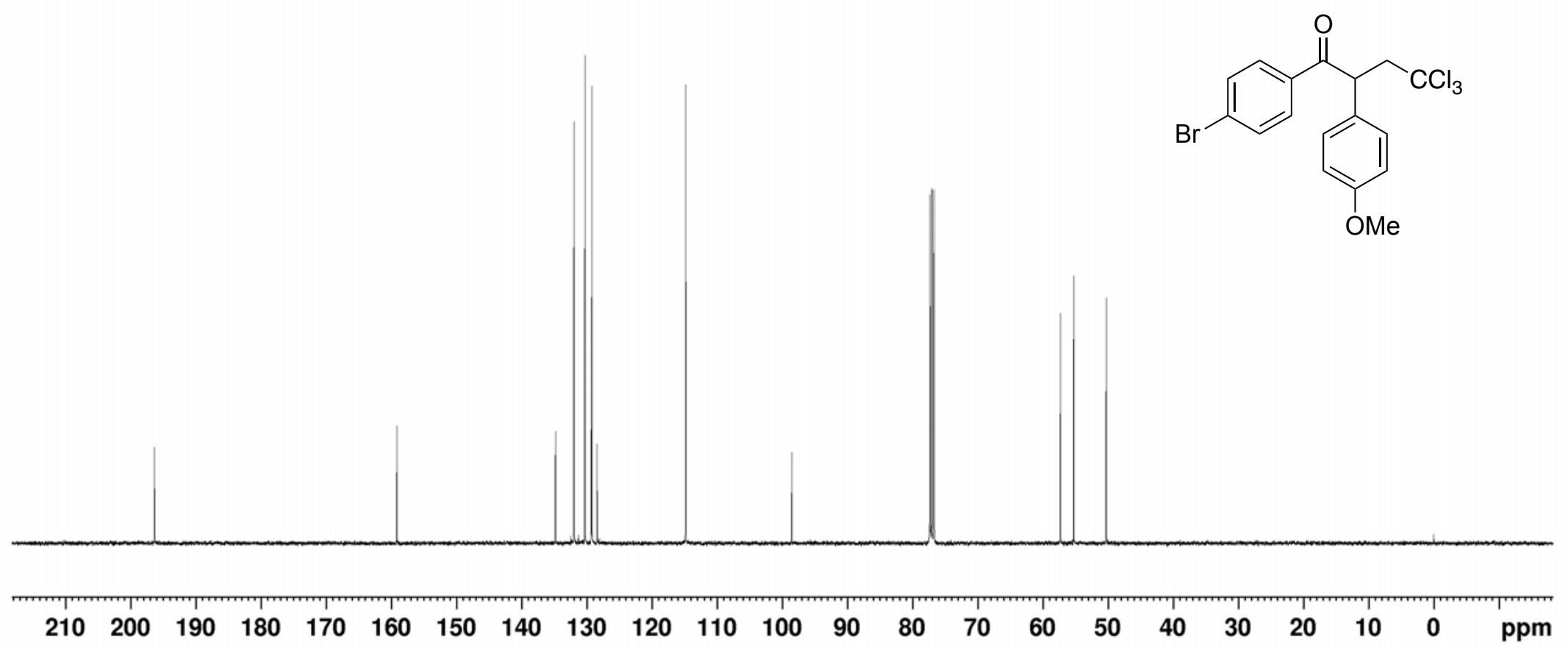

${ }^{13} \mathrm{C}$ NMR spectrum of $\mathbf{4 d b}\left(\mathrm{CDCl}_{3}, 100.6 \mathrm{MHz}\right)$ 


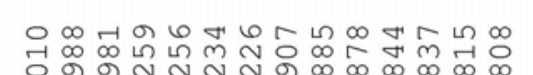 orrarríri $\underbrace{2}$}
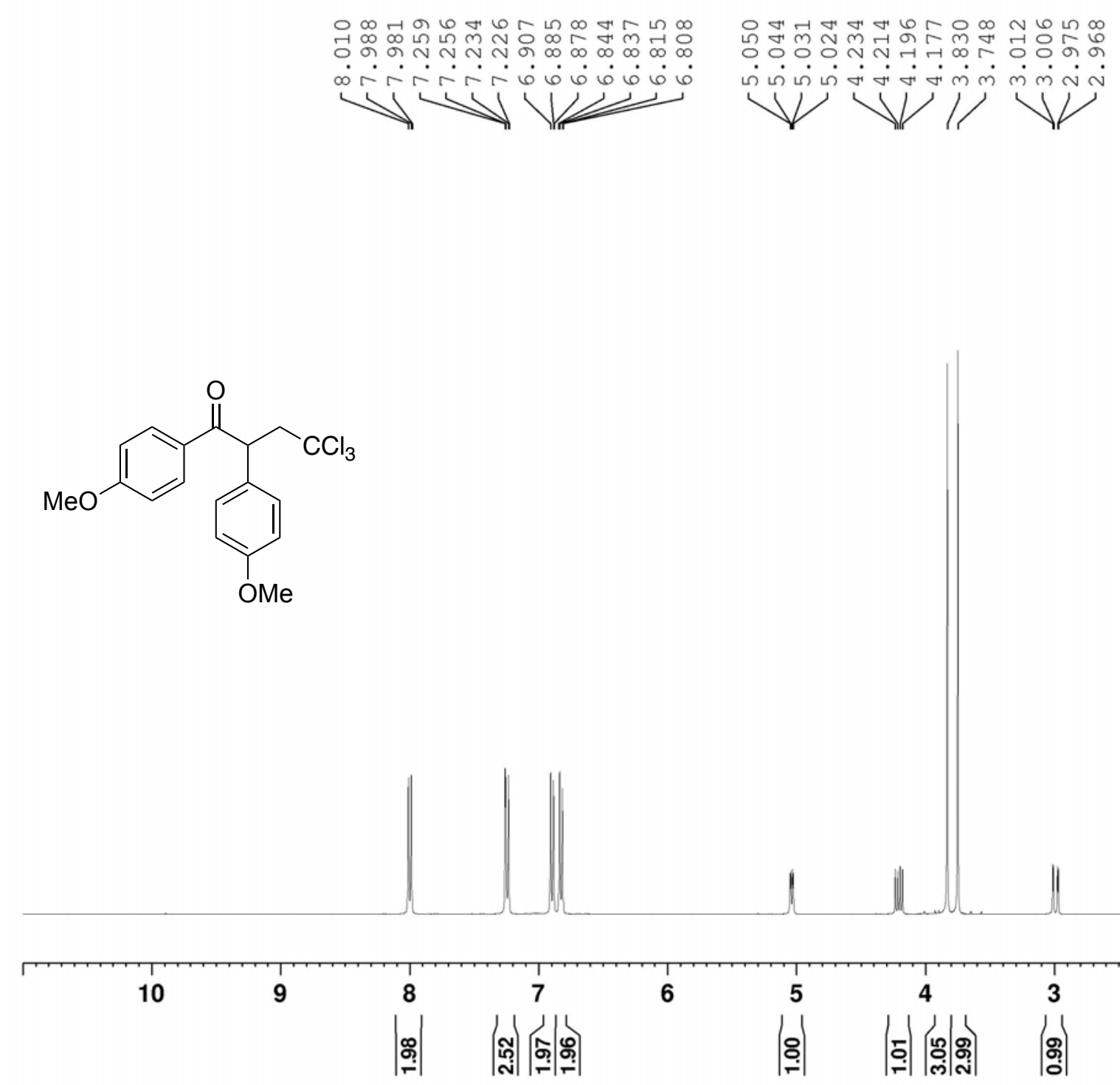

.

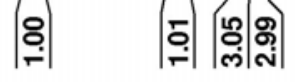
3
|すু)

${ }^{1} \mathrm{H}$ NMR spectrum of $\mathbf{4 e b}\left(\mathrm{CDCl}_{3}, 400 \mathrm{MHz}\right)$ 

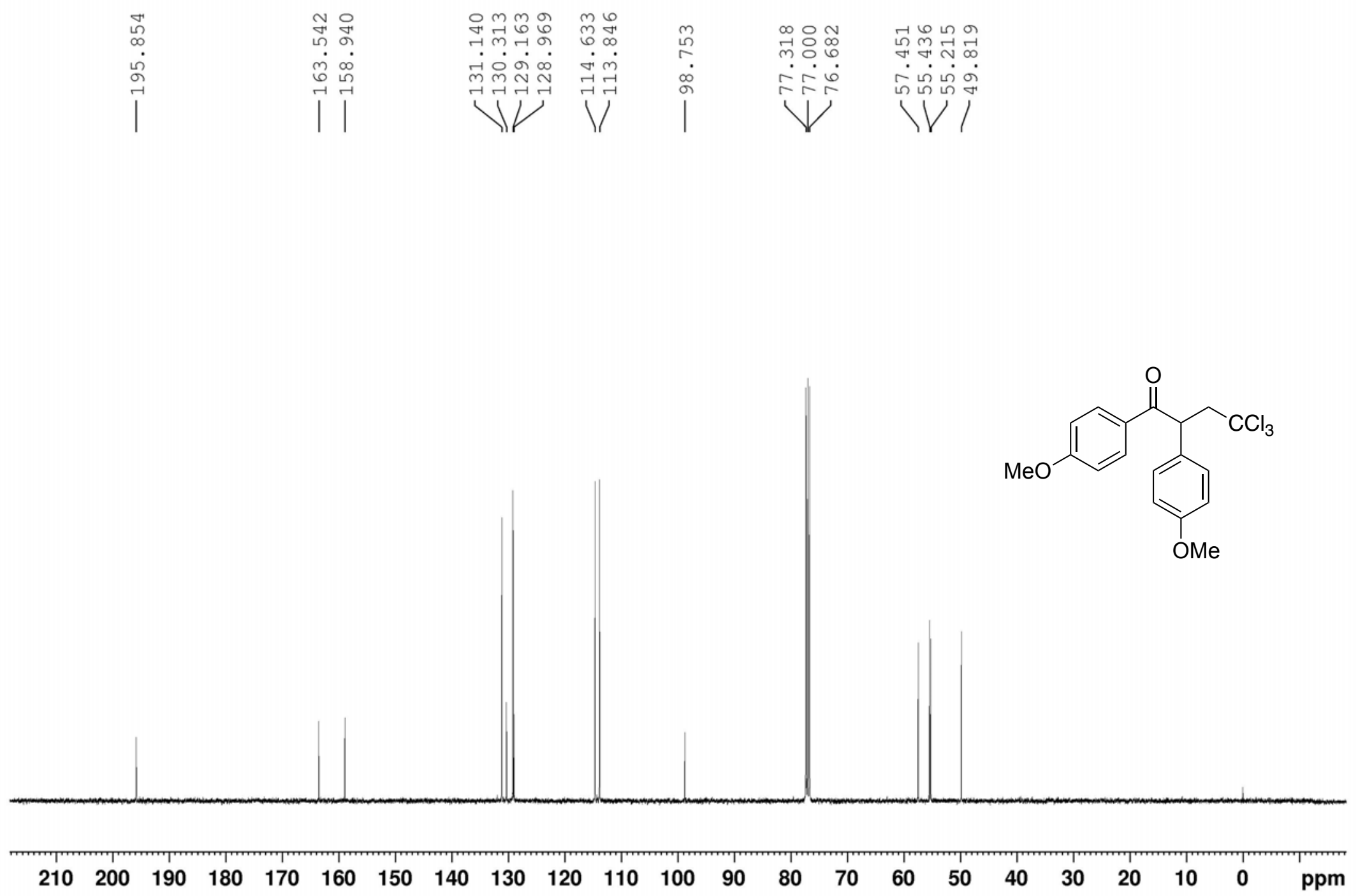

${ }^{13} \mathrm{C}$ NMR spectrum of $4 \mathbf{e b}\left(\mathrm{CDCl}_{3}, 100.6 \mathrm{MHz}\right)$ 


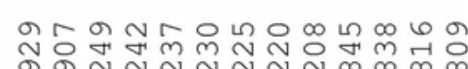

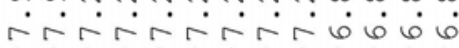

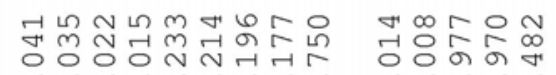

nं
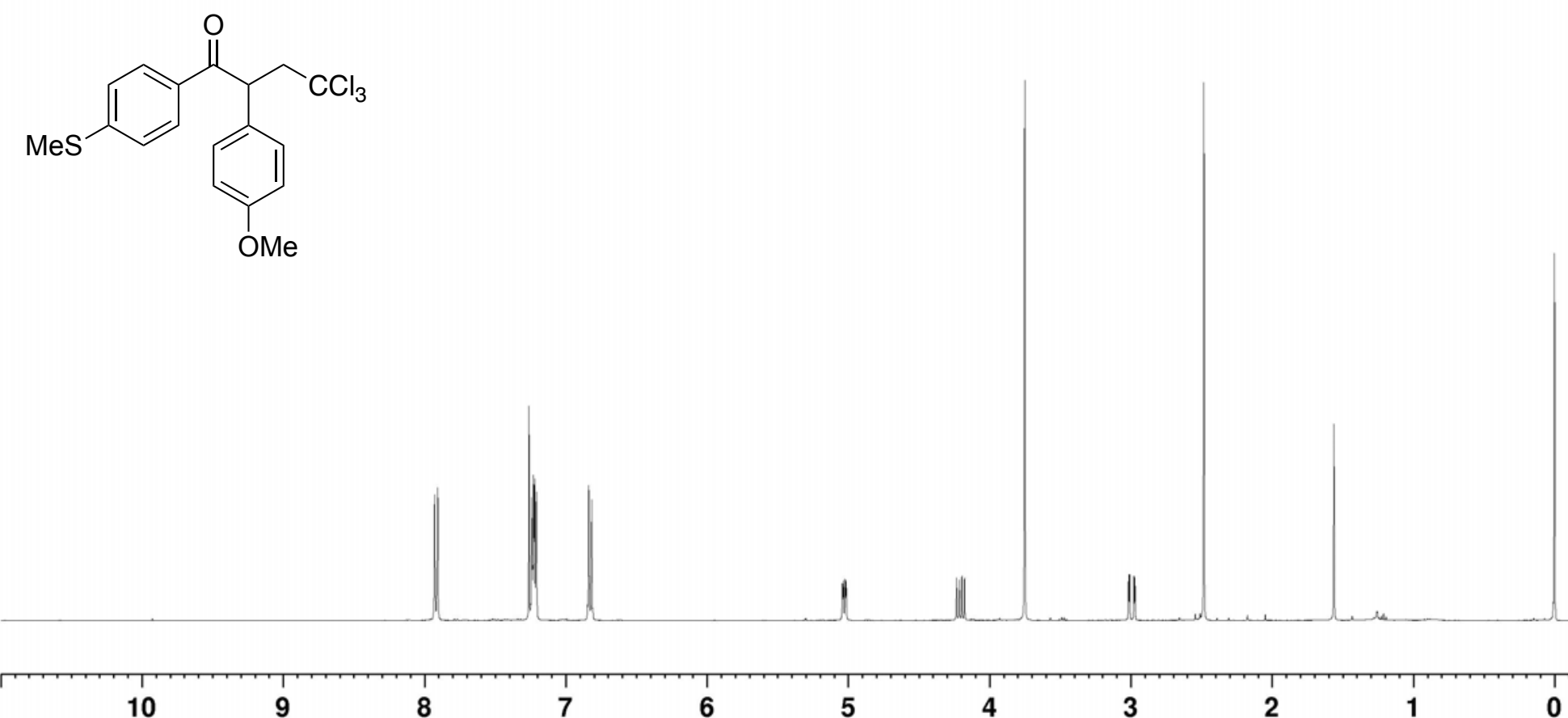

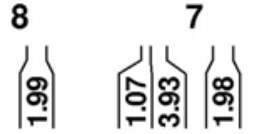
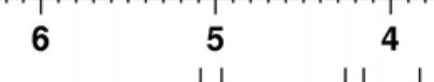

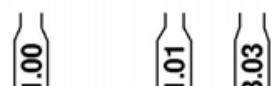

3
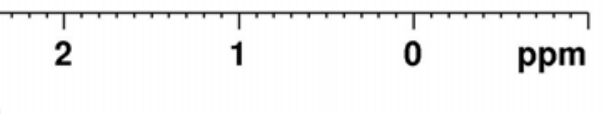

|ำ

${ }^{1} \mathrm{H}$ NMR spectrum of $\mathbf{4} \mathbf{f b}\left(\mathrm{CDCl}_{3}, 400 \mathrm{MHz}\right)$ 


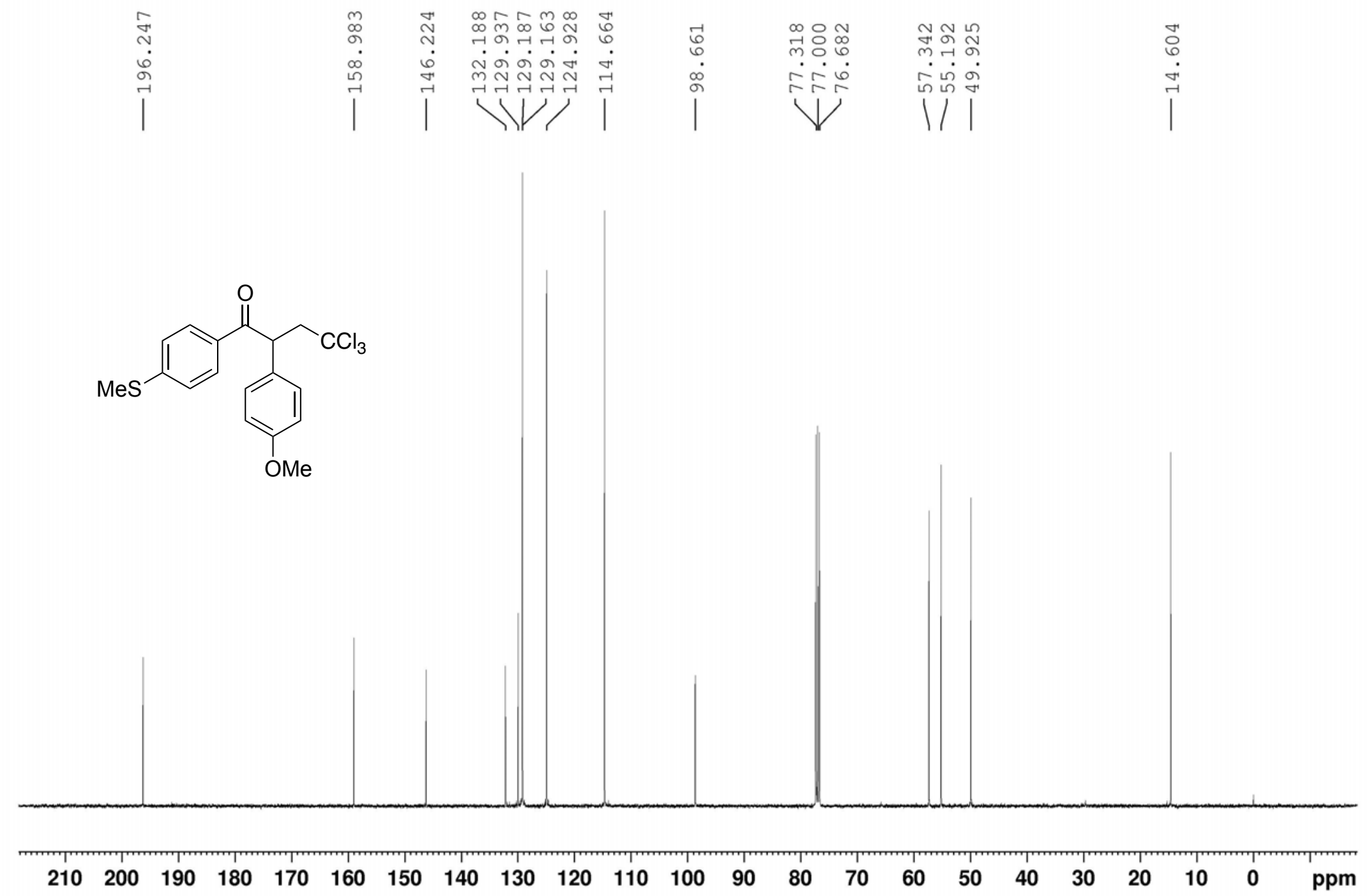

${ }^{13} \mathrm{C}$ NMR spectrum of $\mathbf{4 f b}\left(\mathrm{CDCl}_{3}, 100.6 \mathrm{MHz}\right)$ 

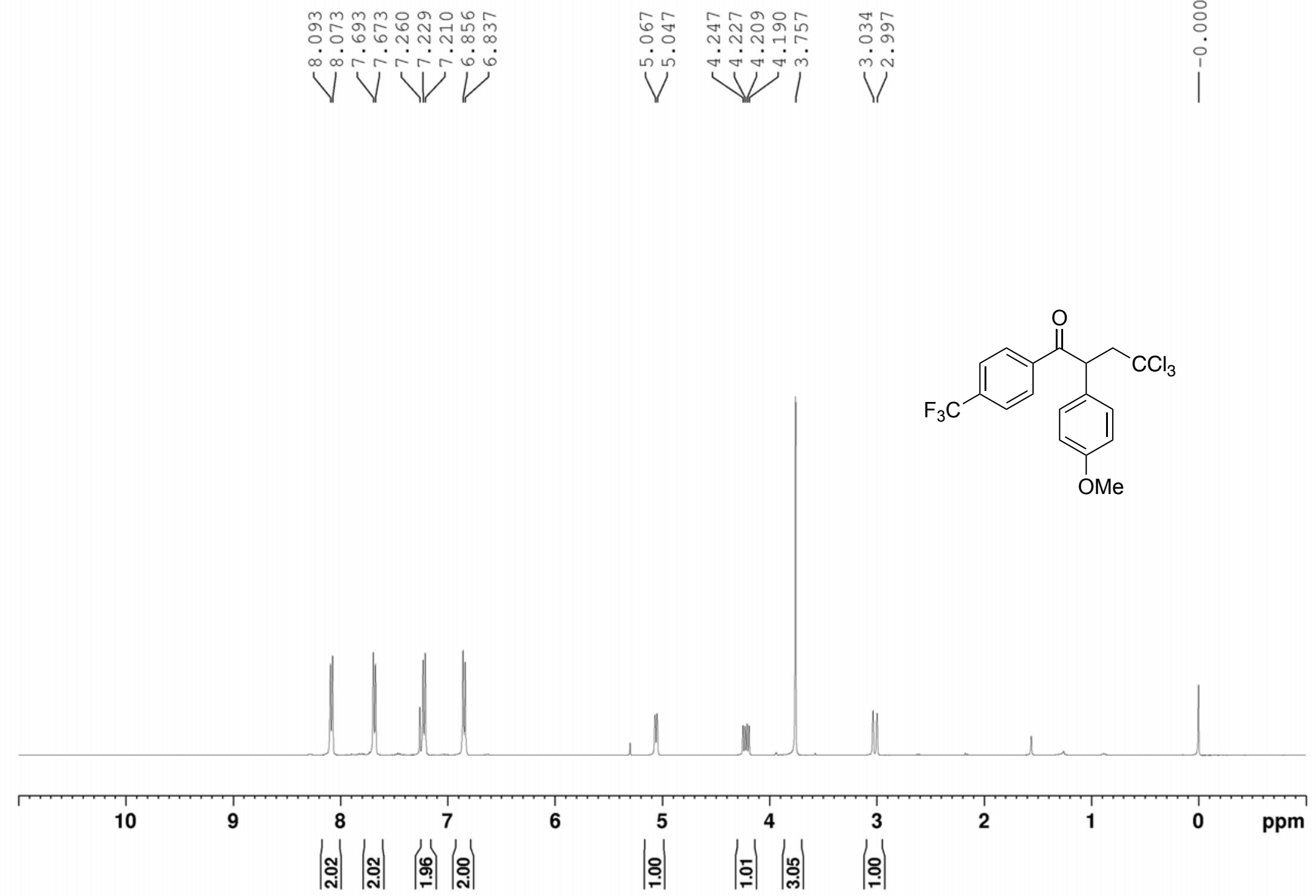

${ }^{1} \mathrm{H}$ NMR spectrum of $\mathbf{4 g b}\left(\mathrm{CDCl}_{3}, 400 \mathrm{MHz}\right)$ 

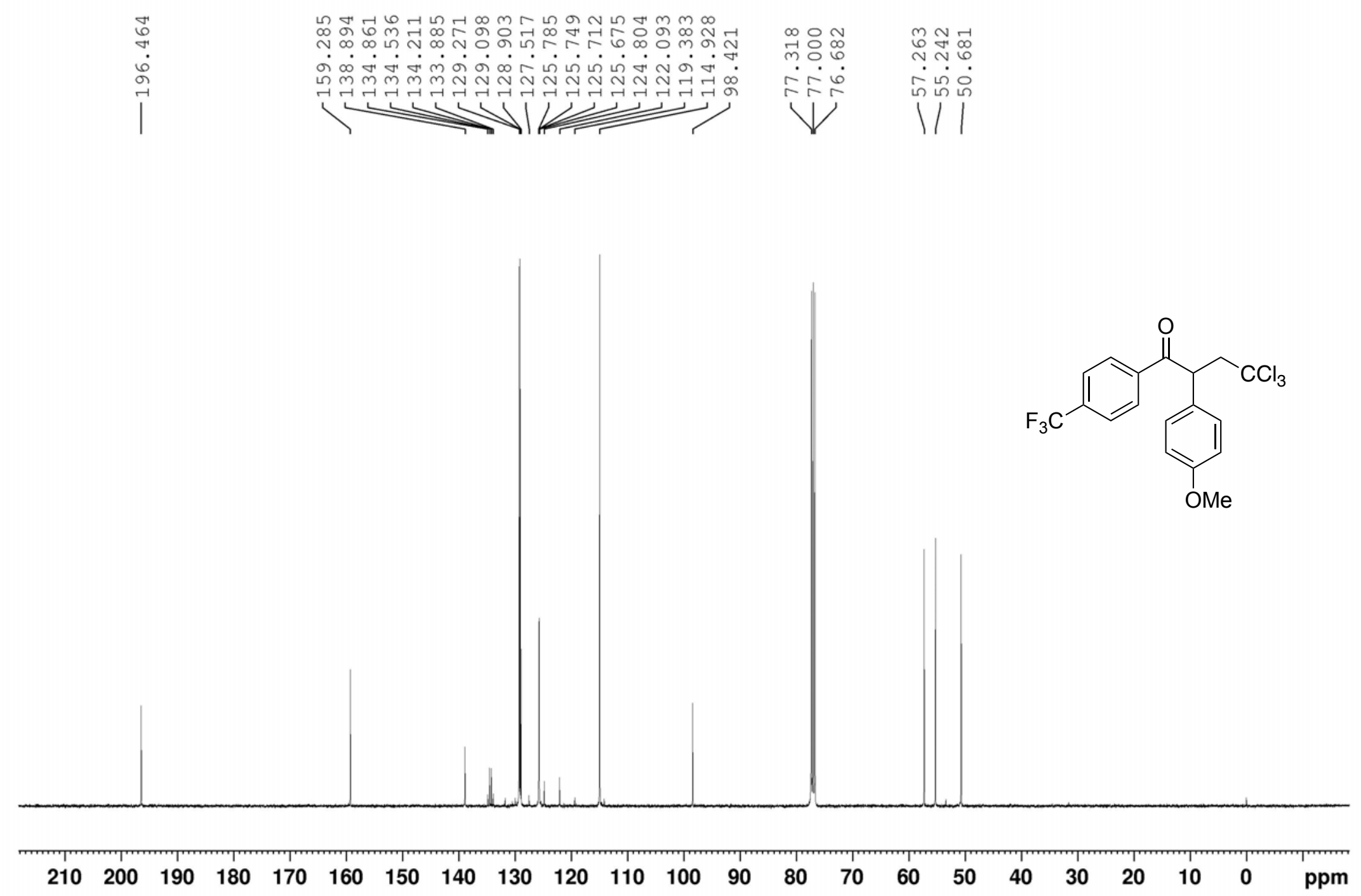

${ }^{13} \mathrm{C} \mathrm{NMR}$ spectrum of $\mathbf{4 g b}\left(\mathrm{CDCl}_{3}, 100.6 \mathrm{MHz}\right)$ 

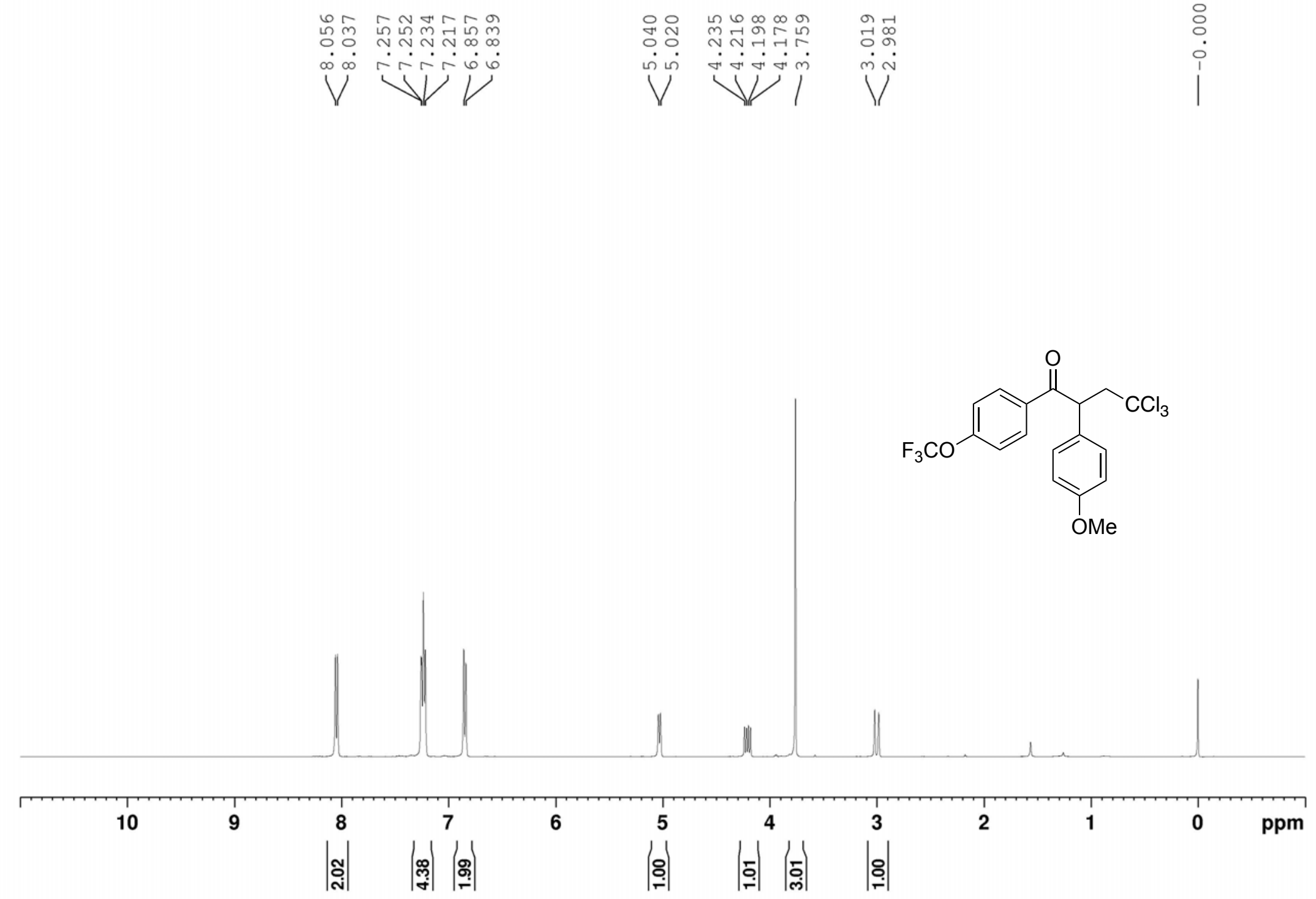

${ }^{1} \mathrm{H}$ NMR spectrum of $\mathbf{4 h b}\left(\mathrm{CDCl}_{3}, 400 \mathrm{MHz}\right)$ 


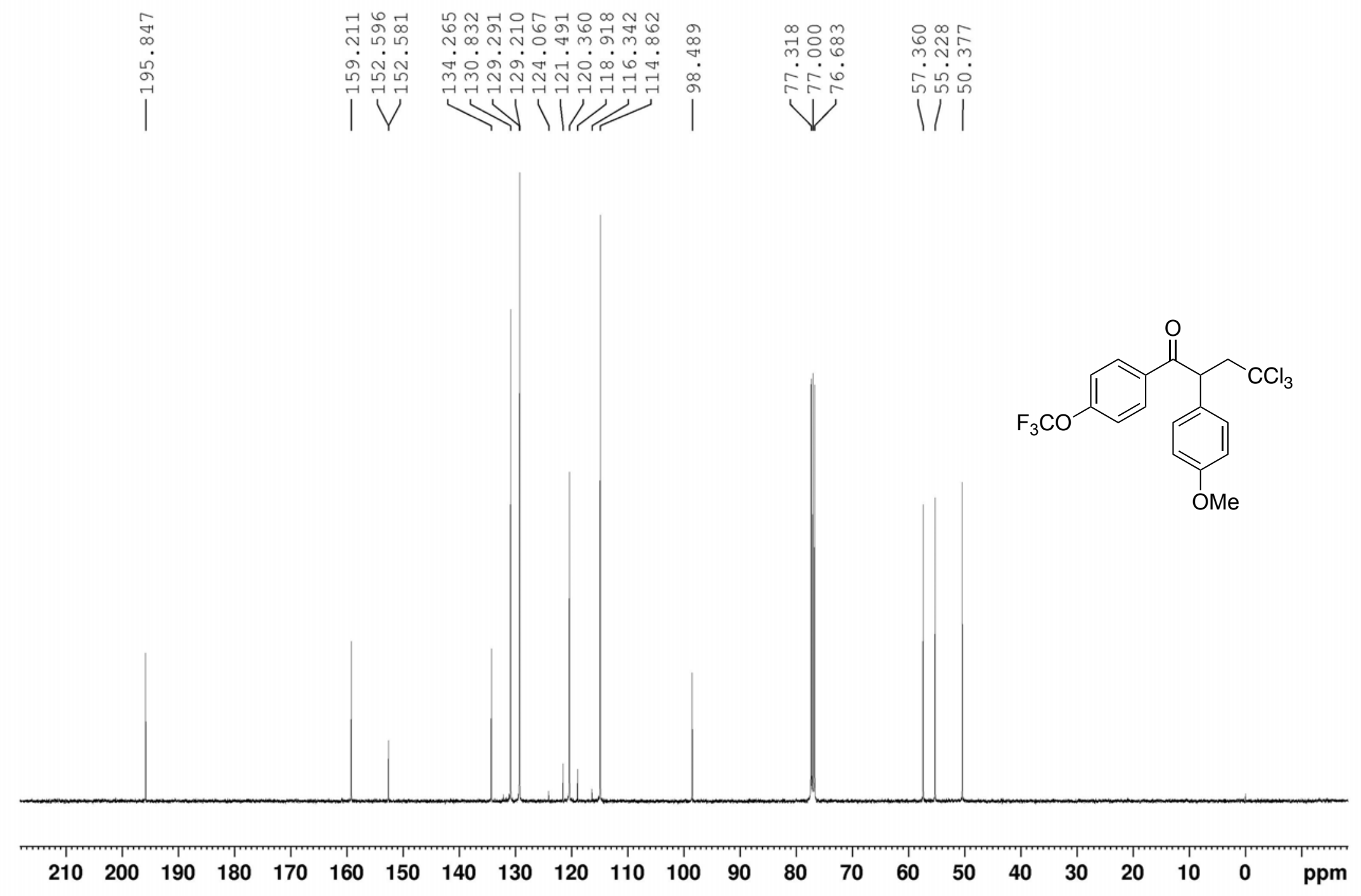

${ }^{13} \mathrm{C}$ NMR spectrum of $\mathbf{4 h b}\left(\mathrm{CDCl}_{3}, 100.6 \mathrm{MHz}\right)$ 

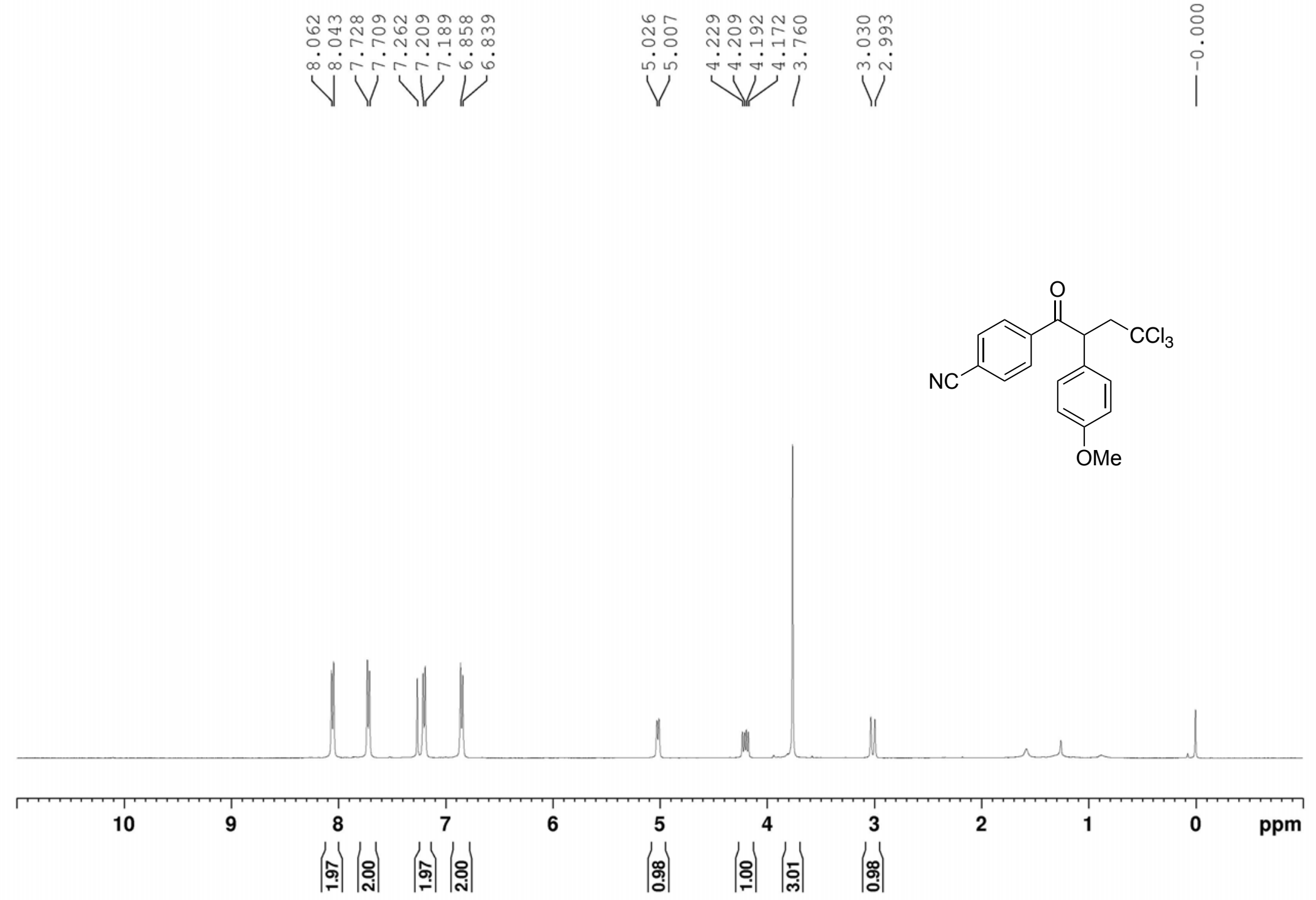

${ }^{1} \mathrm{H}$ NMR spectrum of $\mathbf{4 i b}\left(\mathrm{CDCl}_{3}, 400 \mathrm{MHz}\right)$ 


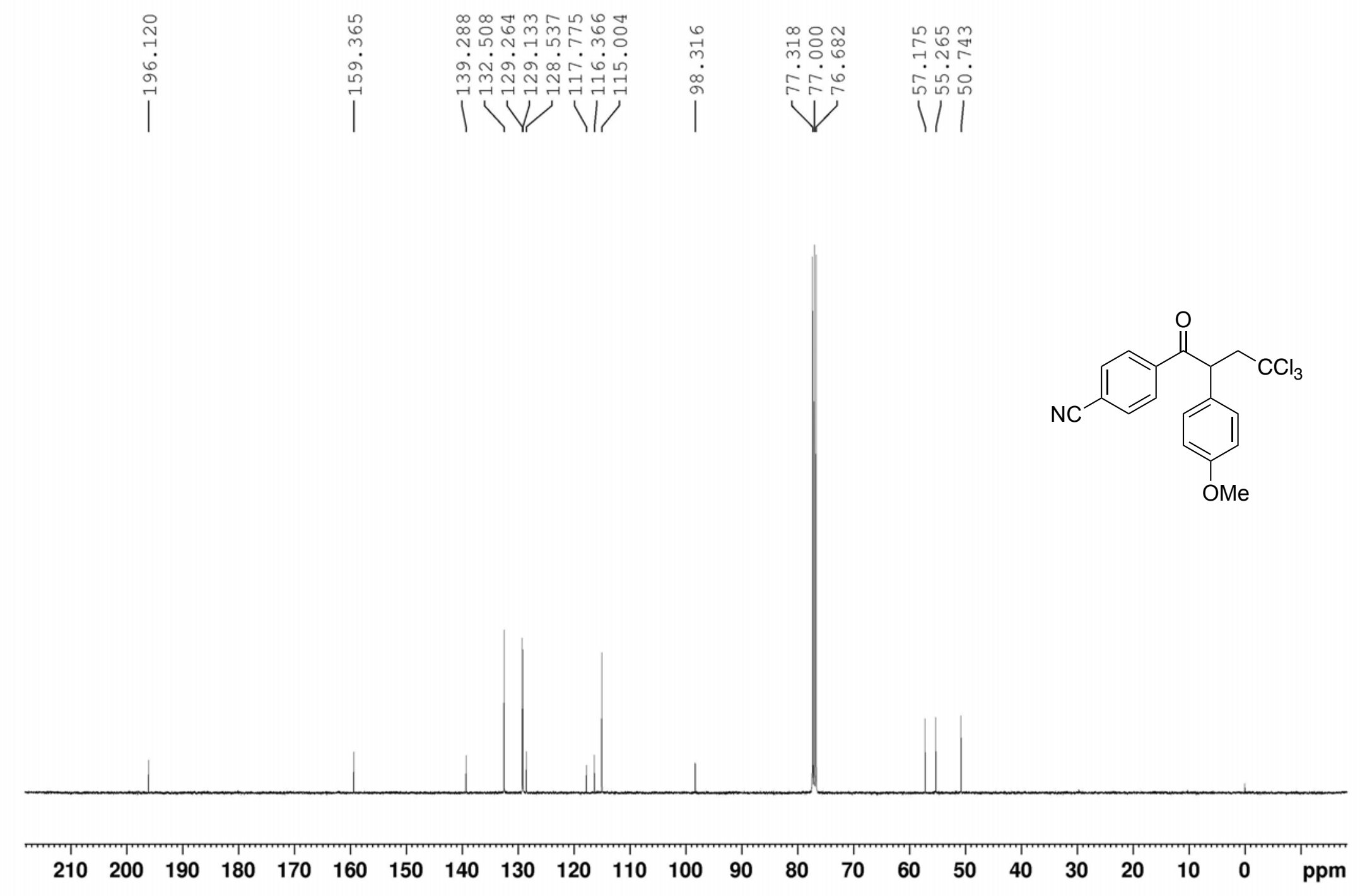

${ }^{13} \mathrm{C}$ NMR spectrum of $4 \mathbf{i b}\left(\mathrm{CDCl}_{3}, 100.6 \mathrm{MHz}\right)$ 

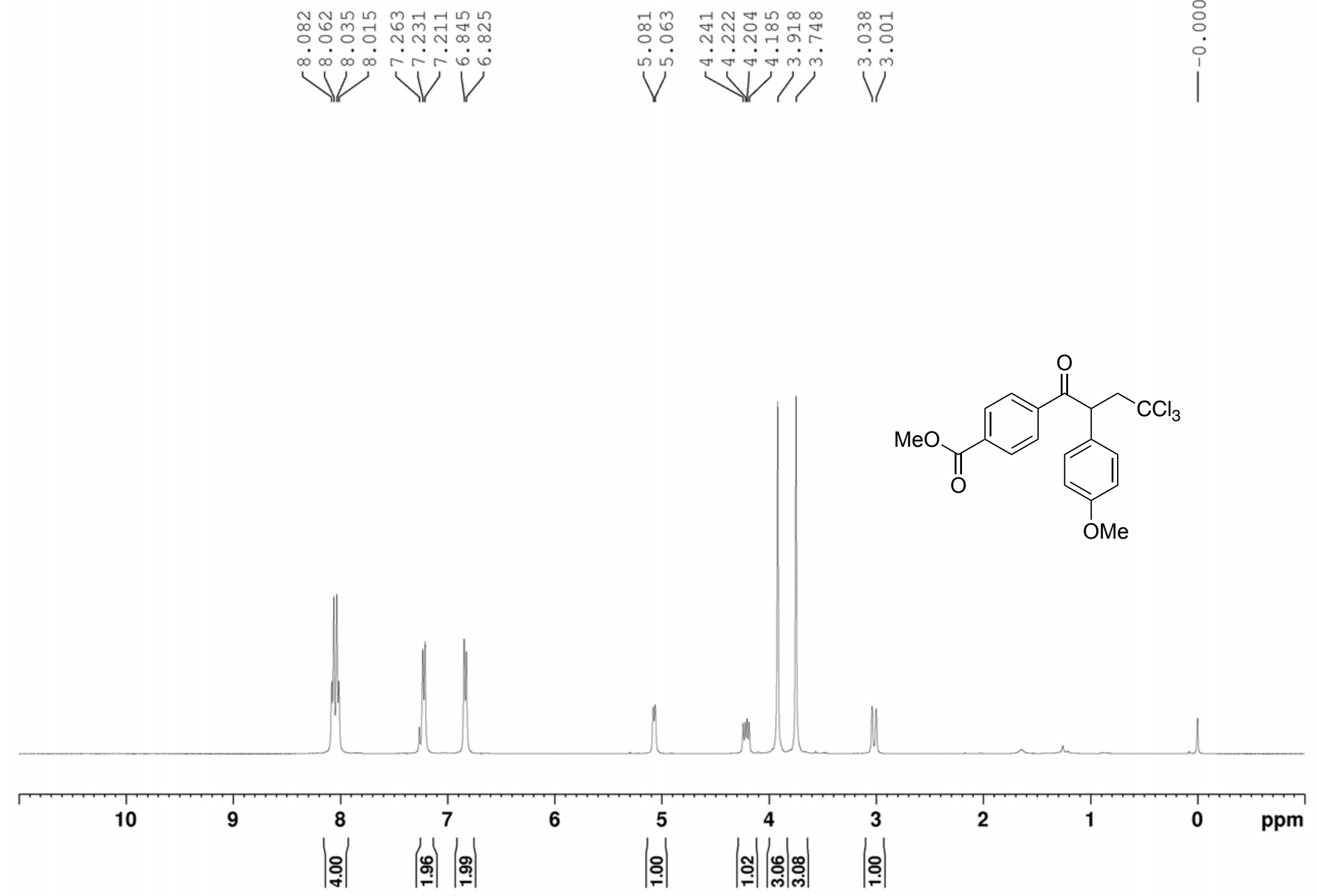

${ }^{1} \mathrm{H}$ NMR spectrum of $\mathbf{4 j b}\left(\mathrm{CDCl}_{3}, 400 \mathrm{MHz}\right)$ 


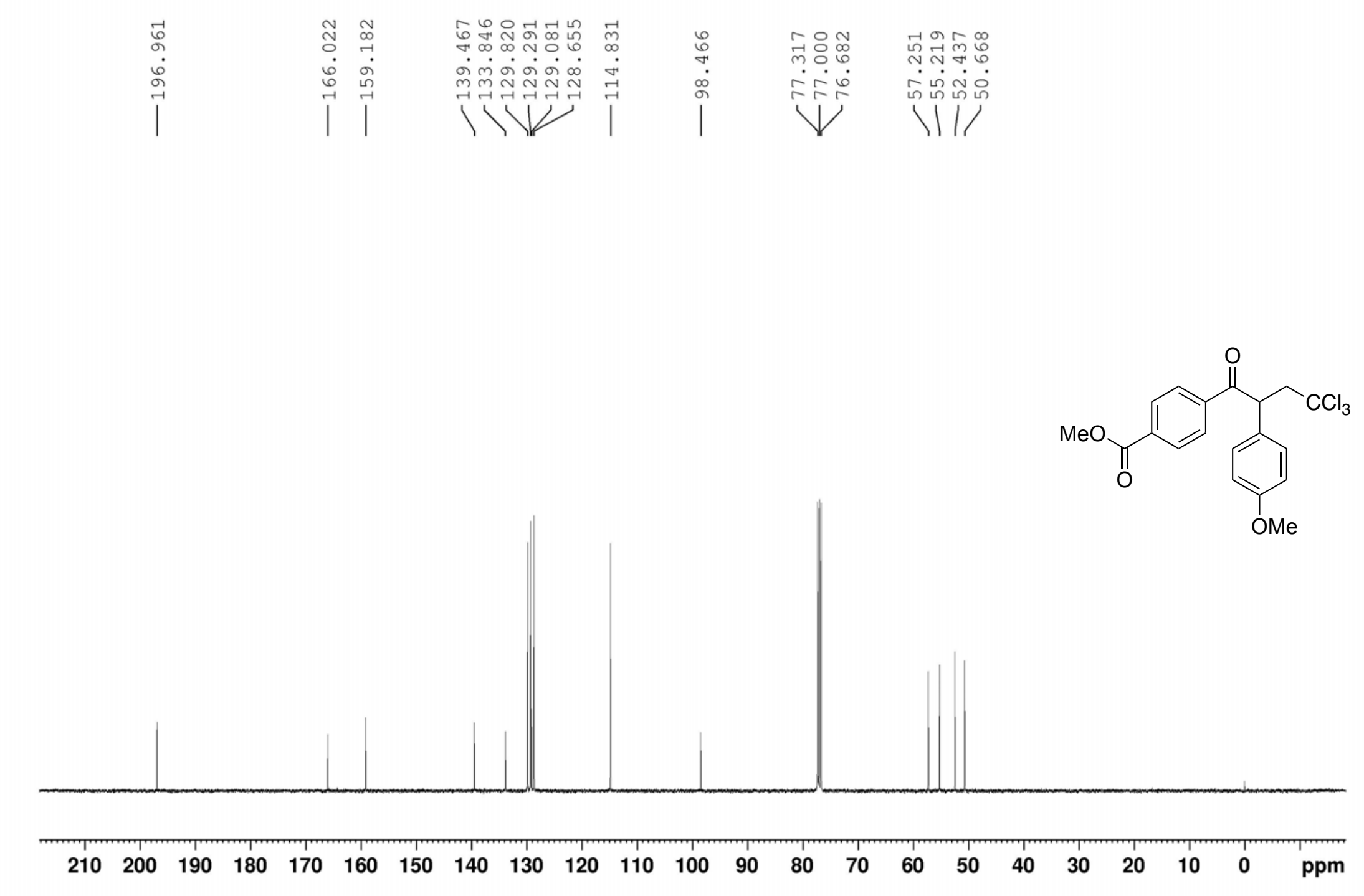

${ }^{13} \mathrm{C}$ NMR spectrum of $\mathbf{4 j b}\left(\mathrm{CDCl}_{3}, 100.6 \mathrm{MHz}\right)$ 

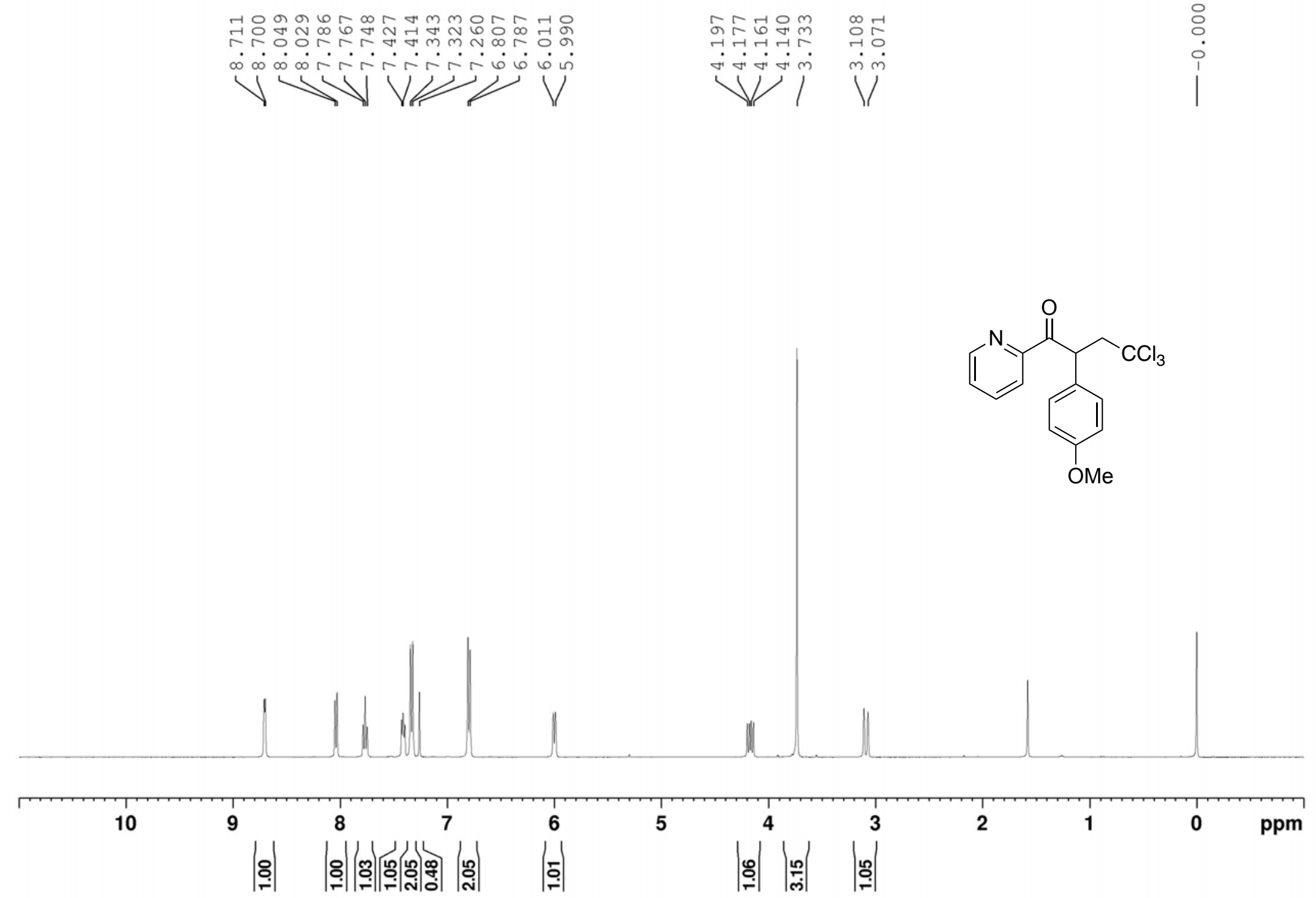

${ }^{1} \mathrm{H}$ NMR spectrum of $\mathbf{4} \mathbf{k b}\left(\mathrm{CDCl}_{3}, 400 \mathrm{MHz}\right)$ 

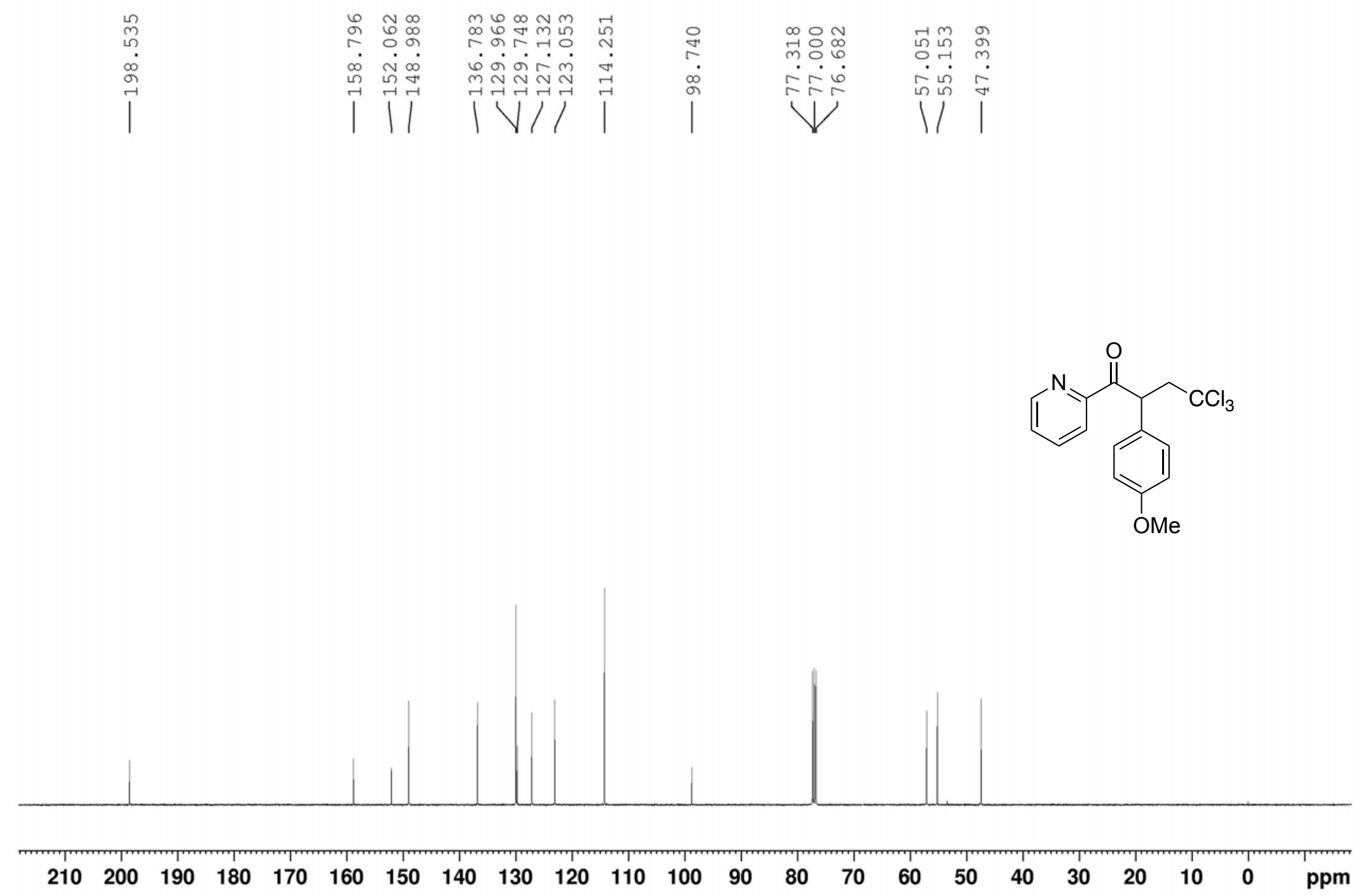

${ }^{13} \mathrm{C}$ NMR spectrum of $\mathbf{4 k b}\left(\mathrm{CDCl}_{3}, 100.6 \mathrm{MHz}\right)$ 


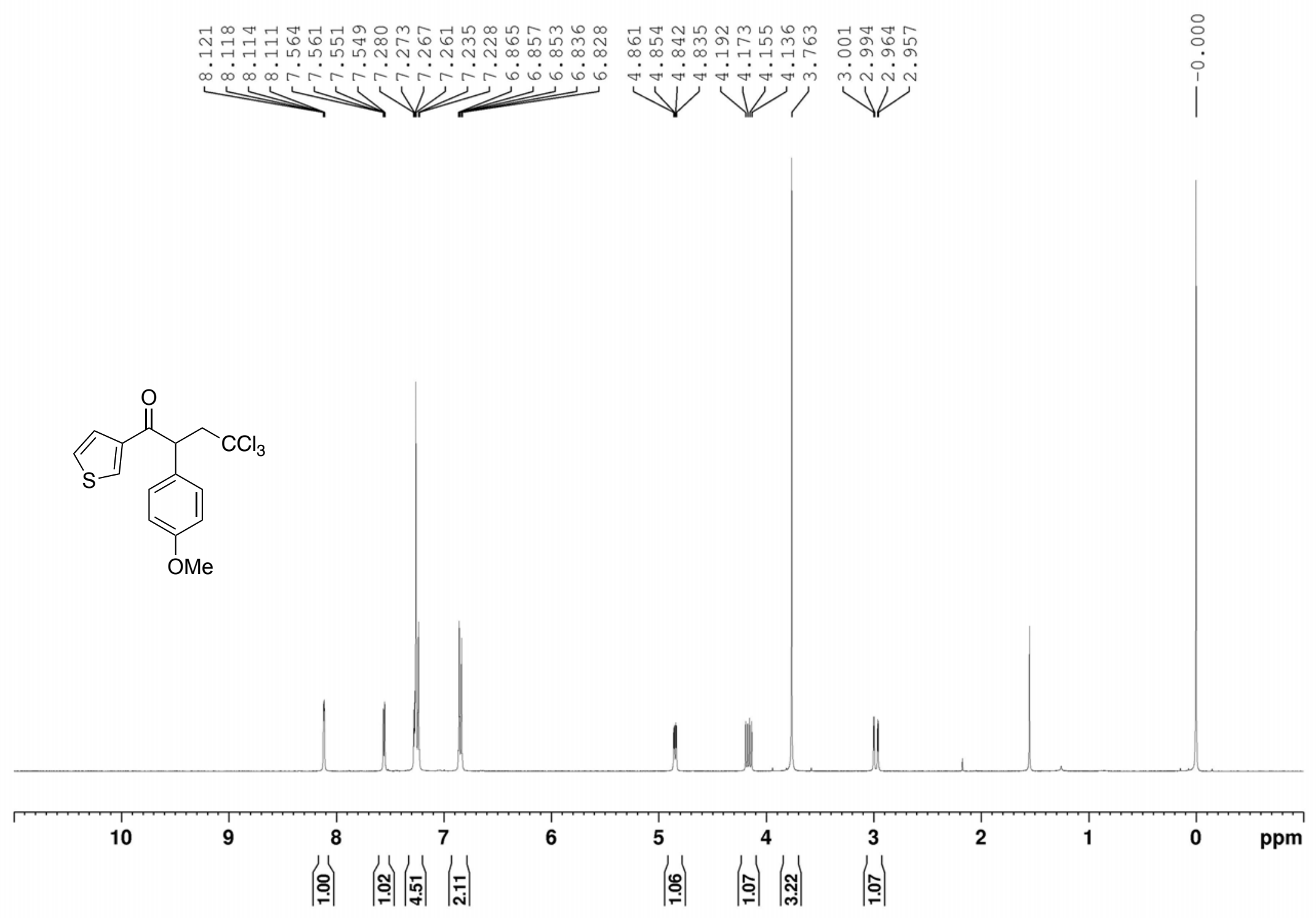

${ }^{1} \mathrm{H}$ NMR spectrum of $4 \mathbf{l b}\left(\mathrm{CDCl}_{3}, 400 \mathrm{MHz}\right)$ 

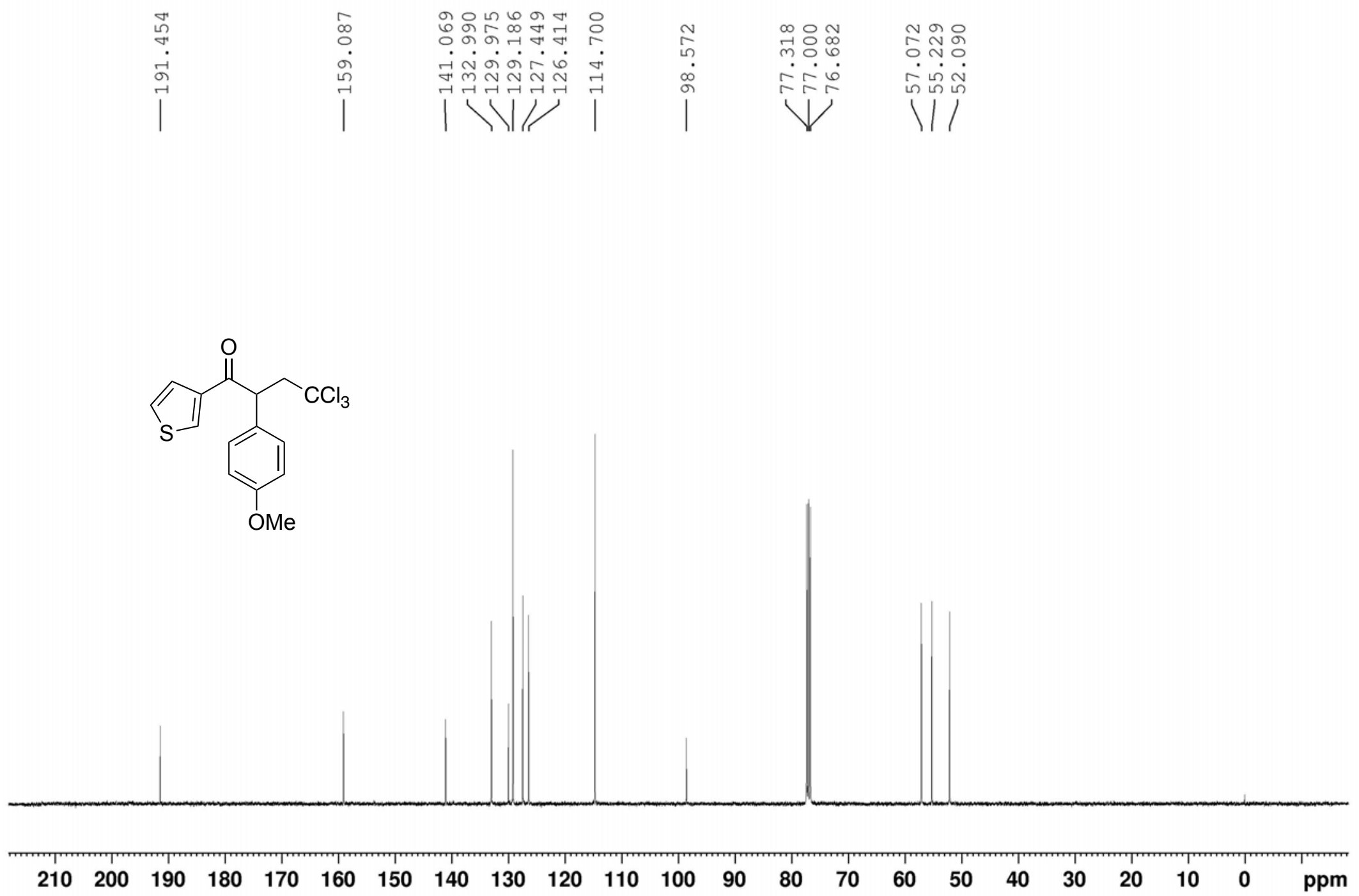

${ }^{13} \mathrm{C}$ NMR spectrum of $4 \mathbf{l b}\left(\mathrm{CDCl}_{3}, 100.6 \mathrm{MHz}\right)$ 


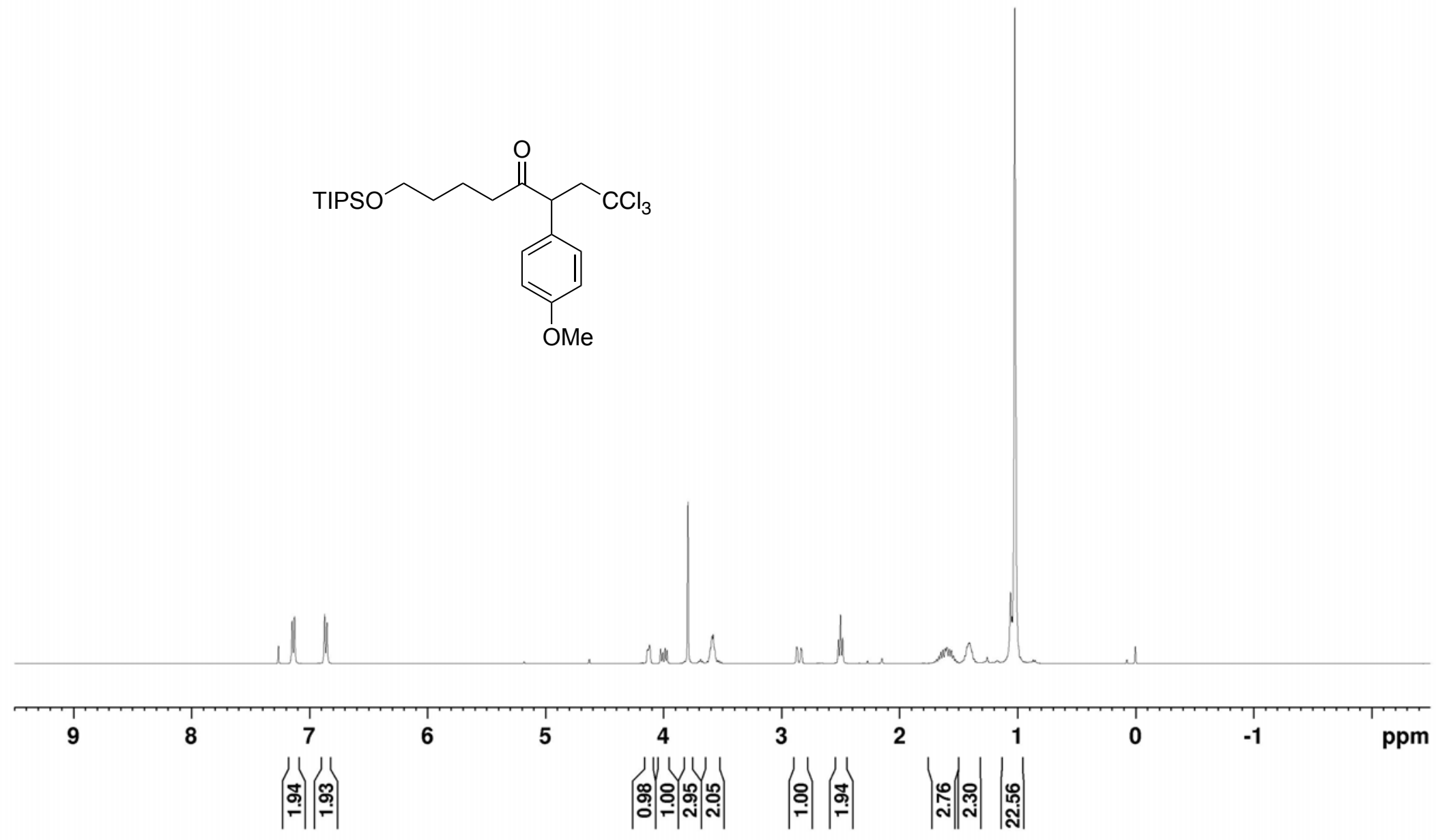

${ }^{1} \mathrm{H}$ NMR spectrum of $\mathbf{4 m b}\left(\mathrm{CDCl}_{3}, 400 \mathrm{MHz}\right)$ 


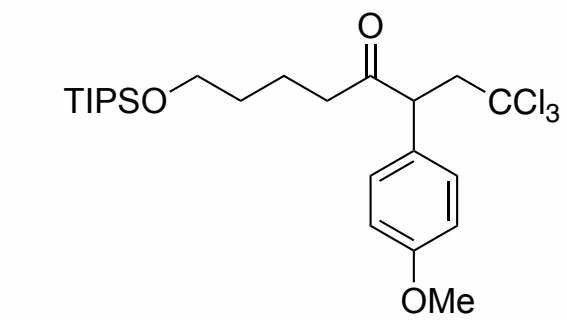

${ }^{13} \mathrm{C}$ NMR spectrum of $\mathbf{4 m b}\left(\mathrm{CDCl}_{3}, 100.6 \mathrm{MHz}\right)$ 


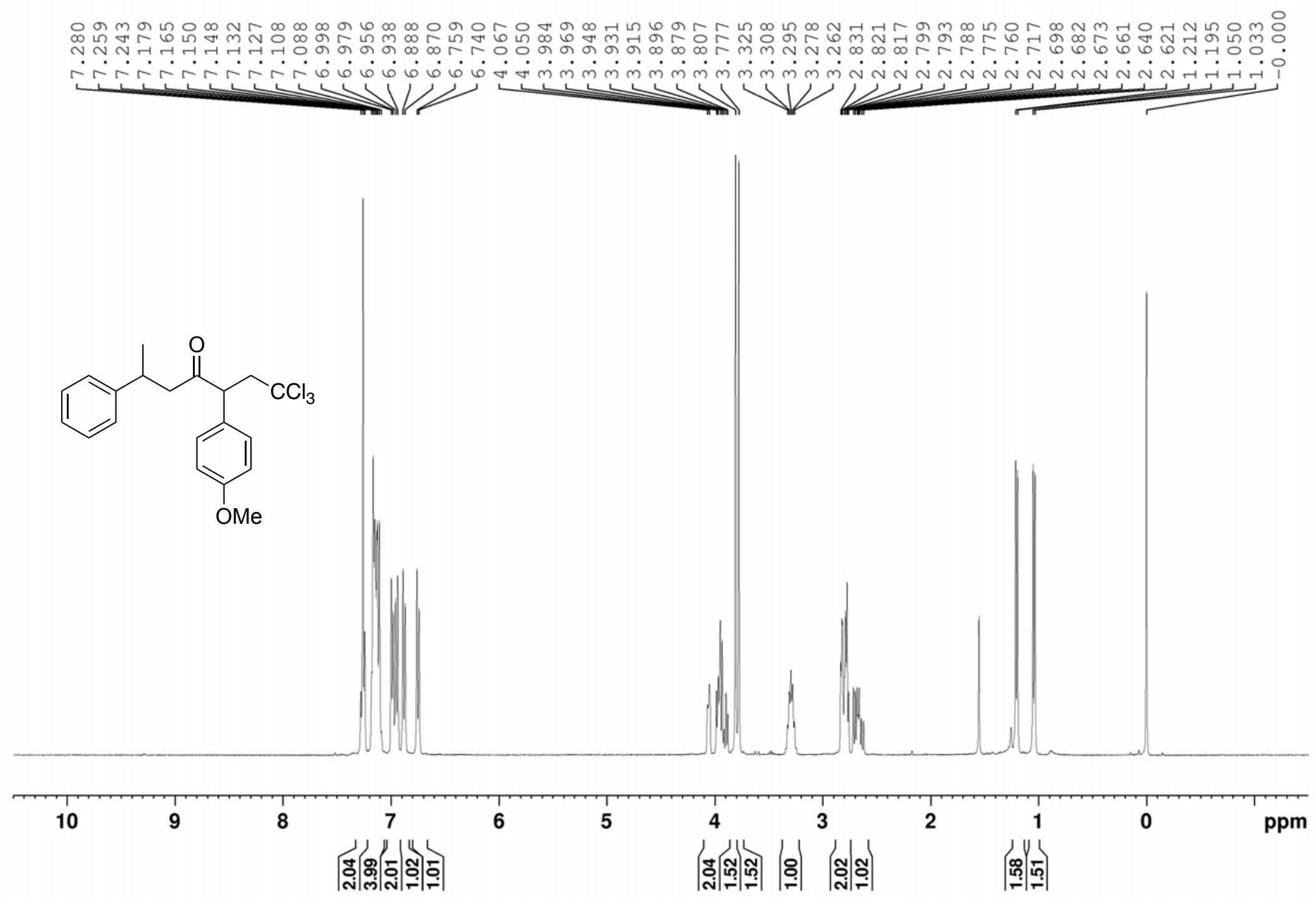

${ }^{1} \mathrm{H}$ NMR spectrum of $\mathbf{4} \mathbf{n b}\left(\mathrm{CDCl}_{3}, 400 \mathrm{MHz}\right)$ 


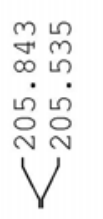
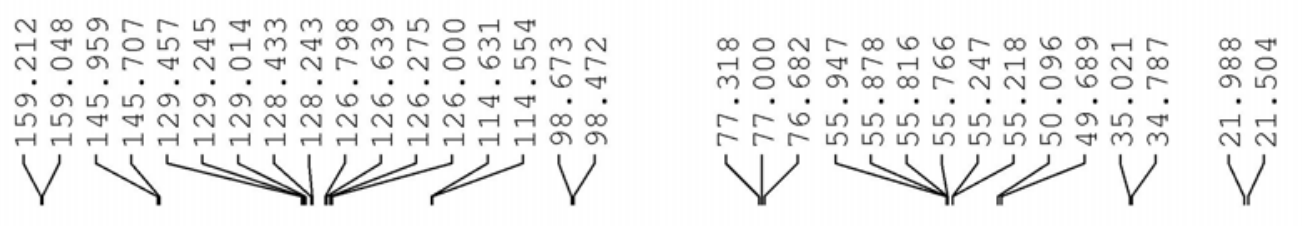<smiles>COc1ccc(C(CC(Cl)(Cl)Cl)C(=O)CC(C)c2ccccc2)cc1</smiles>
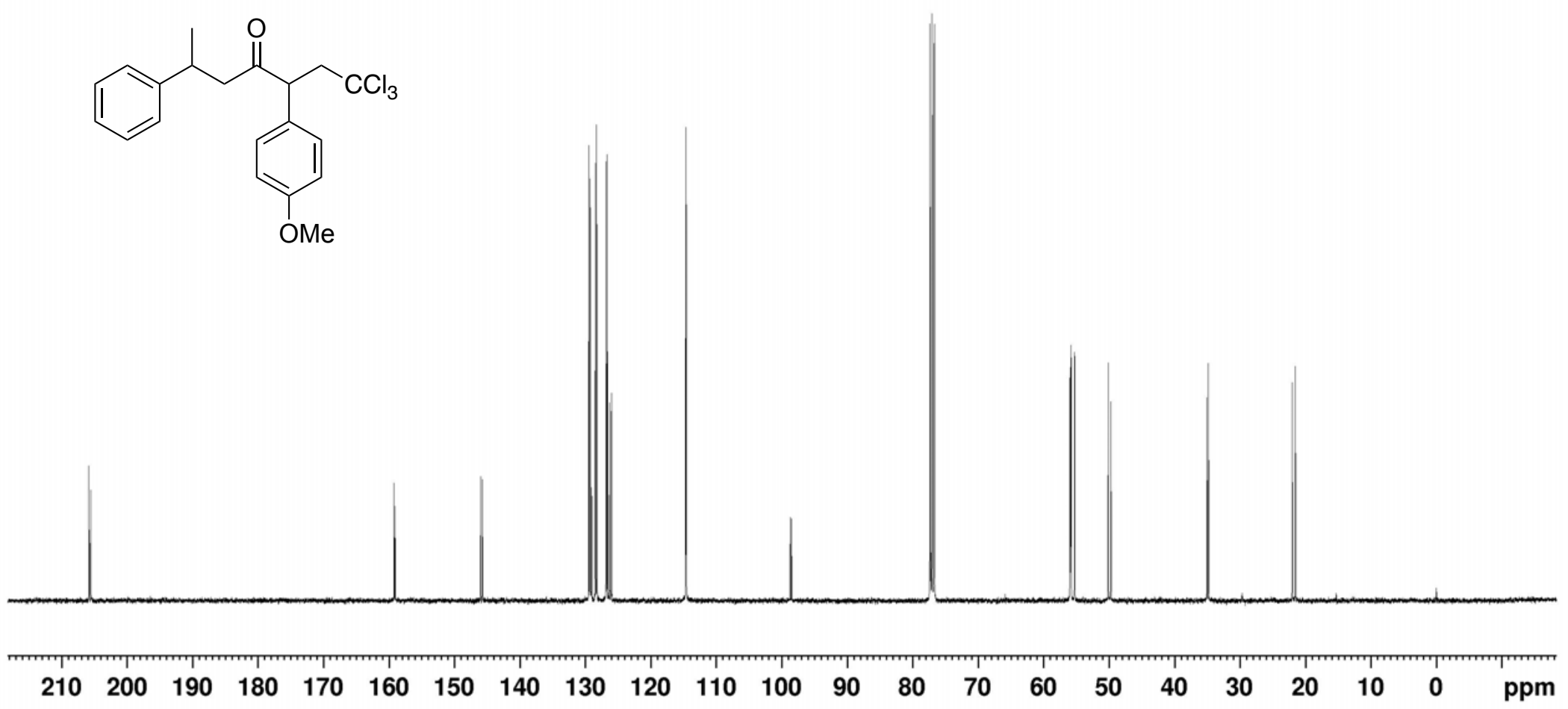

${ }^{13} \mathrm{C}$ NMR spectrum of $\mathbf{4 n b}\left(\mathrm{CDCl}_{3}, 100.6 \mathrm{MHz}\right)$

SS 
(2)
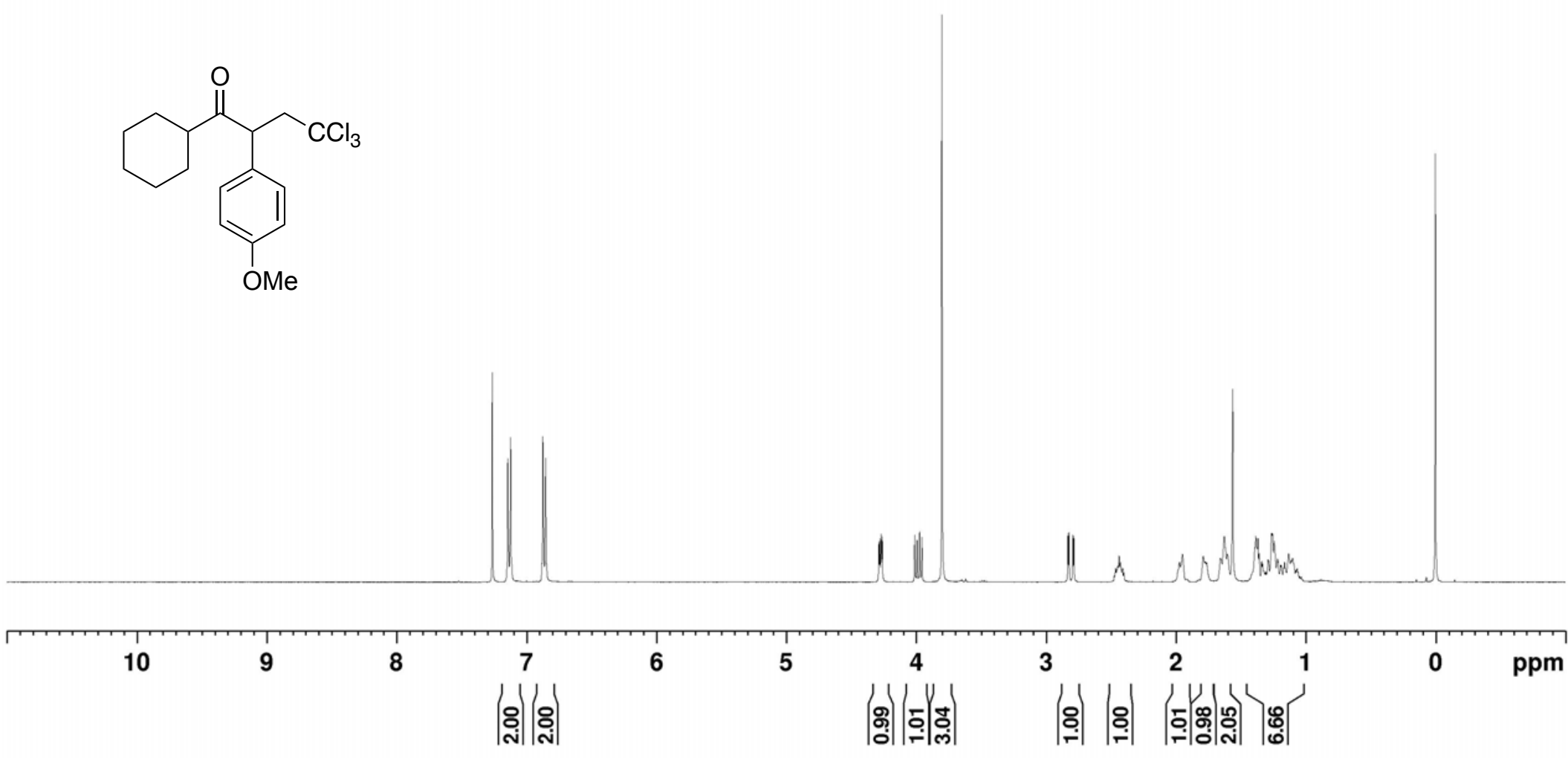

${ }^{1} \mathrm{H}$ NMR spectrum of $\mathbf{4 o b}\left(\mathrm{CDCl}_{3}, 400 \mathrm{MHz}\right)$ 

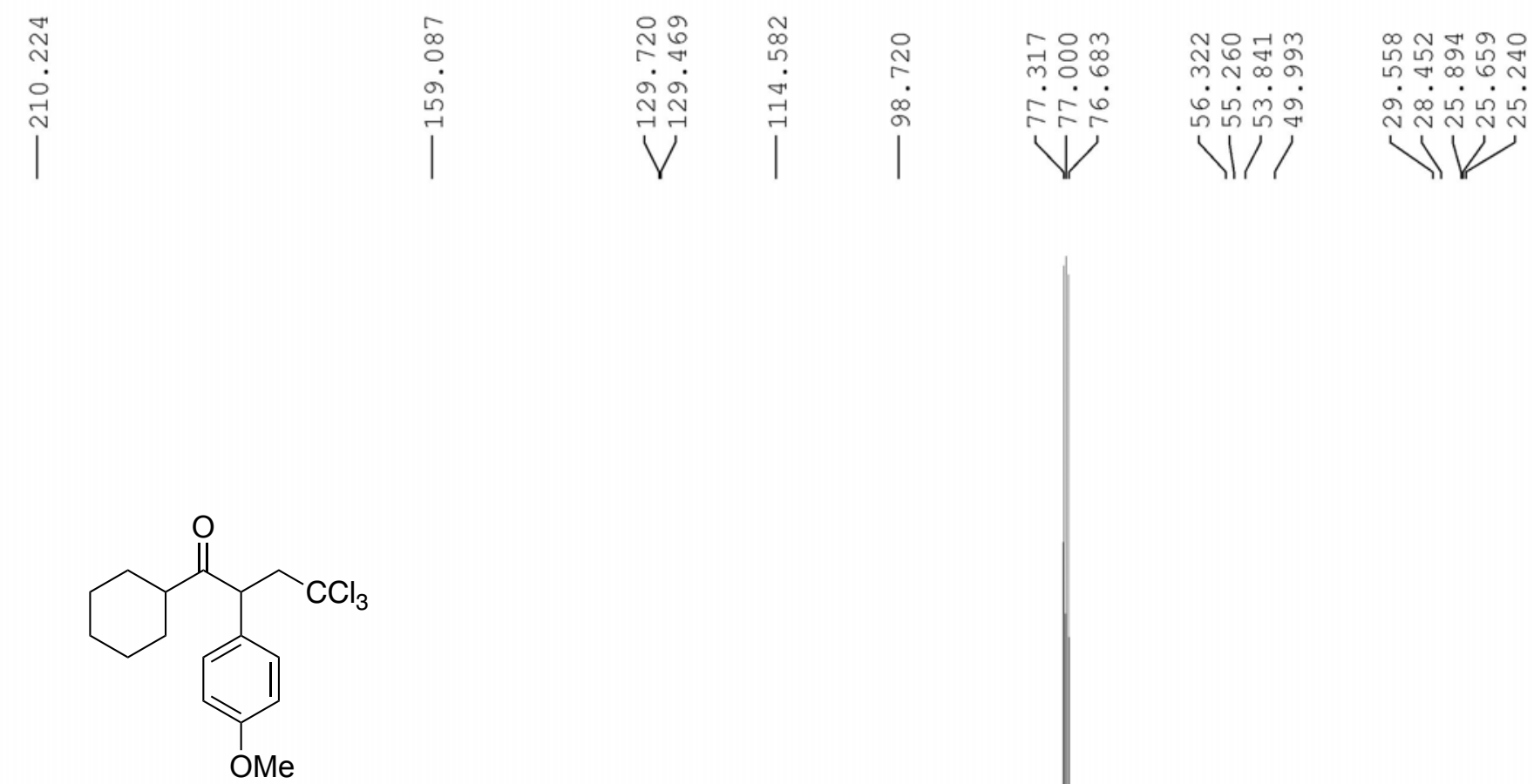

${ }^{13} \mathrm{C}$ NMR spectrum of $\mathbf{4 o b}\left(\mathrm{CDCl}_{3}, 100.6 \mathrm{MHz}\right)$ 


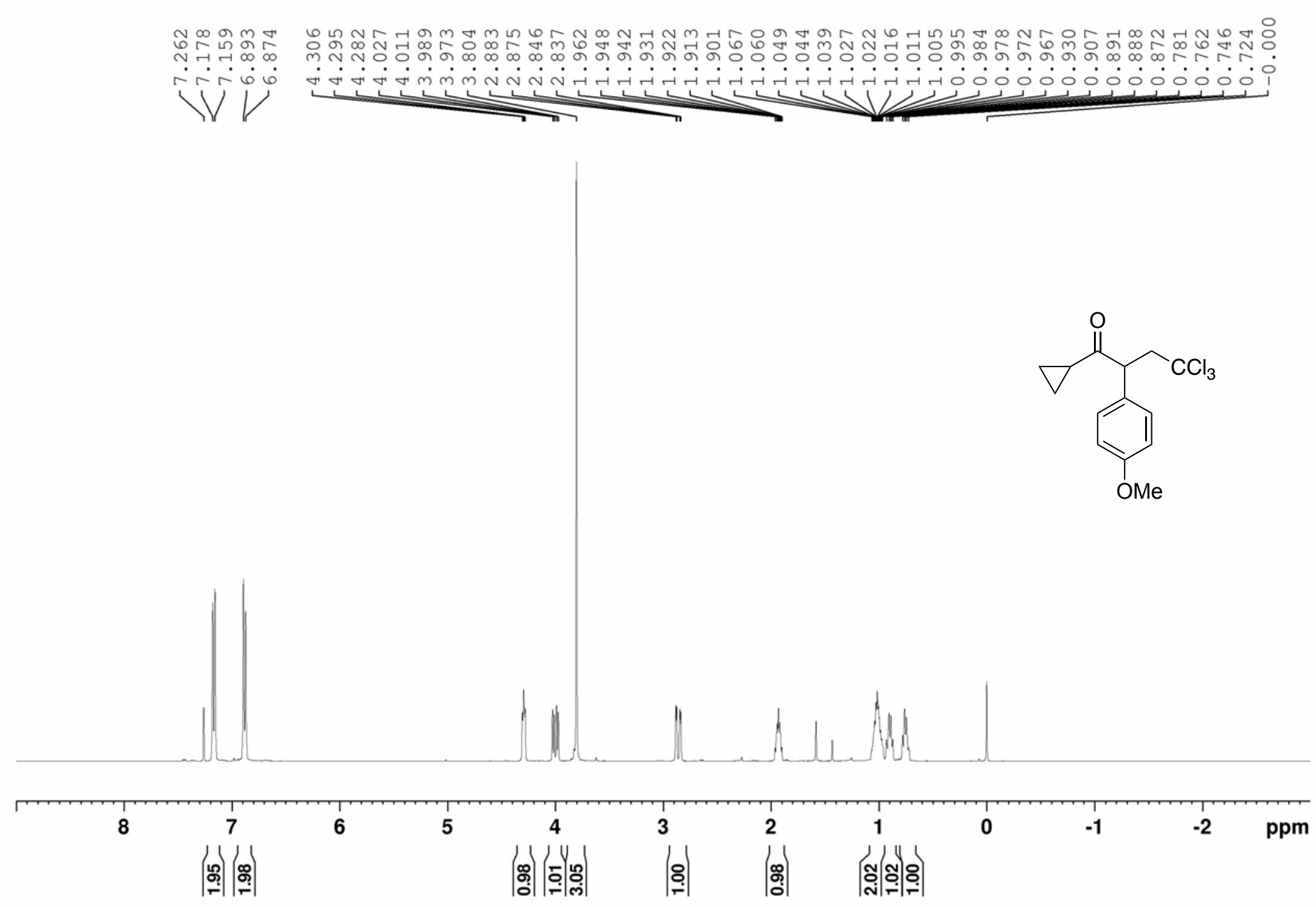

${ }^{1} \mathrm{H}$ NMR spectrum of $\mathbf{4 p b}\left(\mathrm{CDCl}_{3}, 400 \mathrm{MHz}\right)$ 

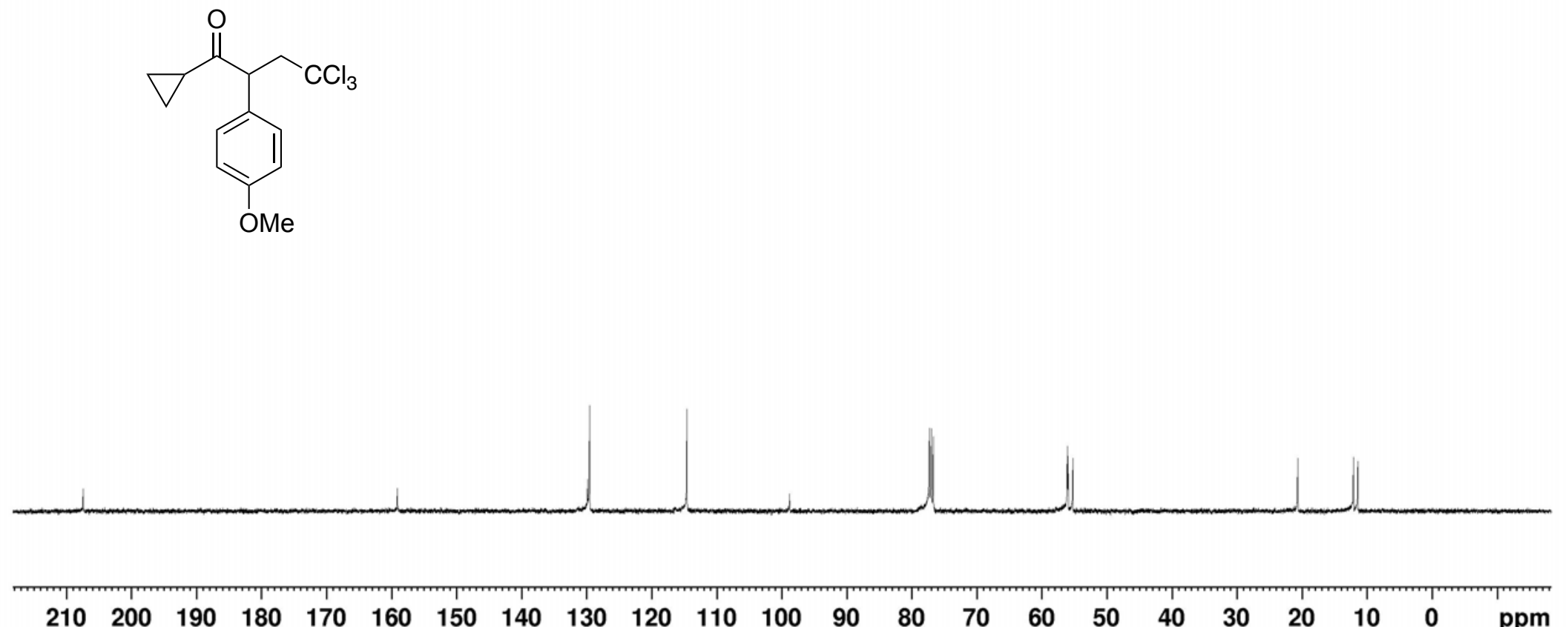

${ }^{13} \mathrm{C}$ NMR spectrum of $\mathbf{4 p b}\left(\mathrm{CDCl}_{3}, 100.6 \mathrm{MHz}\right)$ 


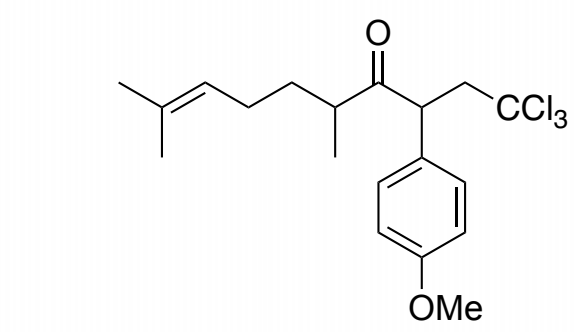

का एका

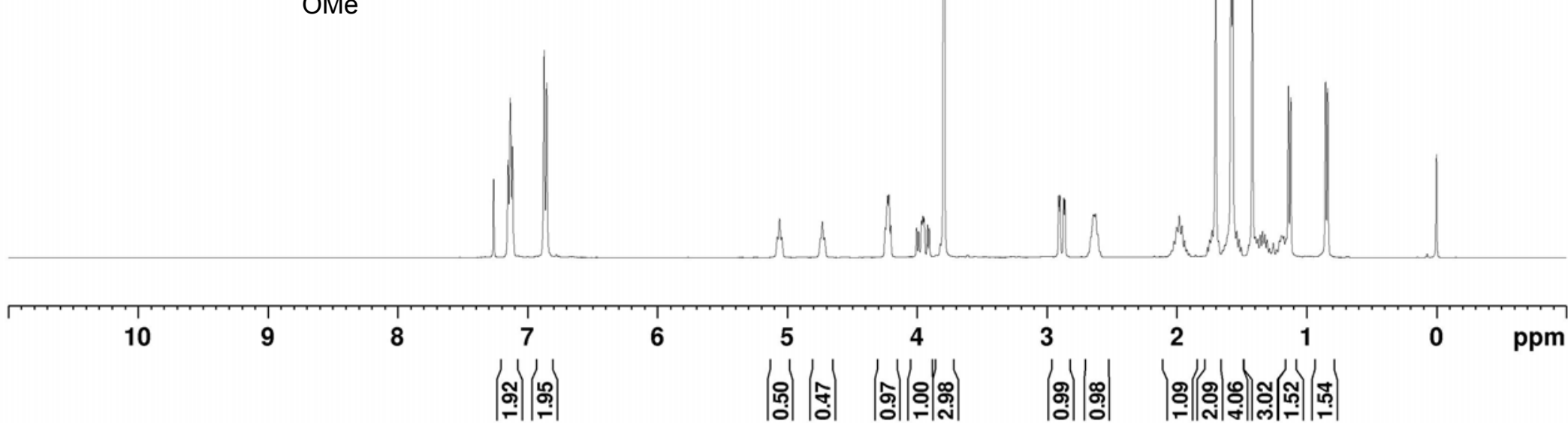

${ }^{1} \mathrm{H}$ NMR spectrum of $\mathbf{4 q b}\left(\mathrm{CDCl}_{3}, 400 \mathrm{MHz}\right)$ 

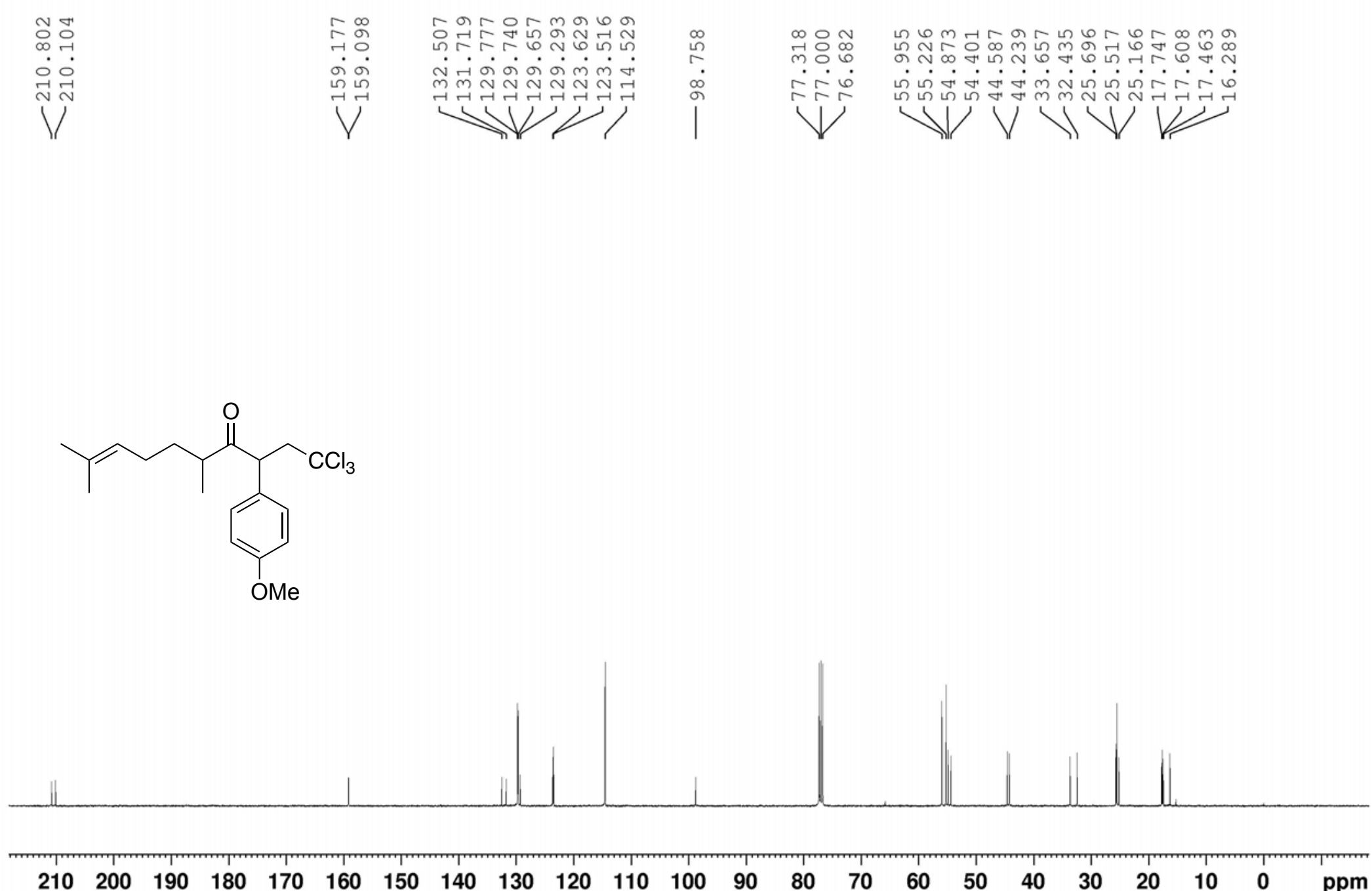

${ }^{13} \mathrm{C}$ NMR spectrum of $\mathbf{4 q b}\left(\mathrm{CDCl}_{3}, 100.6 \mathrm{MHz}\right)$ 

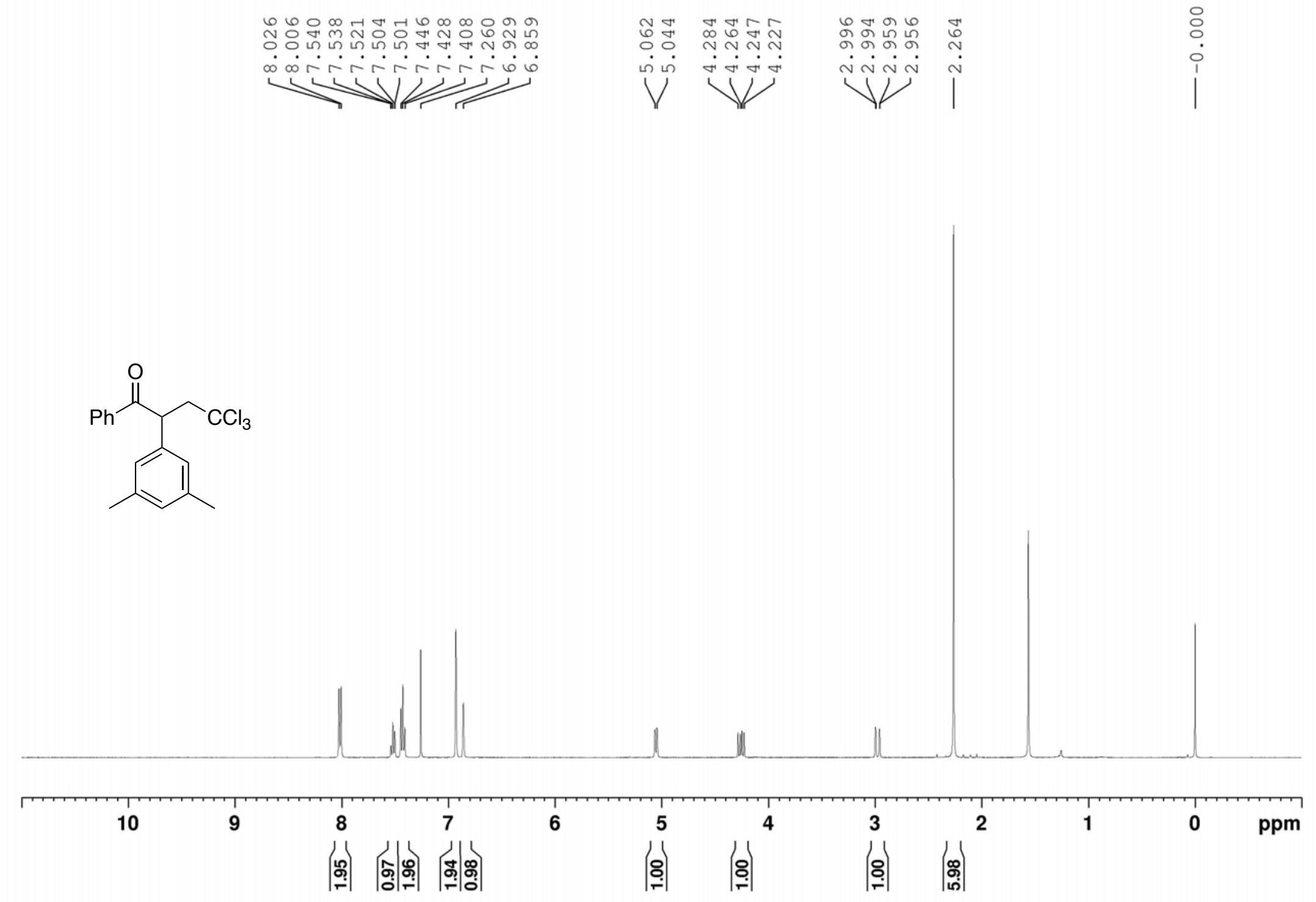

${ }^{1} \mathrm{H}$ NMR spectrum of $4 \mathbf{a c}\left(\mathrm{CDCl}_{3}, 400 \mathrm{MHz}\right)$ 


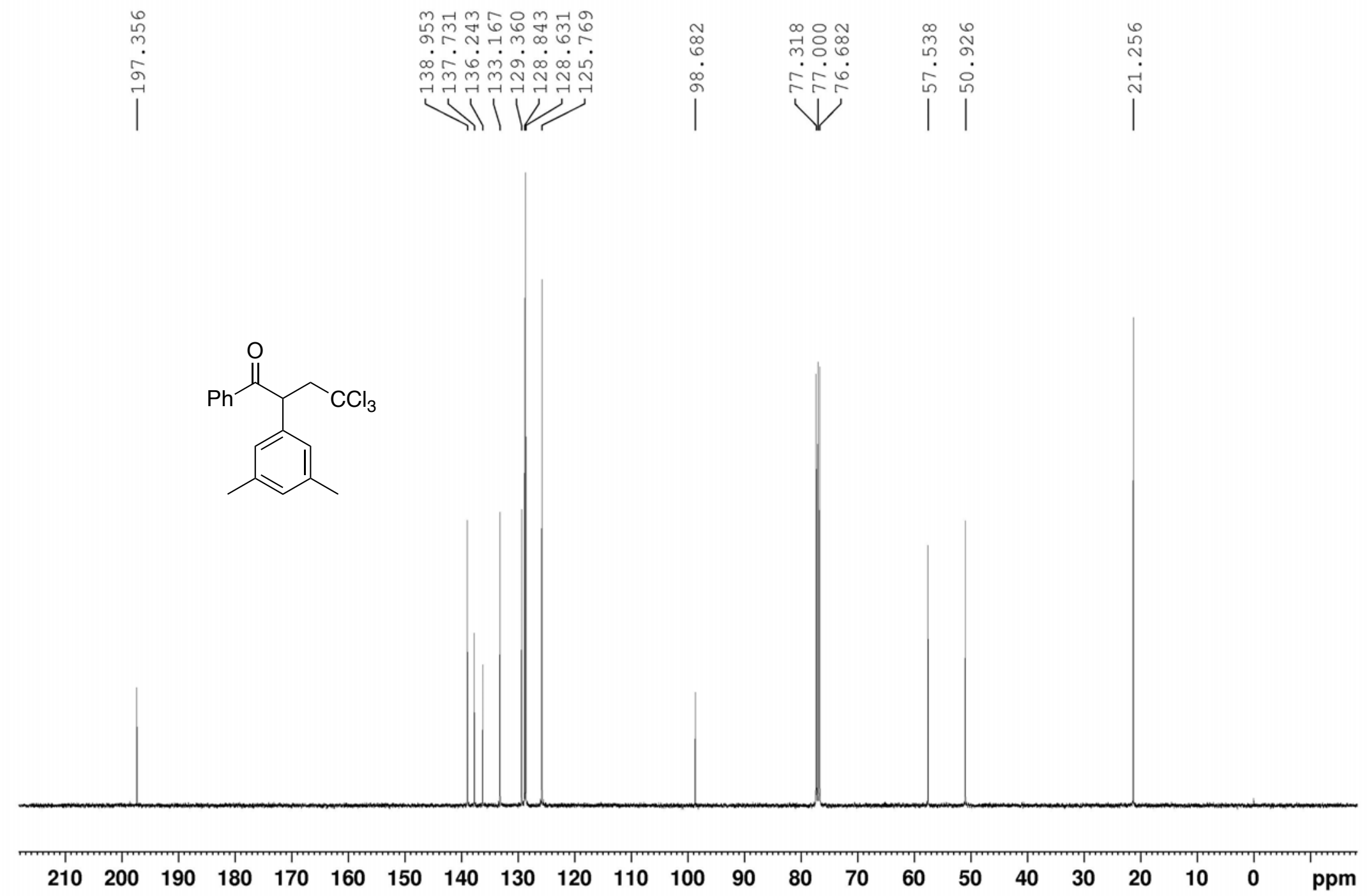

${ }^{13} \mathrm{C}$ NMR spectrum of $4 \mathbf{a c}\left(\mathrm{CDCl}_{3}, 100.6 \mathrm{MHz}\right)$ 

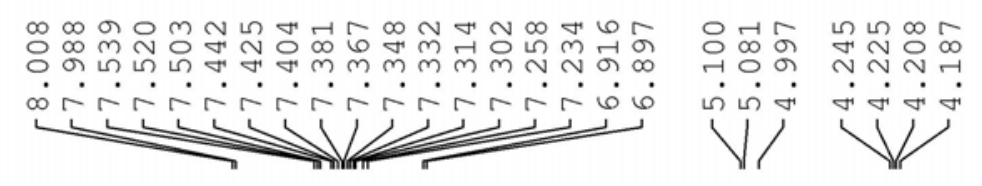

\section{V.}

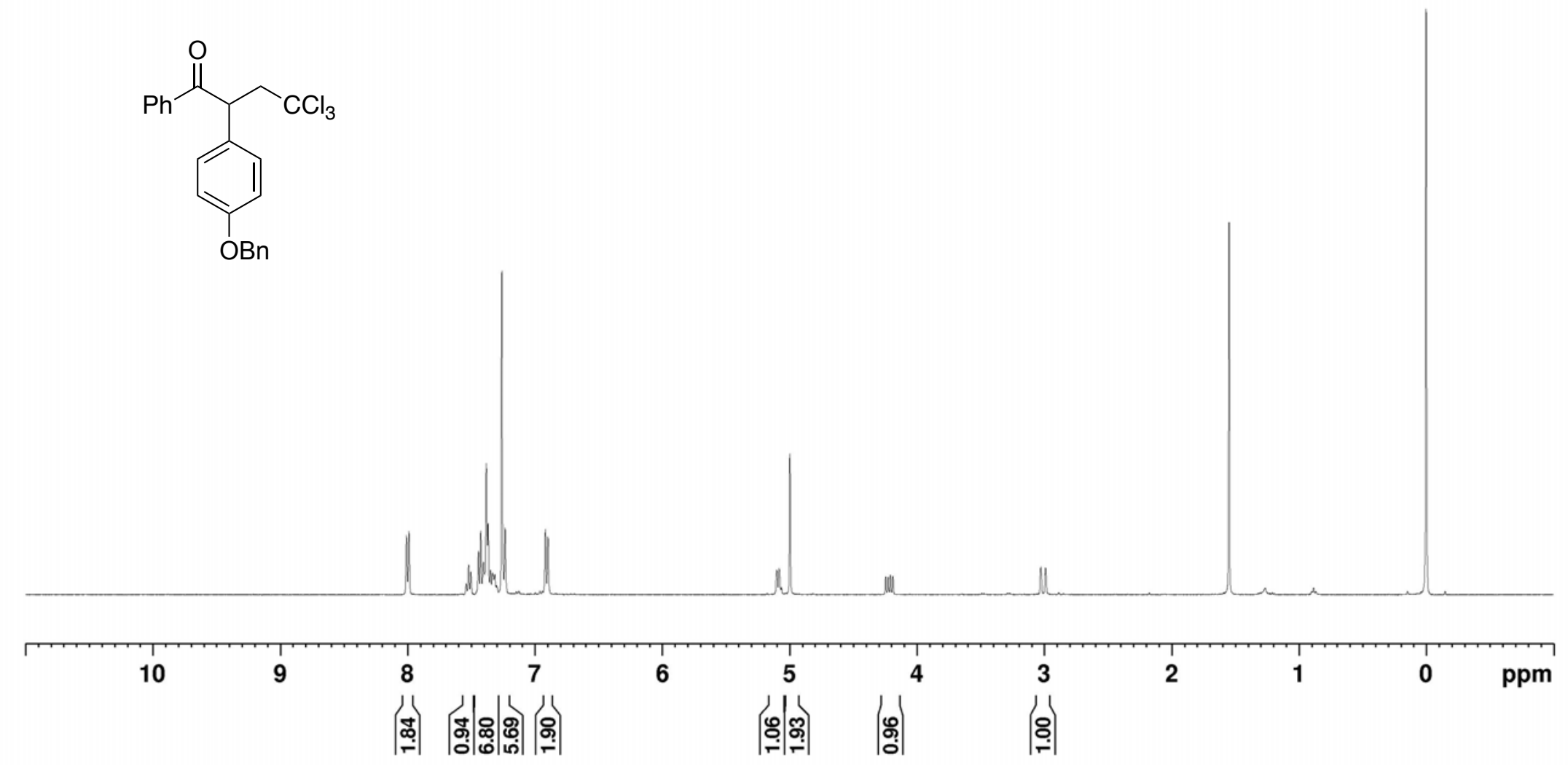

${ }^{1} \mathrm{H}$ NMR spectrum of $\mathbf{4 a d}\left(\mathrm{CDCl}_{3}, 100.6 \mathrm{MHz}\right)$ 

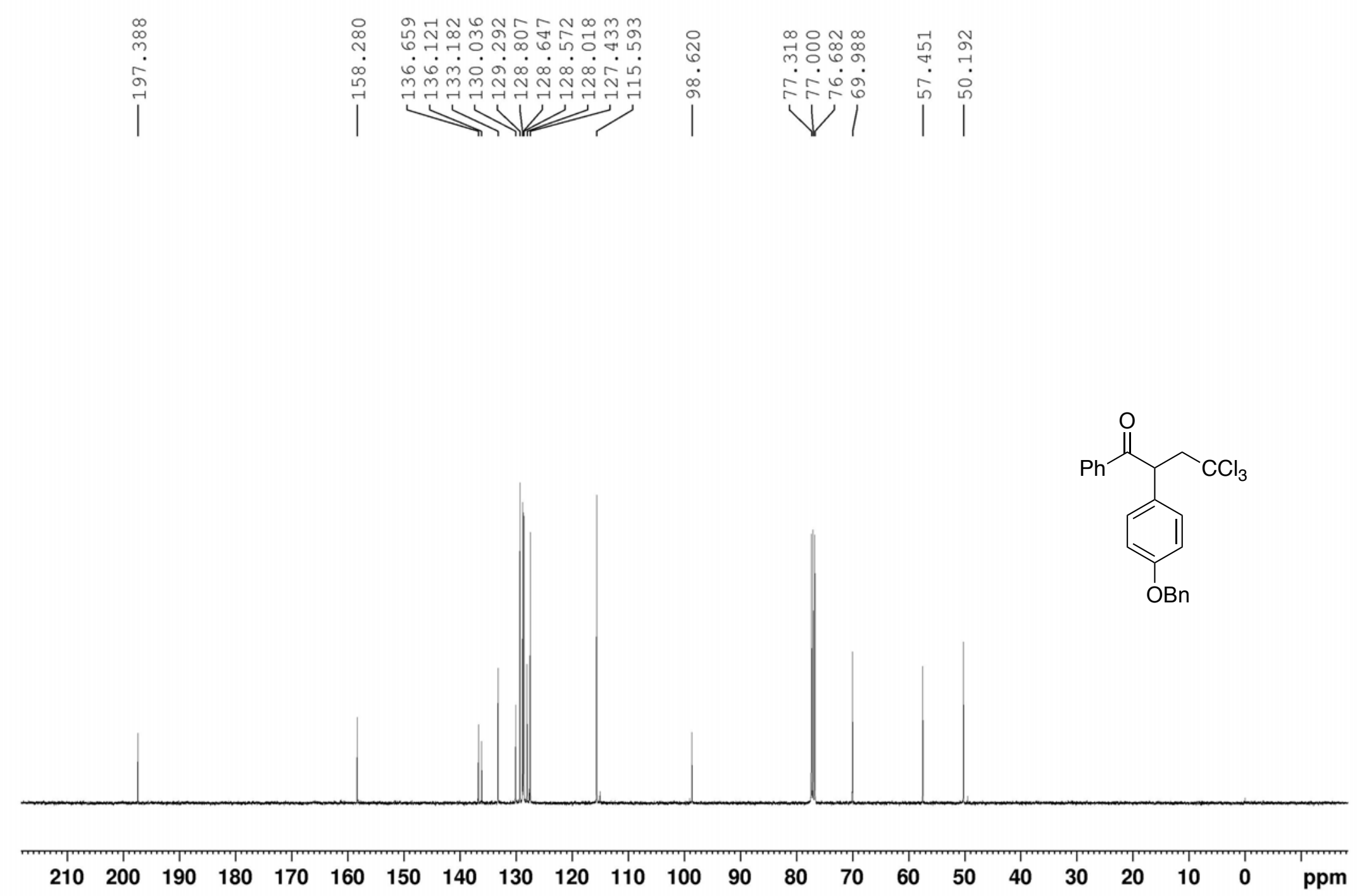

${ }^{13} \mathrm{C} \mathrm{NMR}$ spectrum of $4 \mathbf{a d}\left(\mathrm{CDCl}_{3}, 100.6 \mathrm{MHz}\right)$ 


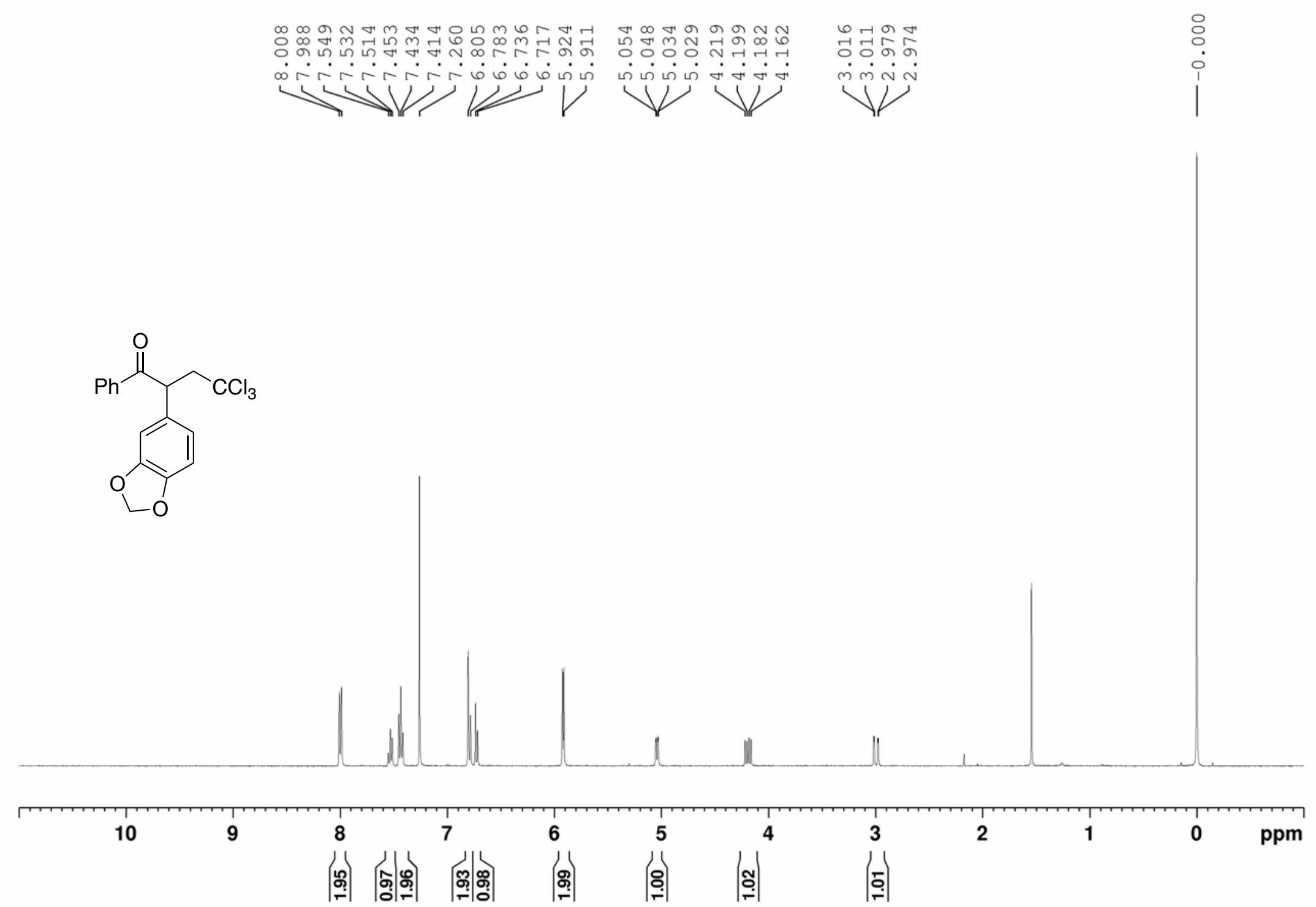

${ }^{1} \mathrm{H}$ NMR spectrum of $\mathbf{4 a e}\left(\mathrm{CDCl}_{3}, 400 \mathrm{MHz}\right)$ 


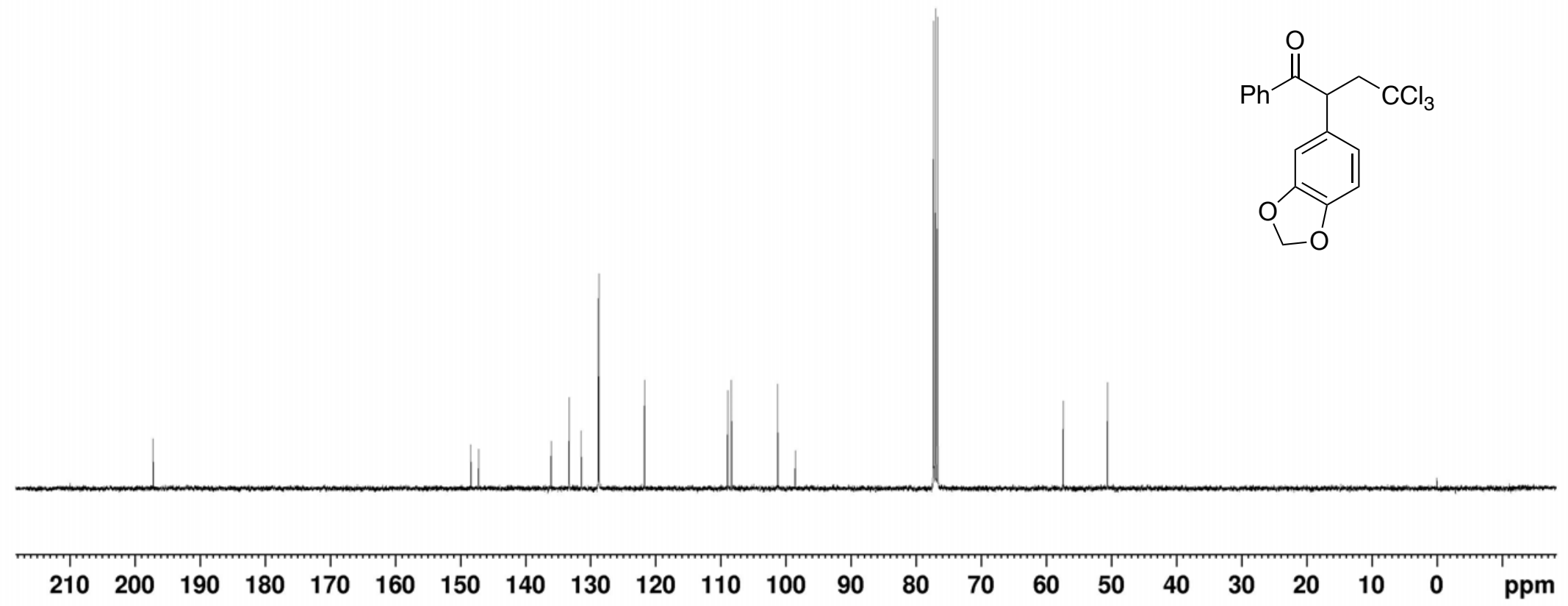

${ }^{13} \mathrm{C}$ NMR spectrum of $4 \mathbf{a e}\left(\mathrm{CDCl}_{3}, 100.6 \mathrm{MHz}\right)$ 

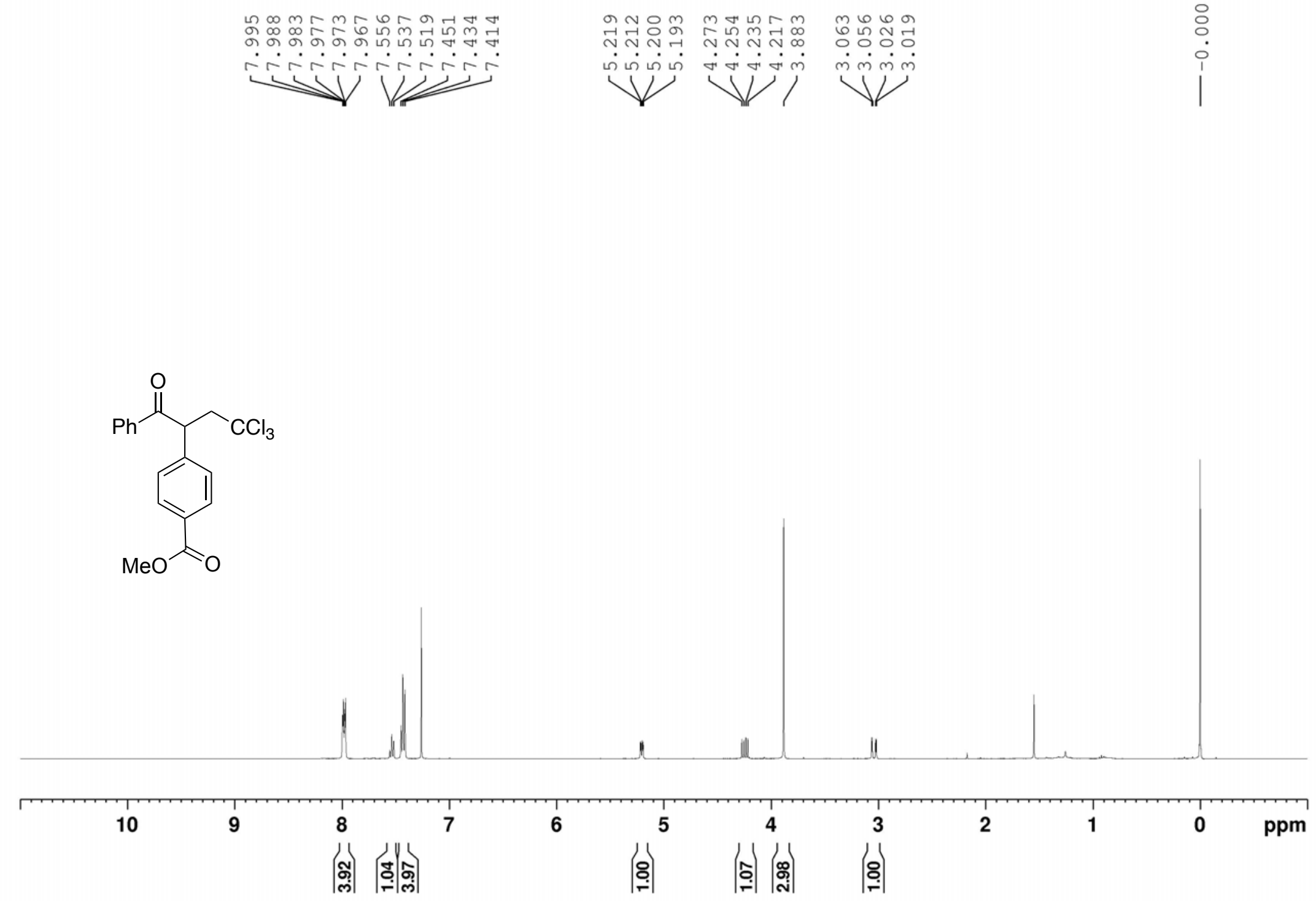

${ }^{1} \mathrm{H}$ NMR spectrum of $\mathbf{4 a f}\left(\mathrm{CDCl}_{3}, 400 \mathrm{MHz}\right)$ 

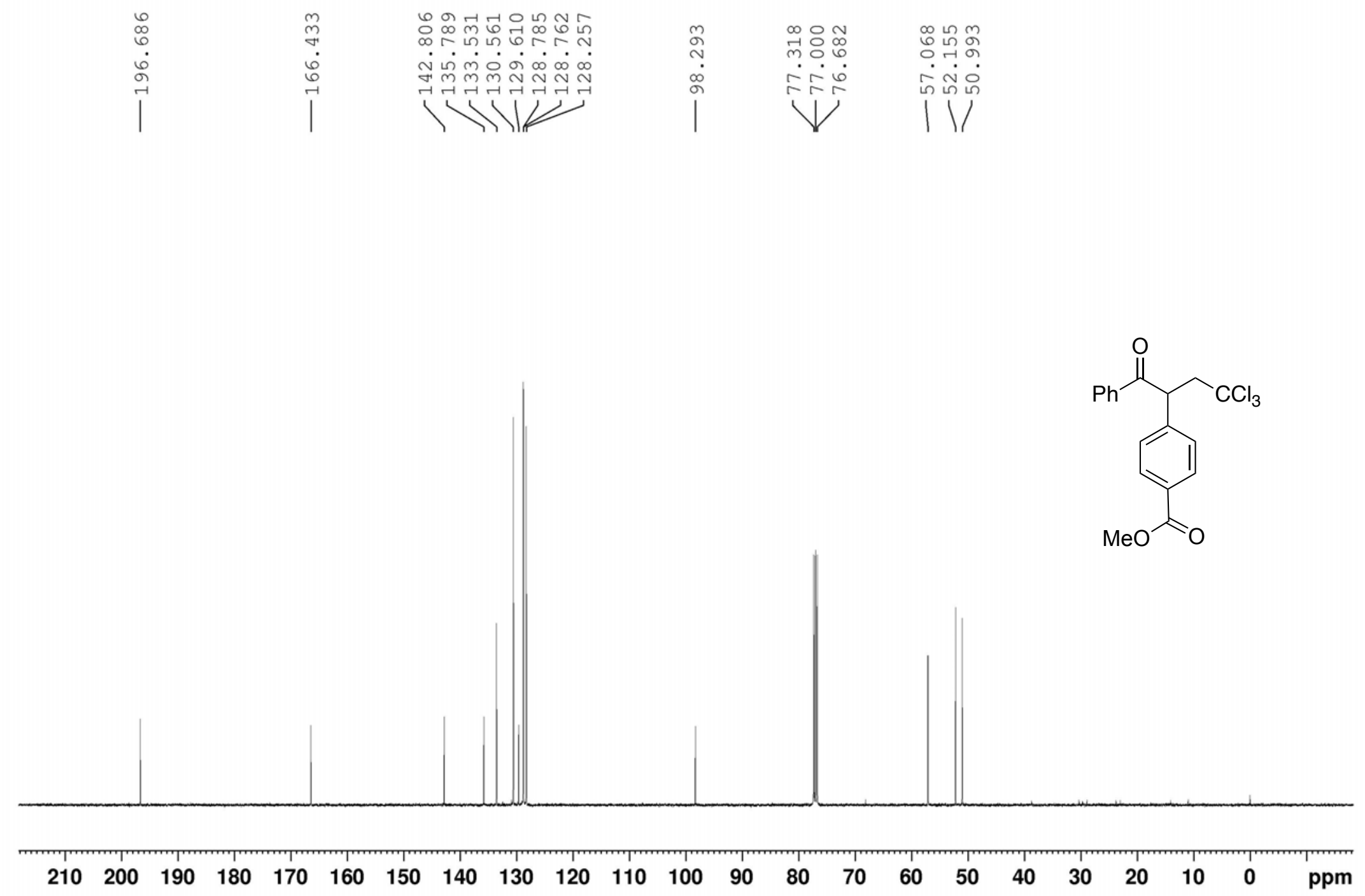

${ }^{13} \mathrm{C}$ NMR spectrum of 4 af $\left(\mathrm{CDCl}_{3}, 100.6 \mathrm{MHz}\right)$ 

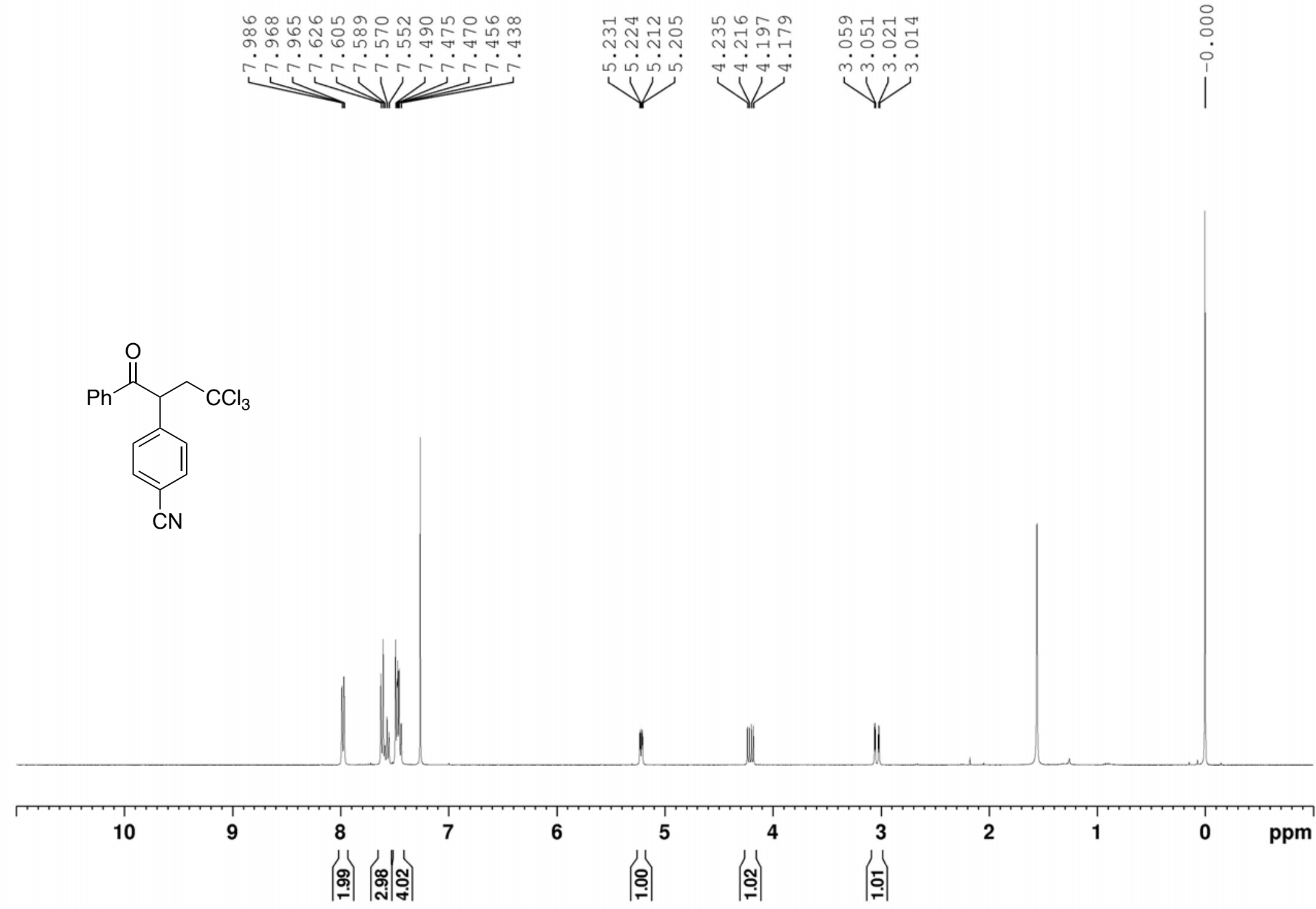

${ }^{1} \mathrm{H}$ NMR spectrum of $\mathbf{4 a g}\left(\mathrm{CDCl}_{3}, 400 \mathrm{MHz}\right)$ 


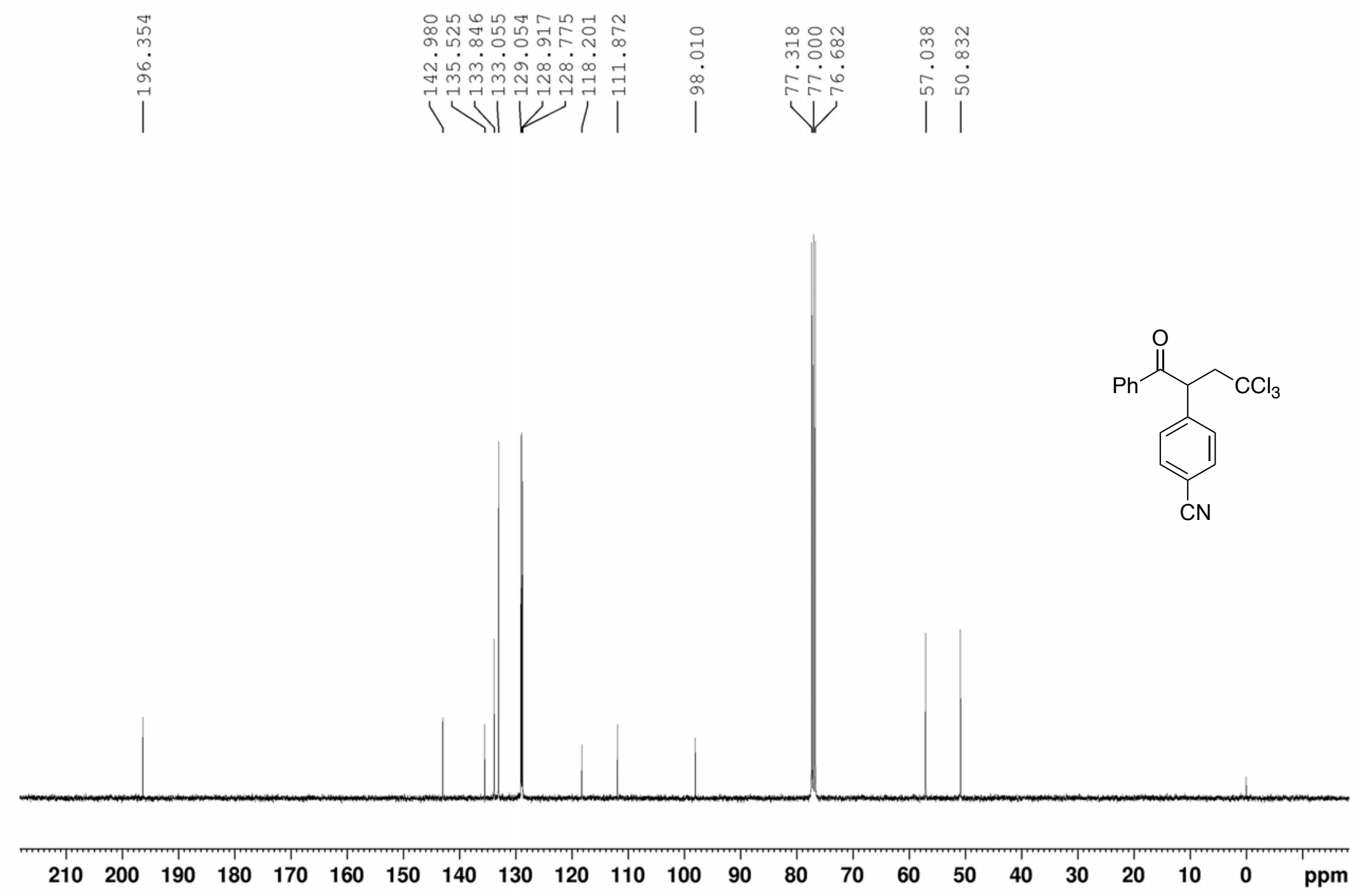

${ }^{13} \mathrm{C}$ NMR spectrum of $\mathbf{4 a g}\left(\mathrm{CDCl}_{3}, 100.6 \mathrm{MHz}\right)$ 


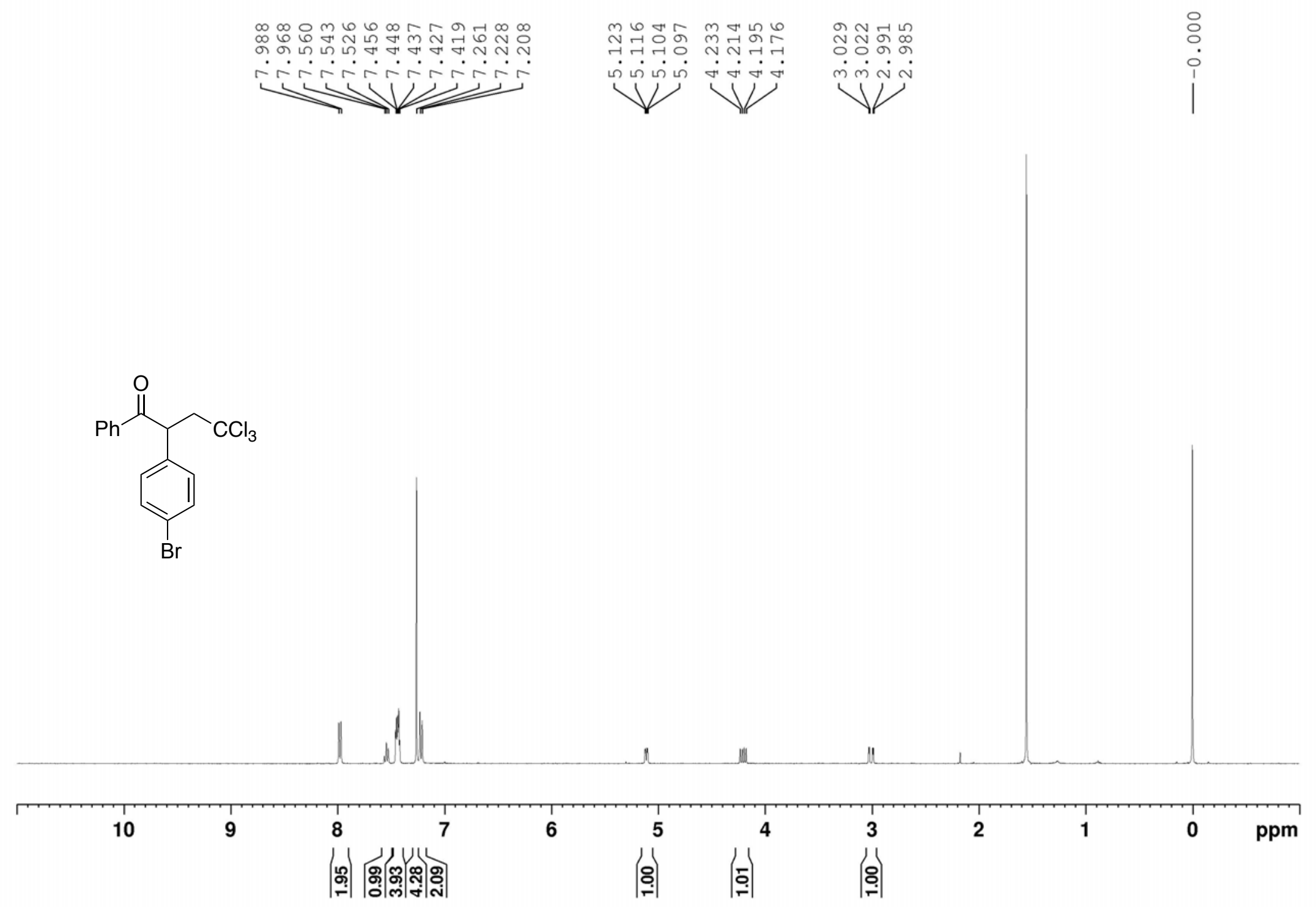

${ }^{1} \mathrm{H}$ NMR spectrum of $\mathbf{4} \mathbf{a h}\left(\mathrm{CDCl}_{3}, 400 \mathrm{MHz}\right)$ 


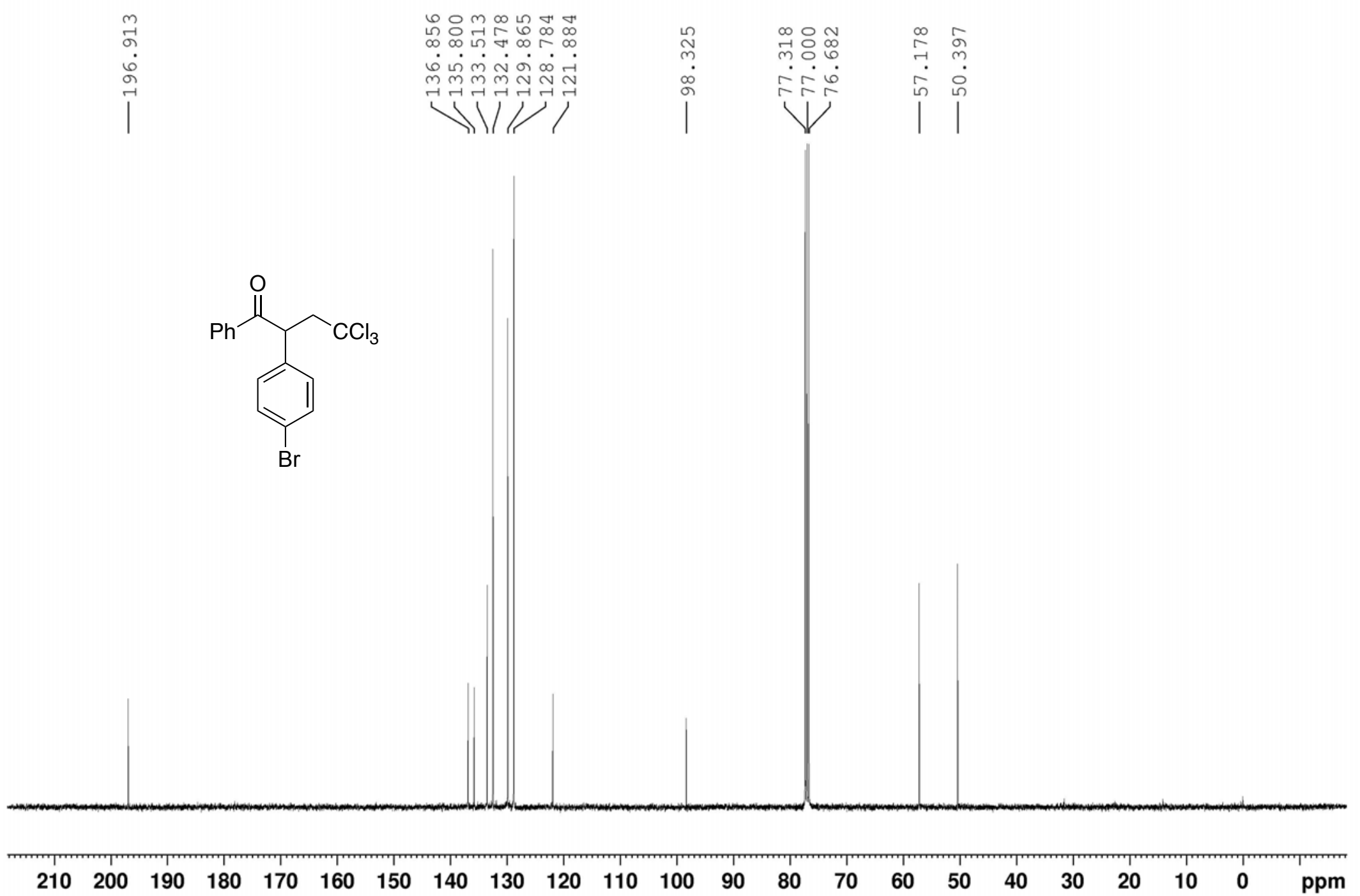

${ }^{13} \mathrm{C}$ NMR spectrum of $\mathbf{4 a h}\left(\mathrm{CDCl}_{3}, 100.6 \mathrm{MHz}\right)$ 

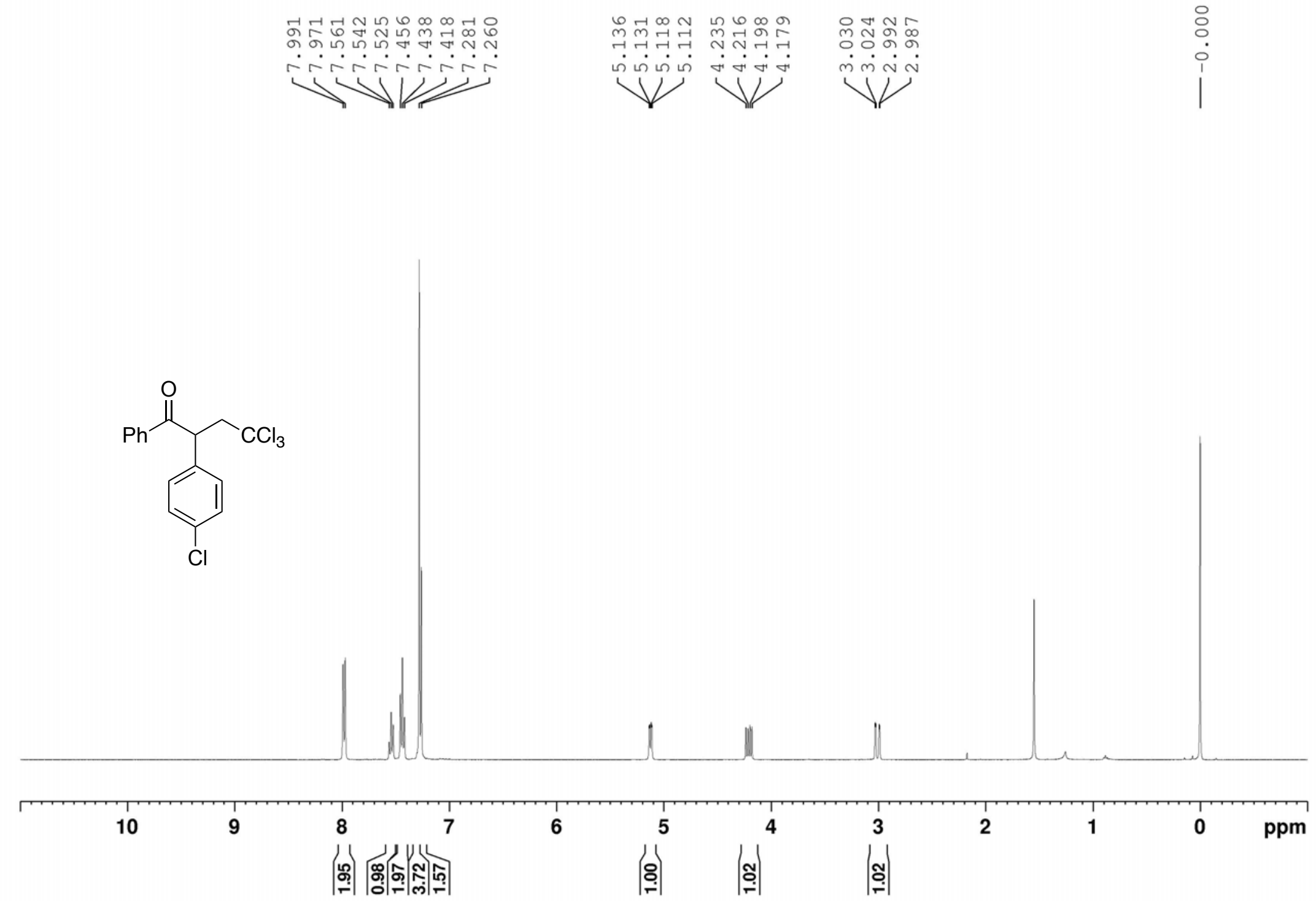

${ }^{1} \mathrm{H}$ NMR spectrum of $\mathbf{4 a i}\left(\mathrm{CDCl}_{3}, 400 \mathrm{MHz}\right)$ 


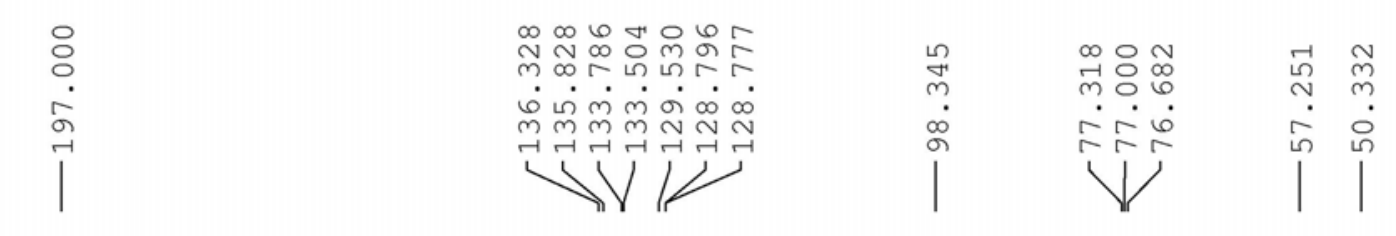

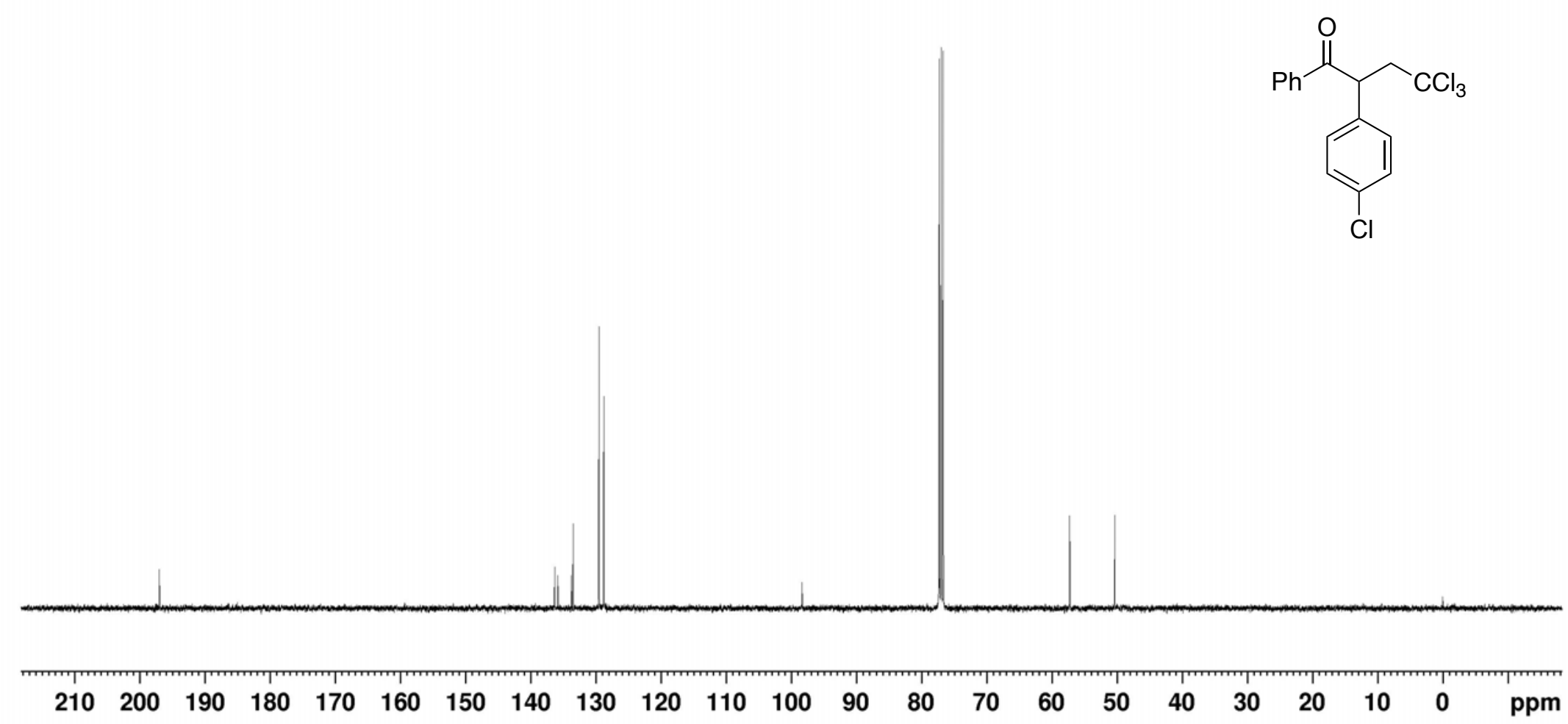

${ }^{13} \mathrm{C}$ NMR spectrum of $4 a \mathbf{a i}\left(\mathrm{CDCl}_{3}, 100.6 \mathrm{MHz}\right)$ 


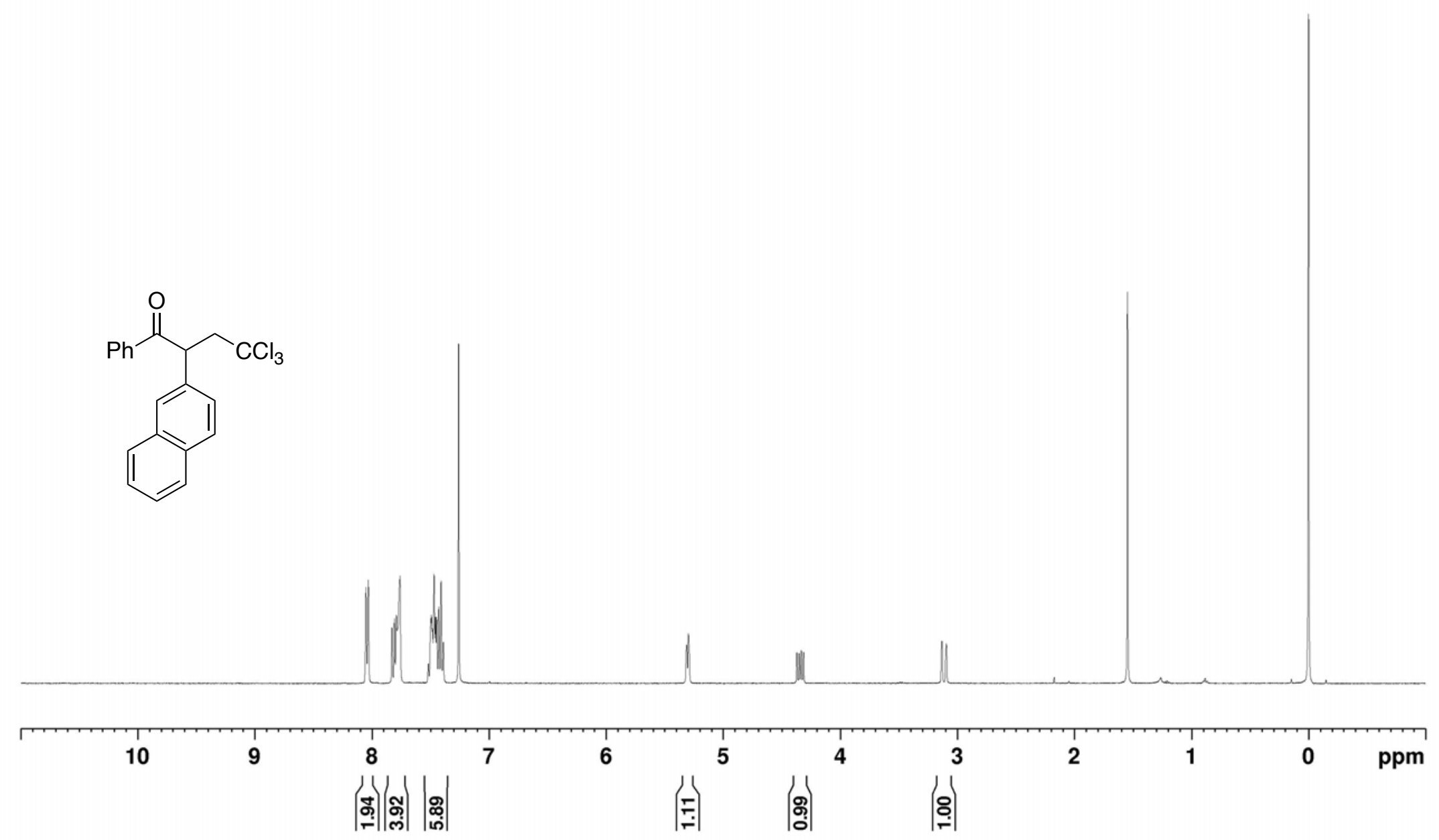

${ }^{1} \mathrm{H}$ NMR spectrum of $\mathbf{4 a j}\left(\mathrm{CDCl}_{3}, 400 \mathrm{MHz}\right)$ 

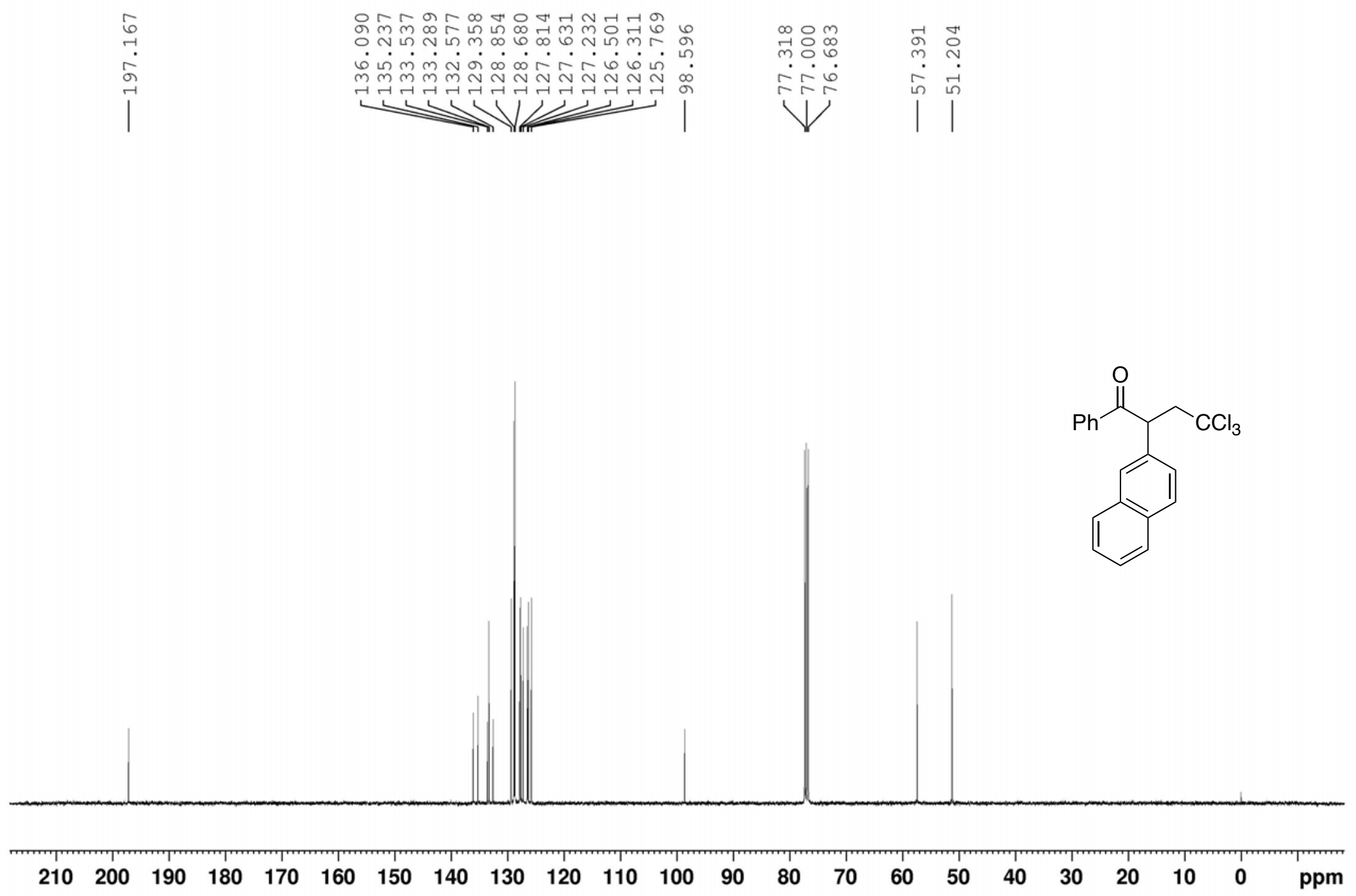

${ }^{13} \mathrm{C}$ NMR spectrum of $4 \mathbf{a j}\left(\mathrm{CDCl}_{3}, 100.6 \mathrm{MHz}\right)$ 


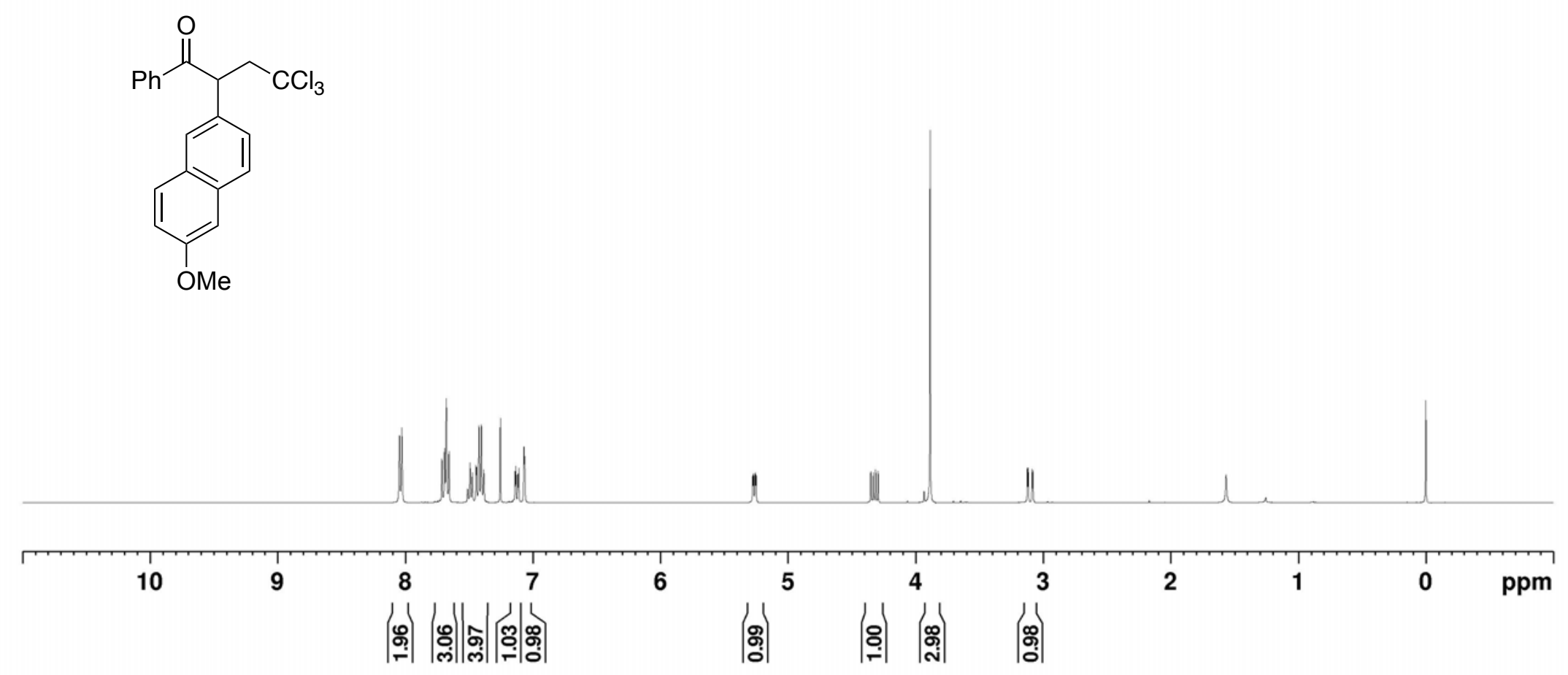

${ }^{1} \mathrm{H}$ NMR spectrum of $\mathbf{4 a k}\left(\mathrm{CDCl}_{3}, 400 \mathrm{MHz}\right)$ 

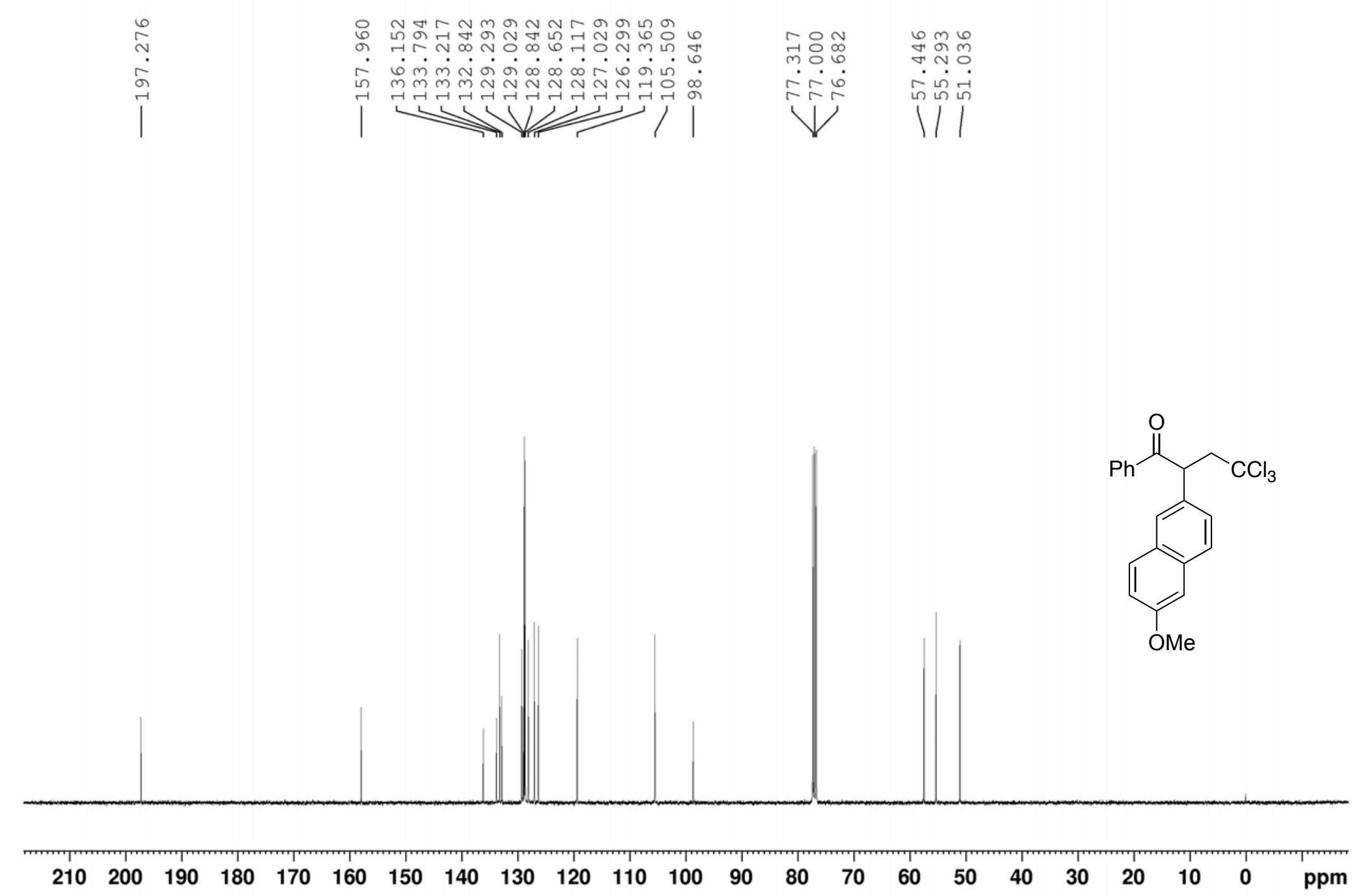

${ }^{13} \mathrm{C}$ NMR spectrum of $4 \mathbf{a k}\left(\mathrm{CDCl}_{3}, 100.6 \mathrm{MHz}\right)$ 

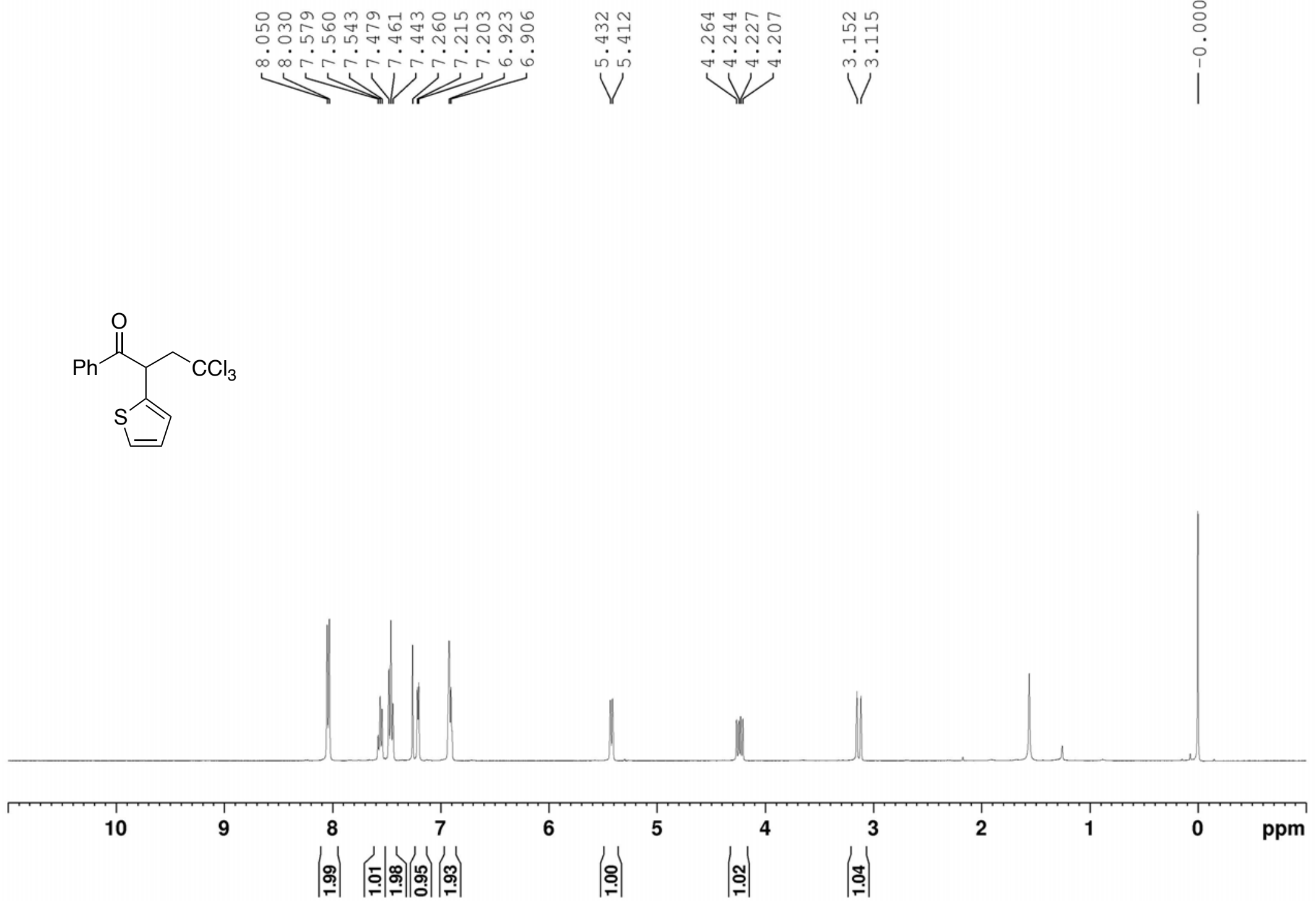

${ }^{1} \mathrm{H}$ NMR spectrum of $\mathbf{4 a l}\left(\mathrm{CDCl}_{3}, 400 \mathrm{MHz}\right)$ 


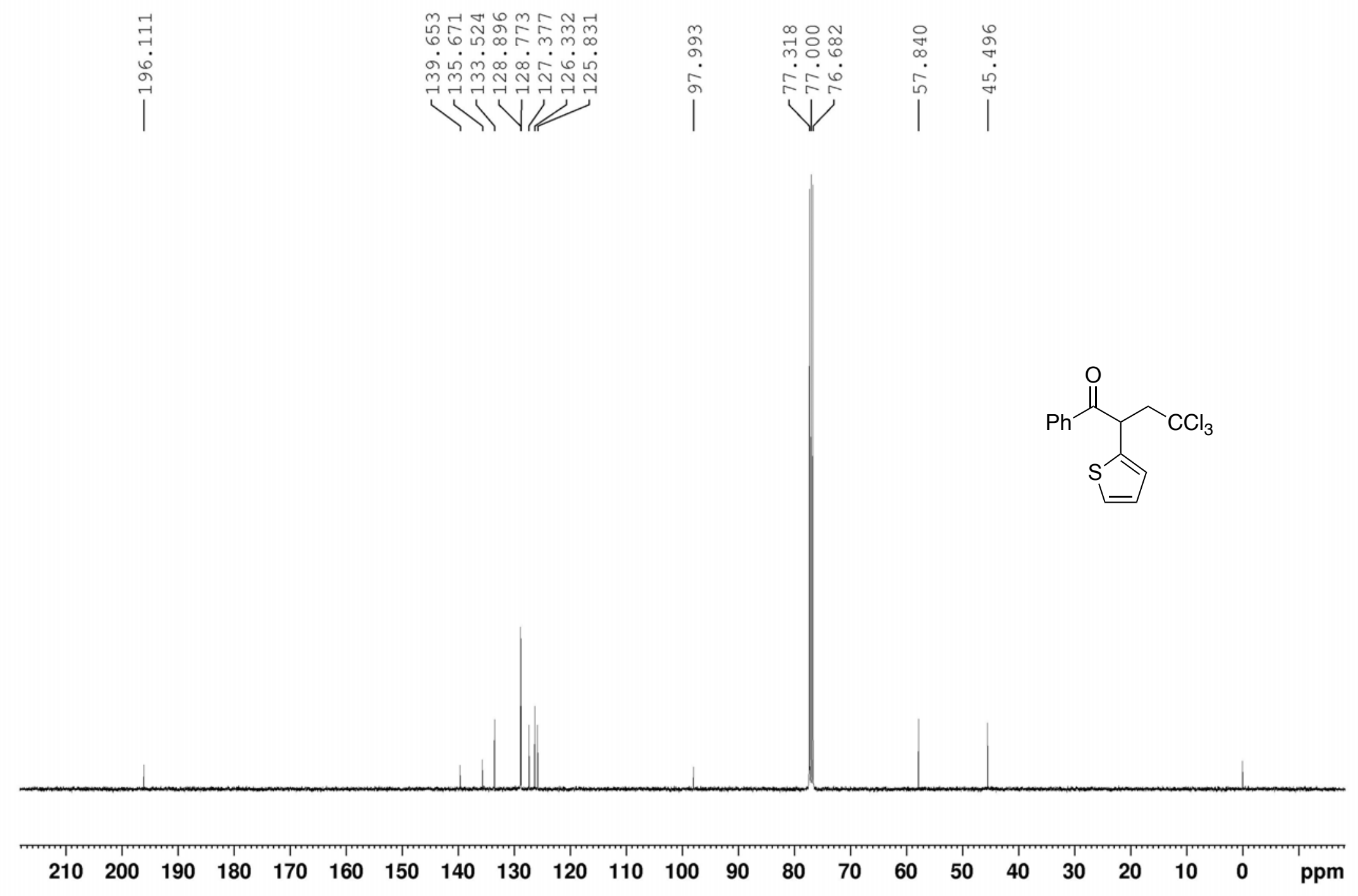

${ }^{13} \mathrm{C}$ NMR spectrum of 4 al $\left(\mathrm{CDCl}_{3}, 100.6 \mathrm{MHz}\right)$ 
<smiles>O=C(c1ccccc1)C(Cl)CC(Cl)(Cl)C(Cl)(Cl)Cl</smiles>

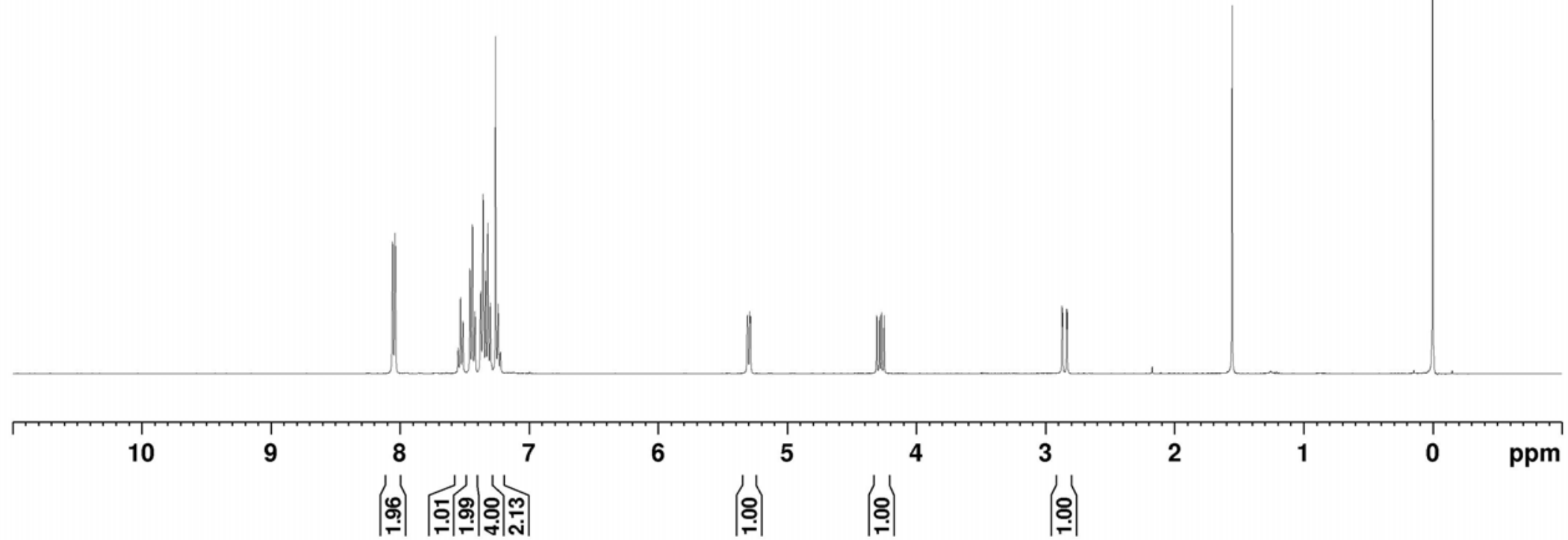

${ }^{1} \mathrm{H}$ NMR spectrum of 7aa $\left(\mathrm{CDCl}_{3}, 400 \mathrm{MHz}\right)$ 

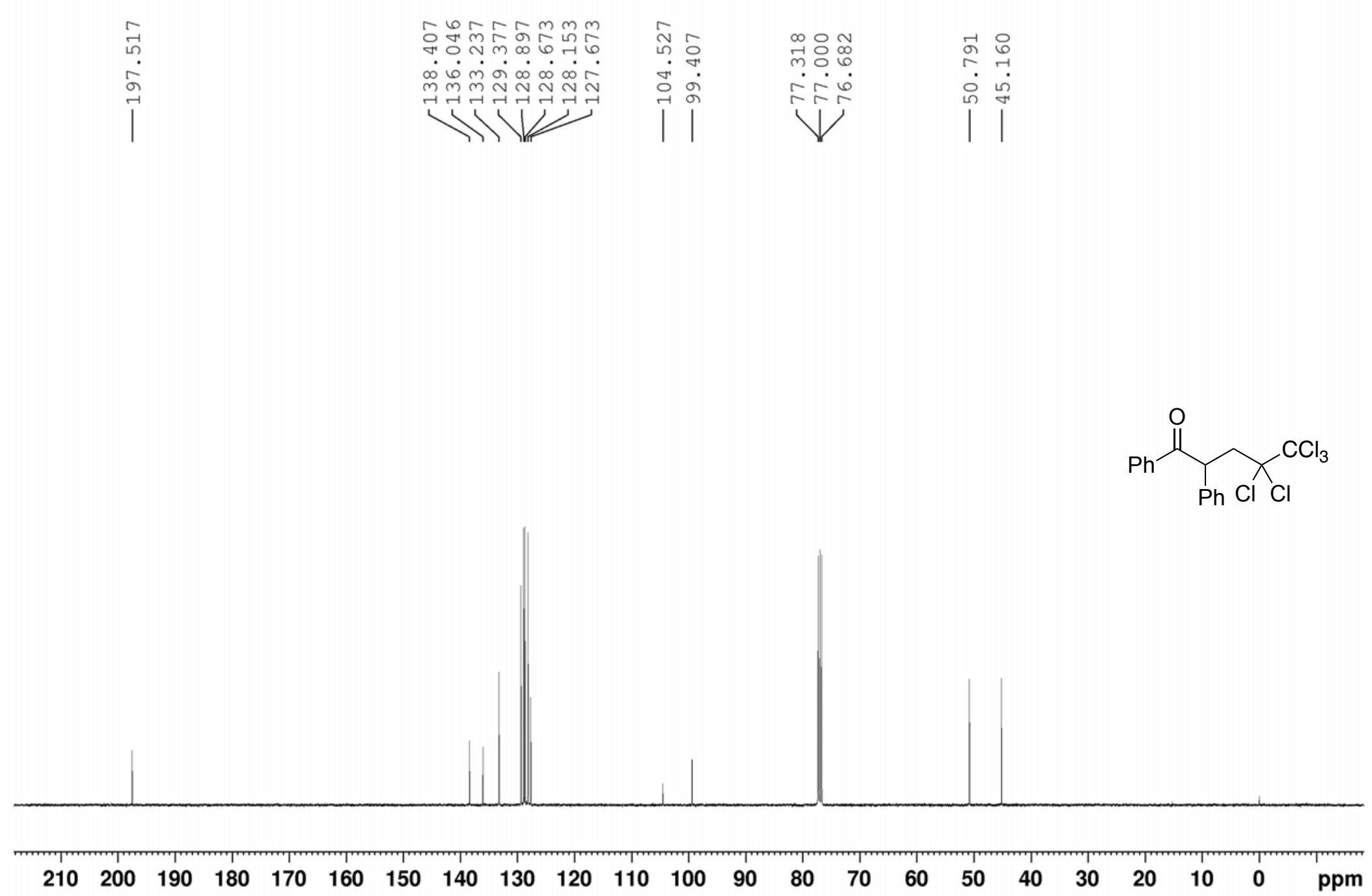

${ }^{13} \mathrm{C}$ NMR spectrum of $7 \mathbf{a a}\left(\mathrm{CDCl}_{3}, 100.6 \mathrm{MHz}\right)$ 

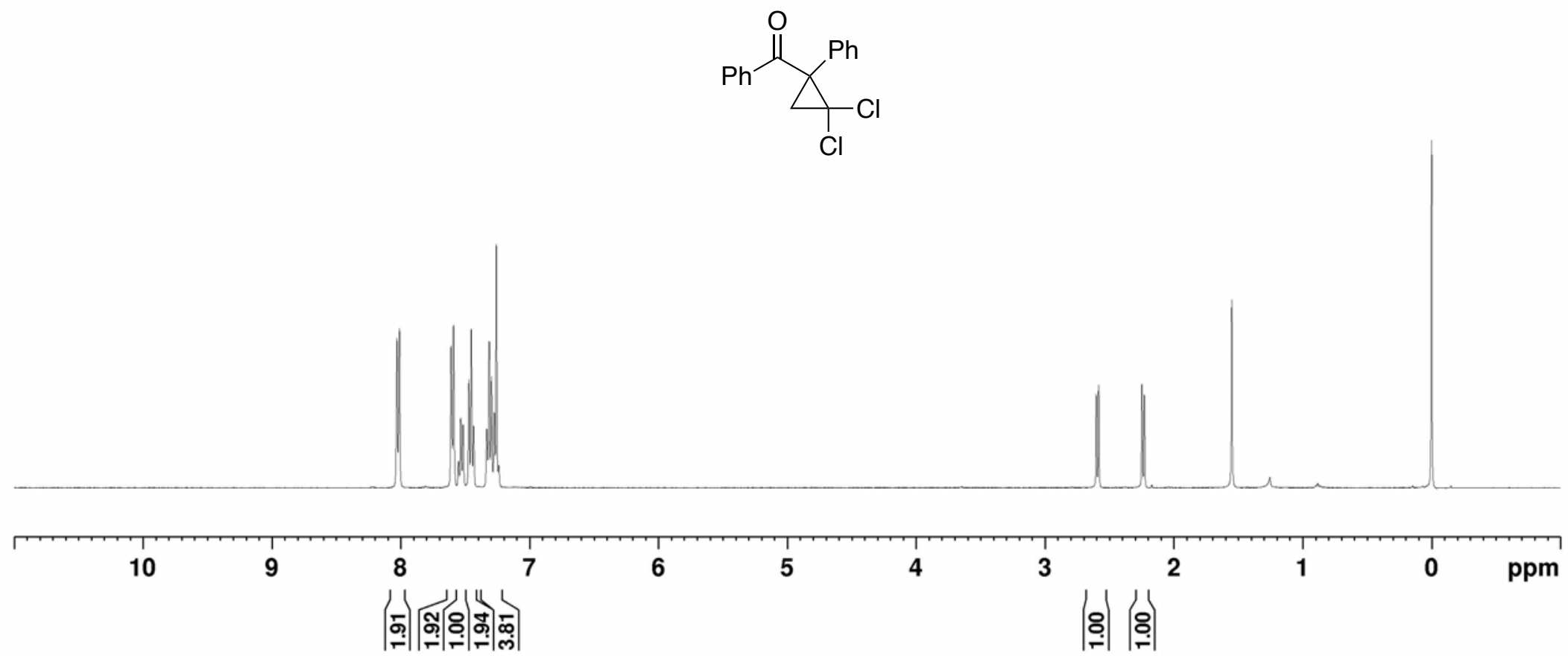

${ }^{1} \mathrm{H}$ NMR spectrum of $\mathbf{5 a a}\left(\mathrm{CDCl}_{3}, 400 \mathrm{MHz}\right)$ 


|

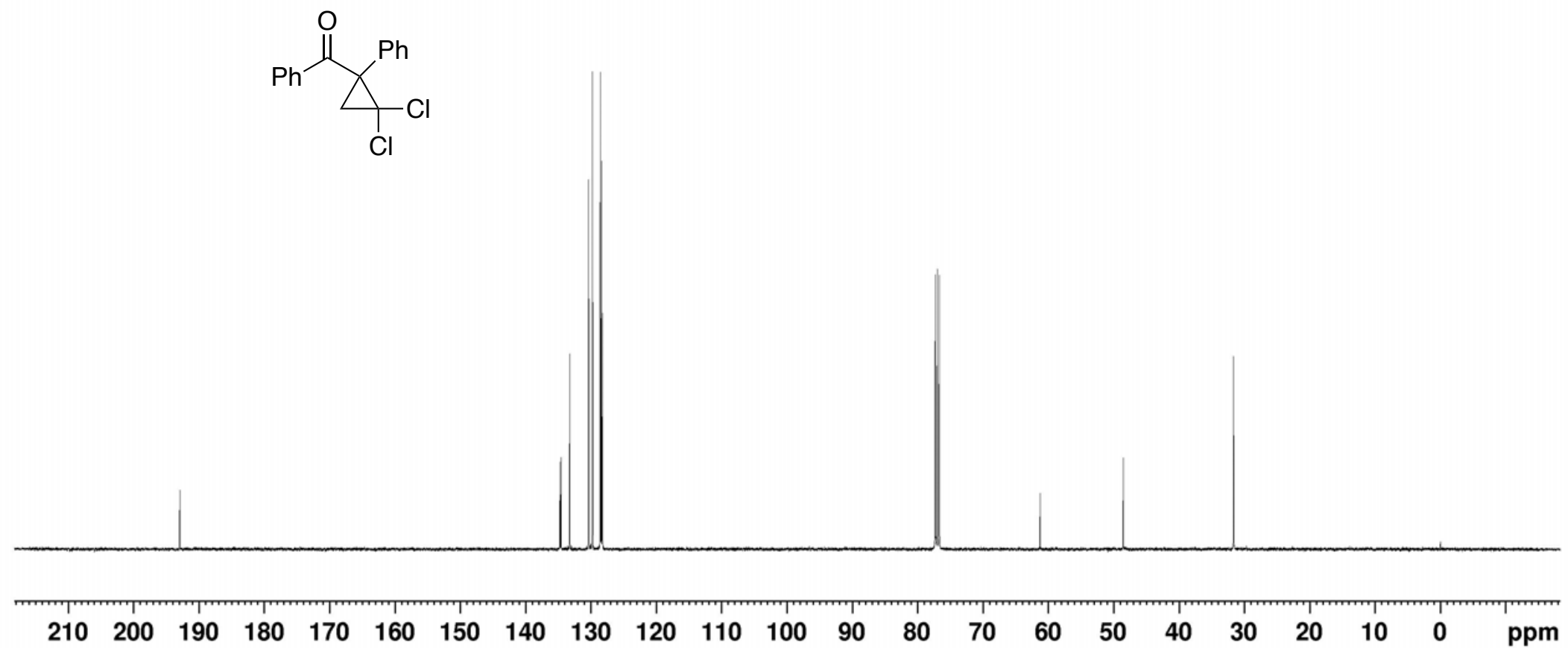

${ }^{13} \mathrm{C} \mathrm{NMR}$ spectrum of $\mathbf{5 a a}\left(\mathrm{CDCl}_{3}, 100.6 \mathrm{MHz}\right)$ 

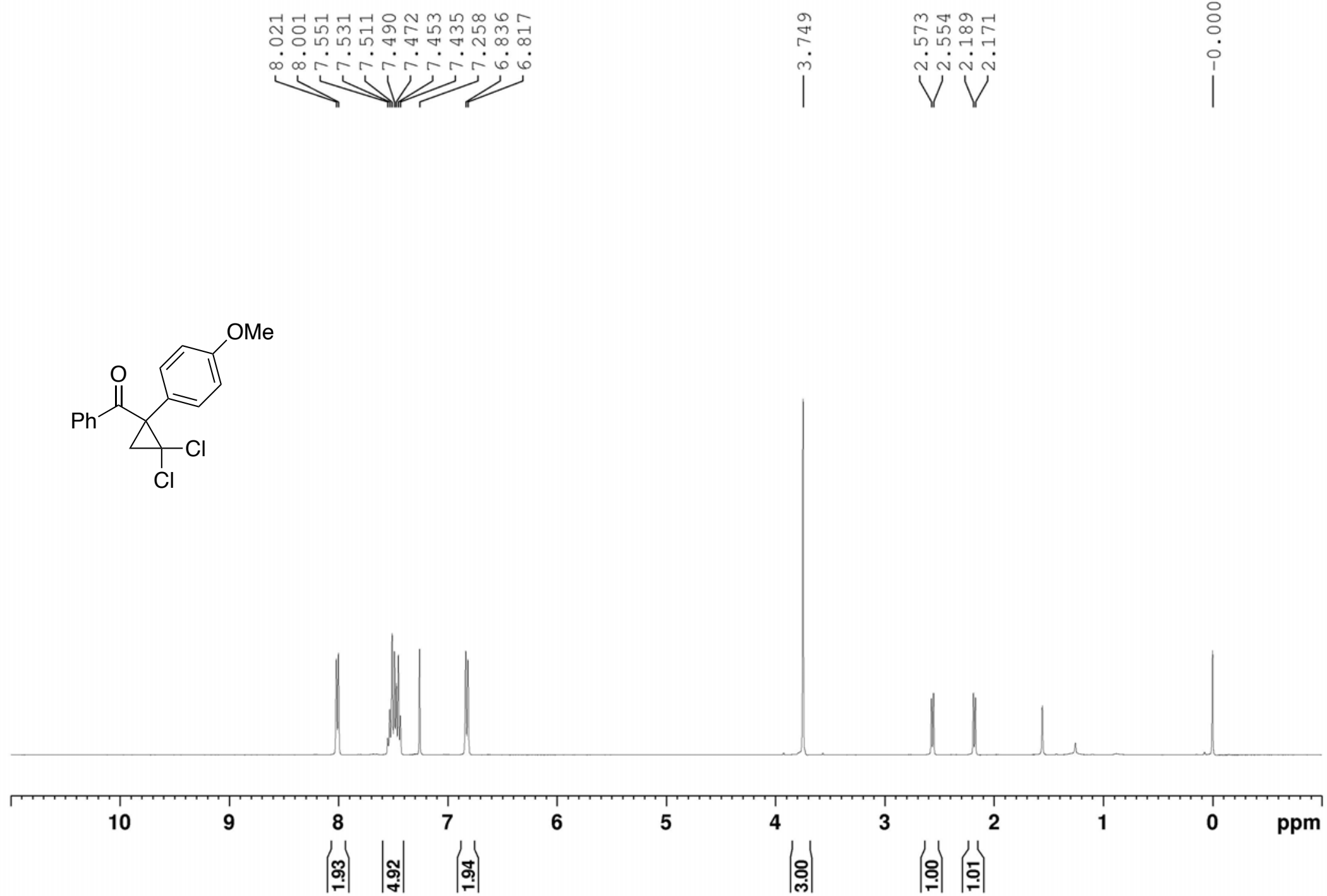

${ }^{1} \mathrm{H}$ NMR spectrum of $\mathbf{5 a b}\left(\mathrm{CDCl}_{3}, 400 \mathrm{MHz}\right)$ 

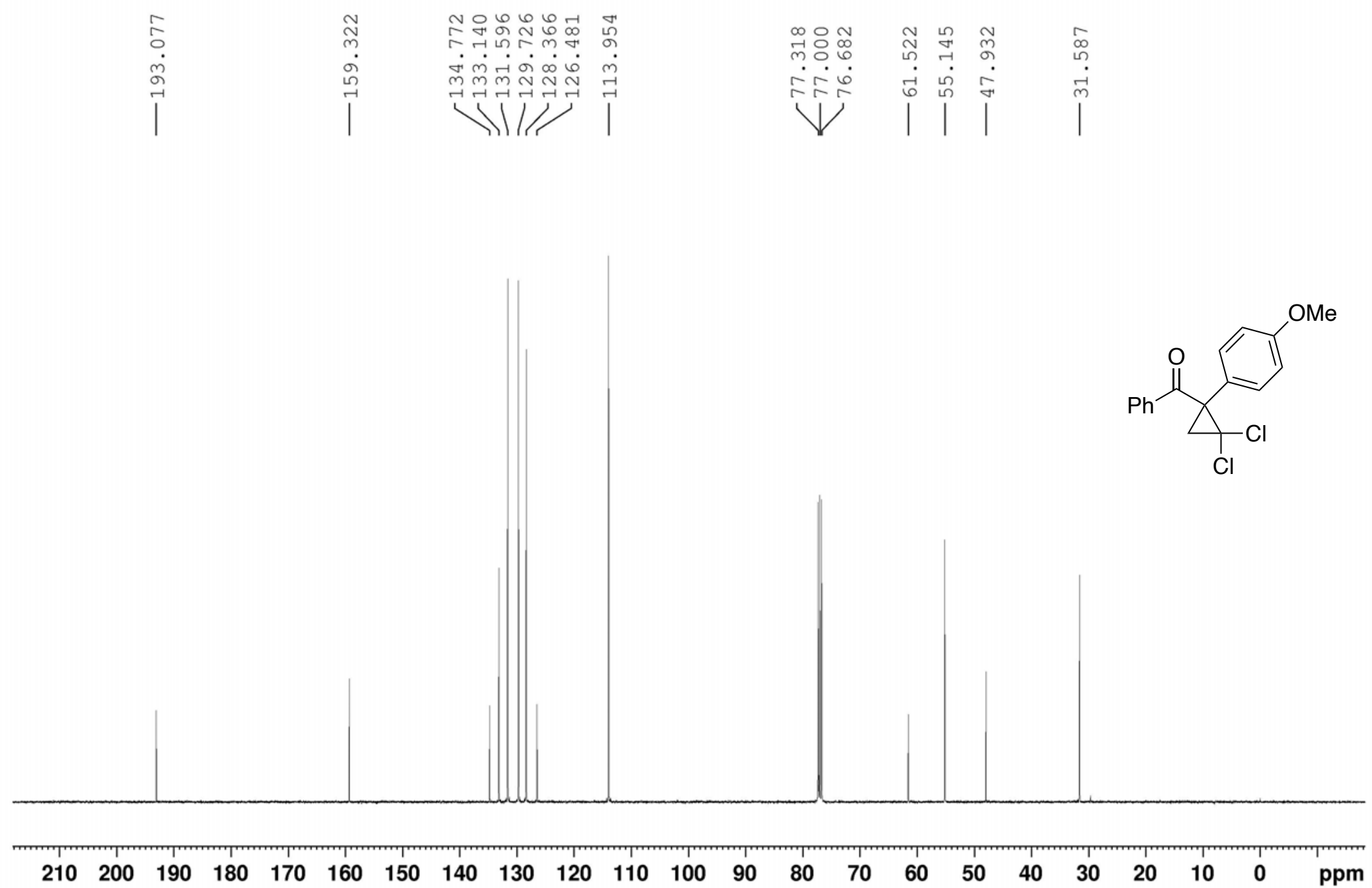

${ }^{13} \mathrm{C}$ NMR spectrum of $\mathbf{5 a b}\left(\mathrm{CDCl}_{3}, 100.6 \mathrm{MHz}\right)$ 

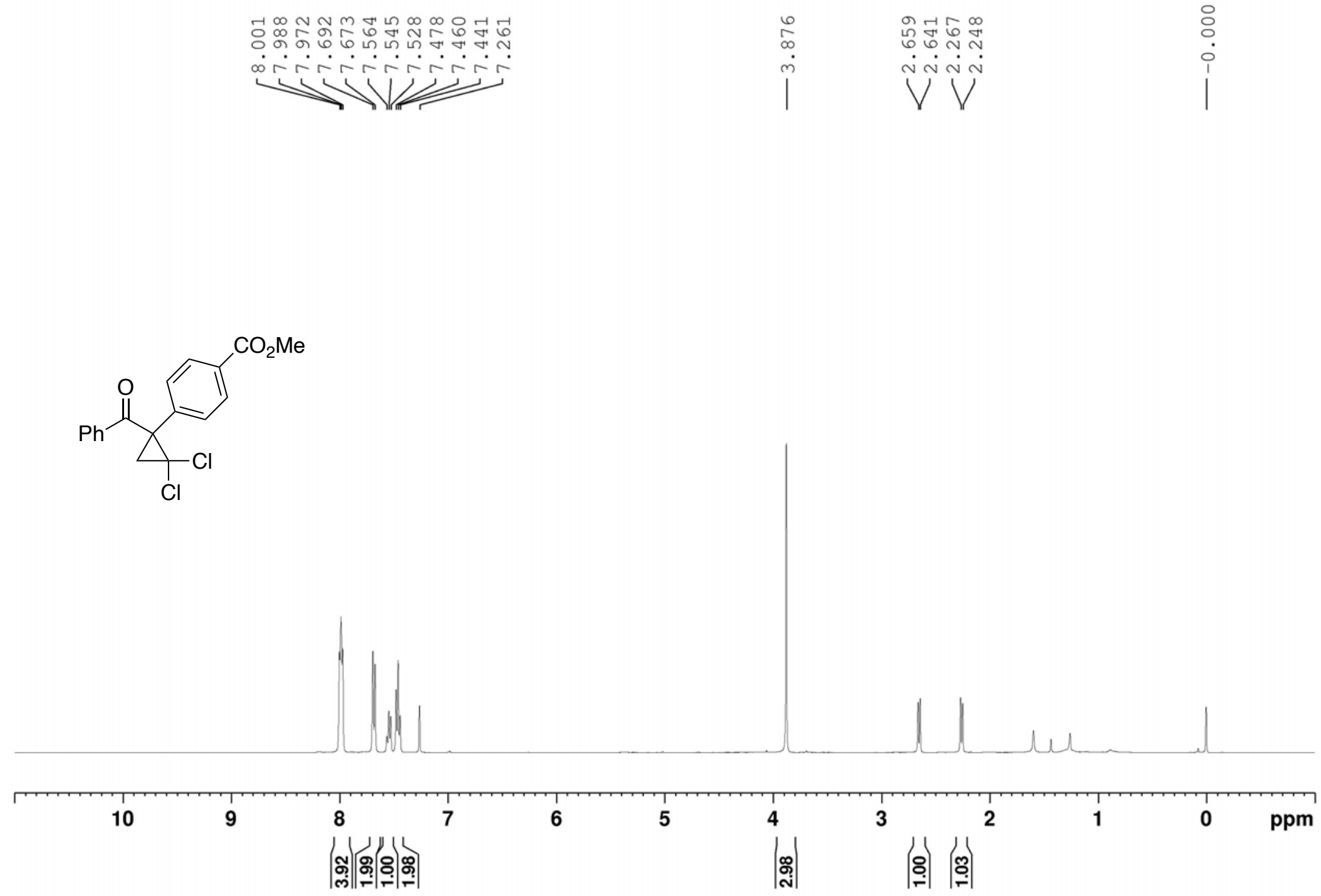

${ }^{1} \mathrm{H}$ NMR spectrum of $\mathbf{5 a f}\left(\mathrm{CDCl}_{3}, 400 \mathrm{MHz}\right)$ 

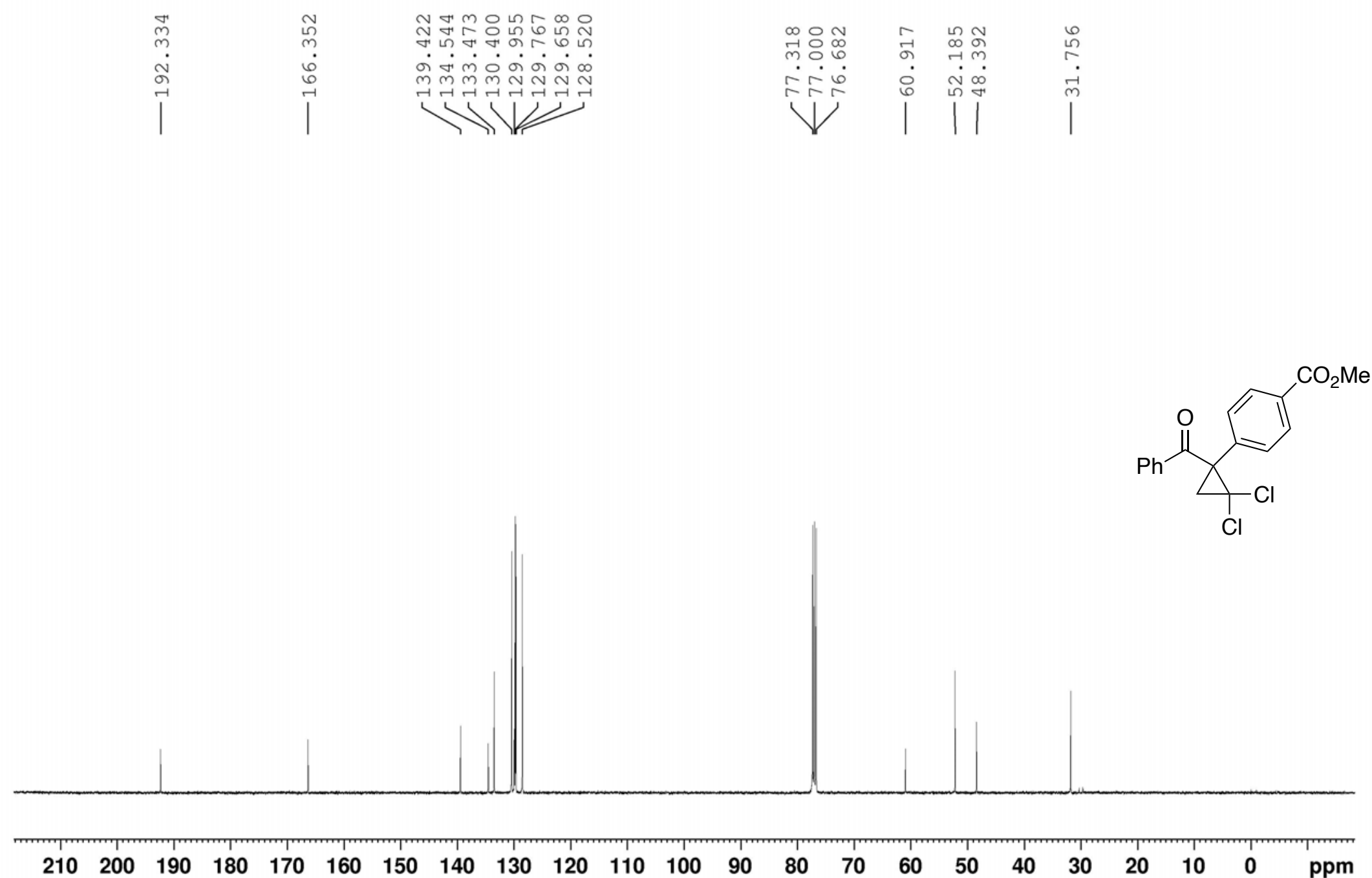

${ }^{13} \mathrm{C}$ NMR spectrum of $\mathbf{5 a f}\left(\mathrm{CDCl}_{3}, 100.6 \mathrm{MHz}\right)$ 


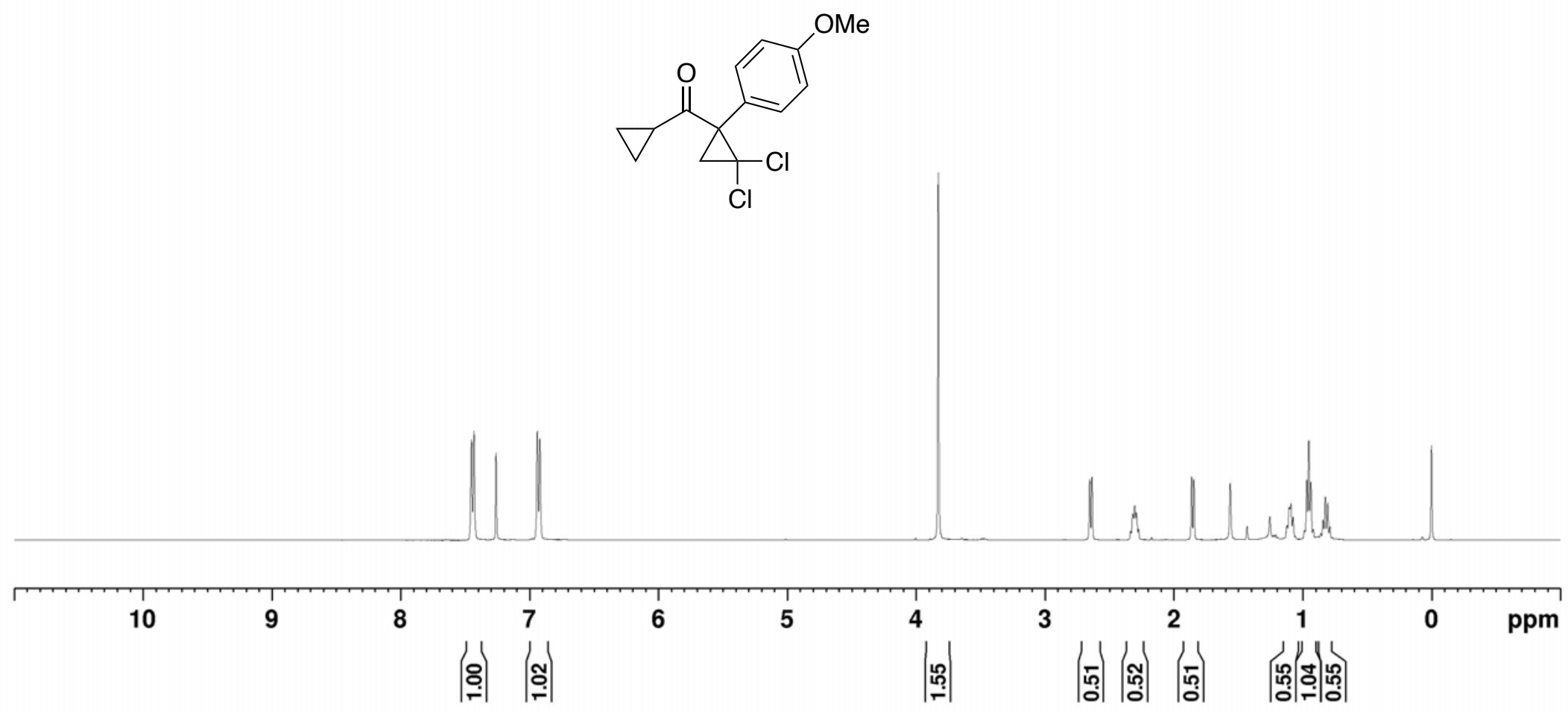

${ }^{1} \mathrm{H}$ NMR spectrum of $\mathbf{5 p b}\left(\mathrm{CDCl}_{3}, 400 \mathrm{MHz}\right)$ 


|
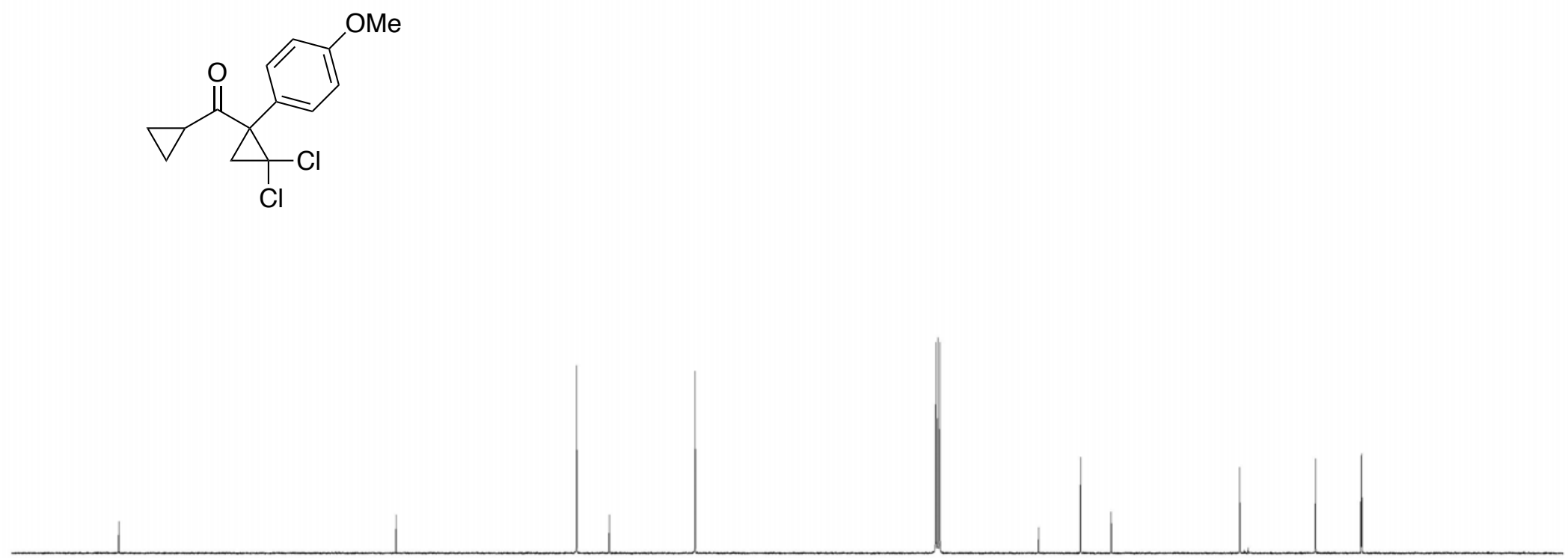

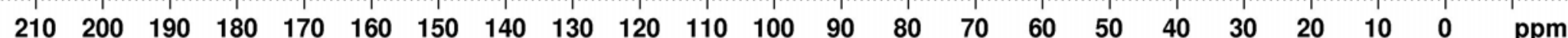

${ }^{13} \mathrm{C}$ NMR spectrum of $\mathbf{5 p b}\left(\mathrm{CDCl}_{3}, 100.6 \mathrm{MHz}\right)$ 